RENATA ISHIBA

\title{
Degeneração e regeneração muscular em modelos murinos com deficiência de disferlina
}

Muscle degeneration and regeneration in dysferlin-deficient murine models

São Paulo 


\title{
Degeneração e regeneração muscular em modelos murinos com deficiência de disferlina
}

\author{
Muscle degeneration and regeneration in \\ dysferlin-deficient murine models
}

Tese apresentada ao Instituto de Biociências da Universidade de São Paulo, para a obtenção de Título de Mestre em Ciências, na Área de Biologia/Genética.

Orientador(a): Profa. Dra. Mariz Vainzof

São Paulo 
Ishiba, Renata

Degeneração e regeneração muscular em modelos murinos com deficiência de disferlina / Renata Ishiba ; Orientadora Mariz Vainzof São Paulo, 2017.

$96 \mathrm{f}$.

Dissertação (Mestrado) - Instituto de Biociências da Universidade de São Paulo. Departamento de Genética e Biologia Evolutiva.

1. Distrofias musculares. 2. Disferlina. 3. Regeneração muscular.

4. Diferenciação muscular.

I. Universidade de São Paulo. Instituto de Biociências. Departamento de Genética e Biologia Evolutiva.

Comissão Julgadora:

$\operatorname{Prof}(a)$. Dr(a).

$\operatorname{Prof}(\mathrm{a}) . \operatorname{Dr}(\mathrm{a})$.

Prof(a). Dr(a). Mariz Vainzof

Orientador(a) 
Dedicatória

À minha avó Rita e aos meus pais 
We never know what life has in store for us. However, it's more gratifying to fight than to surrender to fears and to unknown.

Randy Romain (Autor do livro Facing the challenge. Deficiente físico devido a uma doença degenerativa progressiva de causa desconhecida.) 


\section{Agradecimentos}

Agradeço à Profa Mariz Vainzof, pela orientação, disponibilidade e apoio durante toda a realização deste projeto. Muito obrigada pela oportunidade, pelo aprendizado e pela paciência e carinho com que trata a todos!

Ao Dr. Vincent Mouly e à Dra. Anne Bigot do Institut de Myologie (França), pela colaboração nos experimentos e elaboração do artigo com as células humanas imortalizadas.

Ao pessoal do laboratório: André, Aurea, Camila, Dani, Leo, Letícia, Lucas, Marina, Ster, Tonho e Yumi. Em especial ao Tonho e à Yumi, pelo companheirismo e amizade e por tornarem o ambiente de trabalho mais agradável e divertido. Ao André, pelas conversas e ajuda com os experimentos e procedimentos com os camundongos logo que cheguei ao laboratório. À Ster e à Aurea, pela simplicidade, por serem pessoas agregadoras, sempre atenciosas e dispostas a ajudar. À Dani, que junto com a Ster,

prontamente me ajudou na fase final a revisar os artigos da dissertação. À Letícia, que me iniciou e auxiliou com as culturas de células. Também por ser uma pessoa sempre de bem com a vida, molecona e carinhosa. Ao Leo e ao Lucas, pela convivência divertida, e pelas pérolas e humor negro inacreditáveis. À Marina, pela amizade e conversas animadas.

À querida Lydinha, que quando cheguei ao laboratório já estava praticamente de saída, mas que mesmo assim se tornou alguém com quem sempre posso contar. Obrigada pelo carinho e amizade!

Um agradecimento especial ao Luiz Caires Júnior, pelos direcionamentos nos experimentos. Sua disponibilidade e ajuda clara e metódica, apesar de ter parecido simples, foi essencial na minha fase inicial de aprendizado prático de bancada. Obrigada também à Giu, pela ajuda com protocolos e dicas.

À profa Cláudia Madalena Cabrera Mori da FMVZ-USP, pela doação dos camundongos Swiss.

À Helô pelo apoio com o manejo dos animais do biotério, pela disponibilidade em ajudar sempre da melhor forma e pelo seu bom humor que sempre rendem boas risadas.

À Martinha por toda a ajuda e apoio técnico e por sempre me tratar com carinho e atenção. 
Aos funcionários do Centro de Estudos do Genoma Humano: Wagner, Van, Marta, Daniel, Fernando, Lilian, Neide e tantos outros, por contribuírem direta ou indiretamente para a execução deste projeto.

Ao querido amigo Thiago pelo apoio, por verdadeiramente se importar e trazer mais leveza em várias fases da minha vida. Muito obrigada!

À minha amiga Larissa Shiozawa, pela consideração e carinho. Criamos laços de amizade e de consideração desde os tempos da faculdade, que mesmo com a distância, se mantêm firmes.

Aos amigos Izabel, Alex e Cida. Em especial à Izabel, pelo apoio. Minha admiração pelo seu esforço e postura positiva.

Aos meus pais, Roberto e Sônia, e ao meu irmão, Ishiba, por estarem sempre ao meu lado e não pouparem esforços para me apoiar e incentivar em todos os momentos da minha vida. Obrigada por tudo!

Ao meu sobrinho Rafael, por ter trazido alegrias e descontração para as nossas vidas.

À minha avó Rita (i.m.), pelo amor simples e sincero, pelos ensinamentos de vida, pela convivência doce e divertida, por tentar me fazer rir mesmo nos seus momentos mais difíceis. Obrigada por ter feito parte da minha vida!

Aos meus tios, Natália, Bidinho e Lia, pelo carinho e união de forças nos cuidados com a minha avó.

Ao meu namorado Victor, por estar ao meu lado e cuidar de mim. Por me incentivar e apoiar, tornando mais leve essa fase de conclusão de projetos. Pelo carinho sincero e por sempre me fazer rir. Espero compartilhar ainda muitos bons momentos com você!

À FAPESP-CEPID, CNPq e CAPES pelo auxílio financeiro.

Muito obrigada! 


\section{ÍNDICE}

$\begin{array}{lr}\text { Nota do autor } & 10\end{array}$

Resumo 11

$\begin{array}{lr}\text { Abstract } & 12\end{array}$

Capítulo 1 - Introdução geral 13

1.1.Músculo esquelético e regeneração 13

$\begin{array}{ll}\text { 1.2.Distrofias musculares } & 17\end{array}$

$\begin{array}{ll}\text { Distrofias Musculares de Cinturas (LGMDs) } & 19\end{array}$

1.3.Distrofia Muscular de Cintura tipo 2B (LGMD2B) 21

1.3.1. Gene DYSF e mutações $\quad 21$

1.3.2. Proteína disferlina 22

1.3.3. Reparo de membrana 23

1.3.4. Interações proteicas e o reparo de membrana 26

1.3.5. Miogênese e o tricomplexo DYSF-FAM65B-HDAC6 29

1.4.Modelos animais 31

II - Objetivos 33

Capítulo 2 - Metodologia geral 34

1.2. Camundongos 34

2.1.1. Obtenção dos animais 34

2.1.2. Indução de lesão muscular por eletroporação 34

2.1.3. Coleta, preparação e congelamento dos músculos 35

2.1.4. Cortes histológicos $\quad 35$

2.1.5. Extração de RNA e qRT-PCR 37

2.1.6. Análise estatística 38

2.2. Cultura de células humanas 39

2.2.1. Obtenção das amostras e imortalização 39

2.2.2. Fusão de miotubos $\quad 39$

2.2.3. Diâmetro de miotubos $\quad 40$

2.2.4. Extração de RNA e qRT-PCR 40

2.2.5. Análise estatística 41 


\section{Capítulo 3}

Time course of regeneration is altered in dysferlin-deficient mice 42

$\begin{array}{ll}\text { Abstract } & 43\end{array}$

$\begin{array}{ll}\text { Resumo } & 44\end{array}$

$\begin{array}{ll}\text { Introduction } & 45\end{array}$

$\begin{array}{ll}\text { Materials and methods } & 47\end{array}$

$\begin{array}{ll}\text { Results } & 50\end{array}$

$\begin{array}{ll}\text { Discussion } & 57\end{array}$

$\begin{array}{ll}\text { References } & 62\end{array}$

Capítulo 4

Defective myoblast differentiation in human dysferlin-deficient cells $\quad 67$

$\begin{array}{ll}\text { Abstract } & 68\end{array}$

$\begin{array}{ll}\text { Resumo } & 69\end{array}$

$\begin{array}{ll}\text { Introduction } & 70\end{array}$

$\begin{array}{ll}\text { Materials and methods } & 71\end{array}$

$\begin{array}{ll}\text { Results } & 74\end{array}$

$\begin{array}{ll}\text { Discussion } & 78\end{array}$

$\begin{array}{lr}\text { References } & 82\end{array}$

Capítulo 5 - Discussão geral e conclusões $\quad 85$

Referências bibliográficas $\quad 89$ 


\section{Nota do autor}

Essa dissertação seguiu o formato de apresentação em capítulos, conforme as diretrizes estabelecidas pelo Instituto de Biociências (IB-USP). No primeiro capítulo é apresentada uma introdução geral, descrevendo aspectos gerais do músculo e da regeneração muscular, bem como reunindo as principais informações disponíveis sobre o papel da disferlina em eventos de degeneração e regeneração muscular. Ao final do capítulo são expostos os principais objetivos do estudo. O Capítulo 2 traz a metodologia geral compilada. Os Capítulos 3 e 4 contêm dois manuscritos de artigos científicos, redigidos em inglês, que serão submetidos à publicação em breve. Os demais capítulos foram escritos em português. No Capítulo 5 são apresentadas a discussão geral e as conclusões dos dois trabalhos.

As referências bibliográficas dos artigos estão listadas nos respectivos capítulos de cada manuscrito. Já as referências citadas na introdução geral, metodologia geral, discussão geral e conclusões estão relacionadas ao final da dissertação. Todas as referências foram redigidas seguindo as normas da ABNT. 


\section{Resumo}

ISHIBA, Renata. Degeneração e regeneração muscular em modelos murinos com deficiência de disferlina. 2017. 96 f. Dissertação de Mestrado (Genética) - Instituto de Biociências, Universidade de São Paulo, São Paulo, 2017.

A distrofia muscular de cintura 2B (LGMD2B) é uma doença neuromuscular causada pela redução ou ausência da proteína sarcolemal disferlina. A disferlina está envolvida no reparo de membrana por atuar no tráfego e fusão de vesículas após estresse mecânico e, quando deficiente, as alterações nesta via levam à degeneração progressiva e irreversível das fibras musculares. A disferlina também tem sido implicada na inflamação e na miogênese durante a degeneração e regeneração muscular. Recentemente, identificou-se um tricomplexo formado pela disferlina com duas proteínas citoplasmáticas, FAM65B e HDAC6, no início da diferenciação de mioblastos. Investigar a regulação destas interações é importante para avançar na compreensão das funções da disferlina e seu papel na função muscular. Neste estudo, a miogênese e o reparo muscular foram investigados in vivo e in vitro em modelos com deficiência de disferlina. Para estudar o processo regenerativo in vivo, utilizamos um modelo de eletroporação para induzir degeneração/regeneração no músculo distrófico levemente afetado do camundongo disferlina-deficiente $S J L / J$. A avaliação histopatológica e a expressão relativa dos genes Pax7, Myf5, MyoD e miogenina foram acompanhadas durante a recuperação muscular em diferentes tempos após a lesão. Além disso, investigamos os efeitos da deficiência de disferlina na expressão dos genes Fam65b e Hdac6. Observamos um curso de tempo alterado do processo de degeneração e regeneração, com notável capacidade regenerativa nos camundongos disferlina-deficientes, caracterizada por uma resposta mais rápida e eficaz nos primeiros dias após a lesão, em comparação com os camundongos normais. Além disso, Fam65b e Hdac6 foram ativados nos estágios iniciais da regeneração muscular, também com expressão mais elevada de ambos os genes no camundongo $S J L / J$. Esses resultados podem estar relacionados à uma possível condição pré-ativada do processo regenerativo no músculo de camundongos distróficos jovens. Para os experimentos in vitro, utilizamos células musculares humanas de pacientes com LGMD2B, com deficiência total de disferlina. A diferenciação muscular induziu a formação de miotubos mais finos e com menor frequência de núcleos por miotubo, sugerindo uma progressão retardada da formação de miotubos em células com LGMD2B. A expressão de mRNA de $M Y O D$ e $F A M 65 B$ não foi aparentemente afetada pela deficiência de disferlina durante a diferenciação, enquanto HDAC6 apresentou um pico transitório após 24 horas, apenas nas células normais. Além disso, o pico da miogenina ocorreu mais cedo nas células normais. Portanto, sugerimos que a disferlina estaria menos envolvida nos eventos iniciais de formação de pequenos miotubos, mas poderia desempenhar um papel importante nos estágios posteriores de diferenciação, que envolvem crescimento e alongamento de miotubos. Estes resultados fornecem dados interessantes para investigações adicionais de como a deficiência de disferlina afeta os reguladores miogênicos durante a diferenciação. Em conjunto, nossos dados sugerem que a deficiência de disferlina provoca alterações temporais na progressão dos eventos de regeneração muscular e de miogênese. A identificação de uma possível regulação dos componentes do tricomplexo pela disferlina pode indicar novas direções para investigar esta via como um potencial alvo para terapias.

Palavras-chave: Distrofias musculares; Disferlina; Regeneração muscular; Diferenciação muscular. 
ISHIBA, Renata. Muscle degeneration and regeneration in dysferlin-deficient murine models. 2017. 96 f. M.S. Dissertation (Genetics) - Instituto de Biociências, Universidade de São Paulo, São Paulo, 2017.

Limb girdle muscular dystrophy 2B (LGMD2B) is a neuromuscular disease caused by reduction or absence of the sarcolemmal protein dysferlin. Dysferlin is involved in membrane repair by acting on vesicular traffic and fusion after mechanical stress and, when deficient, changes in this pathway lead to progressive and irreversible degeneration of muscle fibers. Dysferlin has also been implicated in inflammation and myogenesis during muscle degeneration and regeneration. Recently, a tricomplex formed by dysferlin with two cytoplasmic proteins, FAM65B and HDAC6, was identified at the earlier stages of myoblast differentiation. Investigating the regulation of these interactions is important to advance in the understanding of the functions of dysferlin and its role in muscle function. In this study, myogenesis and muscle repair were investigated in vivo and in vitro in models with dysferlin deficiency. To study this effect in the regenerative process of muscle in vivo, we used a model of electroporation inducing muscle degeneration/regeneration in the mildly affected dystrophic muscle of dysferlin-deficient $S J L / J$ mouse. The histopathological evaluation and the relative expression of the genes Pax 7, Myf5, MyoD and myogenin were accompanied during muscle recovery at different time points after injury. In addition, we investigated the effects of dysferlin deficiency in the expression of genes Fam $65 \mathrm{~b}$ and Hdac6. We observed an altered time course of the degeneration and regeneration process, with remarkable regenerative capacity in dysferlin-deficient mice, characterized by a faster and effective response in the first days after injury, as compared to normal mice. Moreover, Fam65b and Hdac6 were activated at the early stages of muscle regeneration, also with higher expression of both genes in the $S J L / J$ mouse. These results may have been due to a possible pre-activated condition of the regenerative process in the muscle of young dystrophic mice. For the in vitro experiments, we used human muscle cells from patients with LGMD2B, with total deficiency of dysferlin. The muscular differentiation induced the formation of thinner myotubes and reduced frequency of myonuclei per myotube, suggesting a delayed progression of myotube formation in LGMD2B cells. mRNA expression of $M Y O D$ and $F A M 65 B$ was not apparently affected by dysferlin deficiency during differentiation, while HDAC6 exhibited a transient peak, only in healthy cells, after 24 hours. In addition, the myogenin peak occurred earlier in healthy cells. Thus, we suggested that dysferlin would be less involved in the first events of formation of early small myotubes, but could play an important role in the later stages of differentiation, which involves myotube growth and elongation. These results provide interesting data for further investigation of how dysferlin deficiency affects myogenic regulators during differentiation. Taken together, our data suggest that dysferlin deficiency causes temporal changes in the progression of the muscle regeneration and myogenesis events. The identification of possible regulation of tricomplex components by dysferlin may indicate new directions for investigating this pathway as a potential target for therapies.

Keywords: Muscular dystrophies; Dysferlin; Muscle regeneration; Muscle differentiation. 


\section{CAPÍTULO 1}

\section{I - Introdução geral}

\subsection{Músculo esquelético e regeneração}

O músculo estriado esquelético representa cerca de $40 \%$ da massa corporal e desempenha importante papel na movimentação voluntária, na respiração e sustentação corporal. Condições genéticas patológicas que levam à progressiva degeneração e fraqueza muscular abrangem um campo de estudos complexo e importante, dado o comprometimento sobre a qualidade de vida dos pacientes. No entanto, até o momento não existem terapias eficazes para o tratamento das doenças neuromusculares, apenas técnicas paliativas para atrasar o curso das manifestações e melhorar as condições de vida do paciente. Por isso, o entendimento dos mecanismos das doenças abre caminhos para potenciais terapias.

Estruturalmente, o músculo é constituído por feixes de fibras musculares alongadas, com formato e tamanho uniformes e múltiplos núcleos de localização periférica. No citoplasma, miofibrilas compostas principalmente por filamentos de actina e miosina conferem as estriações transversais características das unidades contráteis do músculo, denominadas sarcômeros (Clark et al., 2002). Como um tecido mecanicamente ativo, o músculo retém a capacidade de se adaptar a diversos estímulos e se recuperar diante da demanda gerada por atividades como exercícios físicos intensos, crescimento e lesões.

Após dano muscular, eventos dependentes do grau da lesão são desencadeados para restabelecer a homeostase celular. Dois mecanismos de reparo podem ser destacados (Wallace \& McNally, 2009). Em lesões que não comprometem a viabilidade celular, há reparo de membrana, mecanismo que envolve formação, tráfego e fusão de vesículas à região lesionada, requerendo de segundos a poucos minutos para ocorrer (Corrotte et al., 2015). Diante da impossibilidade de recuperar a integridade do sarcolema, o que ocorre em danos severos ou diante estágios crônicos de doenças neuromusculares, há degeneração e necrose das fibras musculares. O reparo muscular é então mediado pela ativação de uma população de células mononucleares denominadas células satélite, em um processo que demanda dias para o restabelecimento muscular (Sambasivan \& Tajbakhsh, 2007; Bentzinger et al., 2012). As células-satélite são assim 
denominadas por se posicionarem entre a lâmina basal e o sarcolema das fibras musculares (Mauro, 1961). Elas constituem de 2-7\% dos núcleos associados a cada fibra muscular (Rudnicki et al., 2008) e atuam como células-tronco musculares, importantes no processo regenerativo na vida adulta. Outros tipos celulares têm também sido implicados em funções miogênicas. Apesar disso, a capacidade regenerativa é essencialmente dependente das células satélite (Sambasivan et al., 2011; Relaix \& Zammit, 2012).

O reparo do tecido muscular na vida adulta é um processo coordenado que recapitula eventos da formação muscular durante o desenvolvimento embrionário, com a expressão de vários determinantes da miogênese em comum (Yan et al., 2003; Bentzinger et al., 2012). Em geral, as células satélite encontram-se quiescentes, sendo ativadas em resposta à lesão. Elas podem ser identificadas pela expressão de Pax7, tanto em seu estado quiescente como ativado. Uma vez ativadas, ocorrem divisões assimétricas, em que a sinalização celular permite que uma parte da população de células satélite seja mantida em estado quiescente para garantir a manutenção do pool de células tronco musculares, enquanto outra parte torna-se comprometida com a diferenciação muscular (Hawke \& Garry, 2001; Charge \& Rudnicki, 2004, Relaix et al., 2006). Elas proliferam e dão origem a células precursoras miogênicas, os mioblastos, que expressam um grupo de fatores de transcrição conhecidos como Fatores Musculares Regulatórios (MRFs). Os MRFs pertencem à superfamília de fatores de transcrição bHLH (basic helix-loop-helix), que inclui MyoD, Myf5, MRF4 e miogenina. Pouco tempo após a ativação e início da proliferação, ainda há expressão de Pax7 e dois fatores regulatórios primários entram em cena, MyoD e Myf5, que agem na ativação e proliferação dos precursores miogênicos. Myf5 promove a autorrenovação de células satélite (Charge \& Rudnicki, 2004), enquanto MyoD promove a progressão das células satélite para a diferenciação terminal, sendo um bom marcador para células satélite ativadas (Megeney et al., 1996). Após a fase de proliferação, Pax7 e Myf5 são reduzidos, os mioblastos se diferenciam em miócitos e se fundem, formando miotubos multinucleados. Em estágios mais avançados da diferenciação, inicia-se a expressão de miogenina e MRF4. Ocorre então a fusão de miotubos a fibras pré-existentes ou a formação de novas fibras por fusão homotípica de mioblastos (Sabourin \& Rudnicki, 2000; Rudnicki et al., 2008) (Fig. 1).

Não há patologias associadas a mutações dos fatores de transcrição miogênicos, no entanto, experimentos de inativação contribuem para a compreensão de suas funções 
no desenvolvimento muscular. Mutações no gene $\operatorname{Pax} 7$ conduzem à ausência de células satélite, por sua atuação como fator de especificação da linhagem miogênica (Seale et al., 2004). Com a inativação do gene $M y o D$, o desenvolvimento muscular é aparentemente normal, mas os níveis de expressão de Myf5 aumentam (Rudnicki et al., 1992). Similarmente, mutações em Myf5 não resultam em alterações na morfologia normal do músculo esquelético, no entanto os camundongos morrem por incapacidade respiratória logo após o nascimento (Braun et al., 1992). Surpreendentemente, em animais duplonocaute $M y o D / M y f 5$ não há formação de músculo esquelético devido à falta de fatores para a determinação miogênica, resultando em morte prematura dos camundongos (Rudnicki et al., 1993). Da mesma forma, mutações no gene da miogenina, causam morte devido à grande redução de massa muscular pela incapacidade de formar fibras secundárias (Venuti et al., 1995).
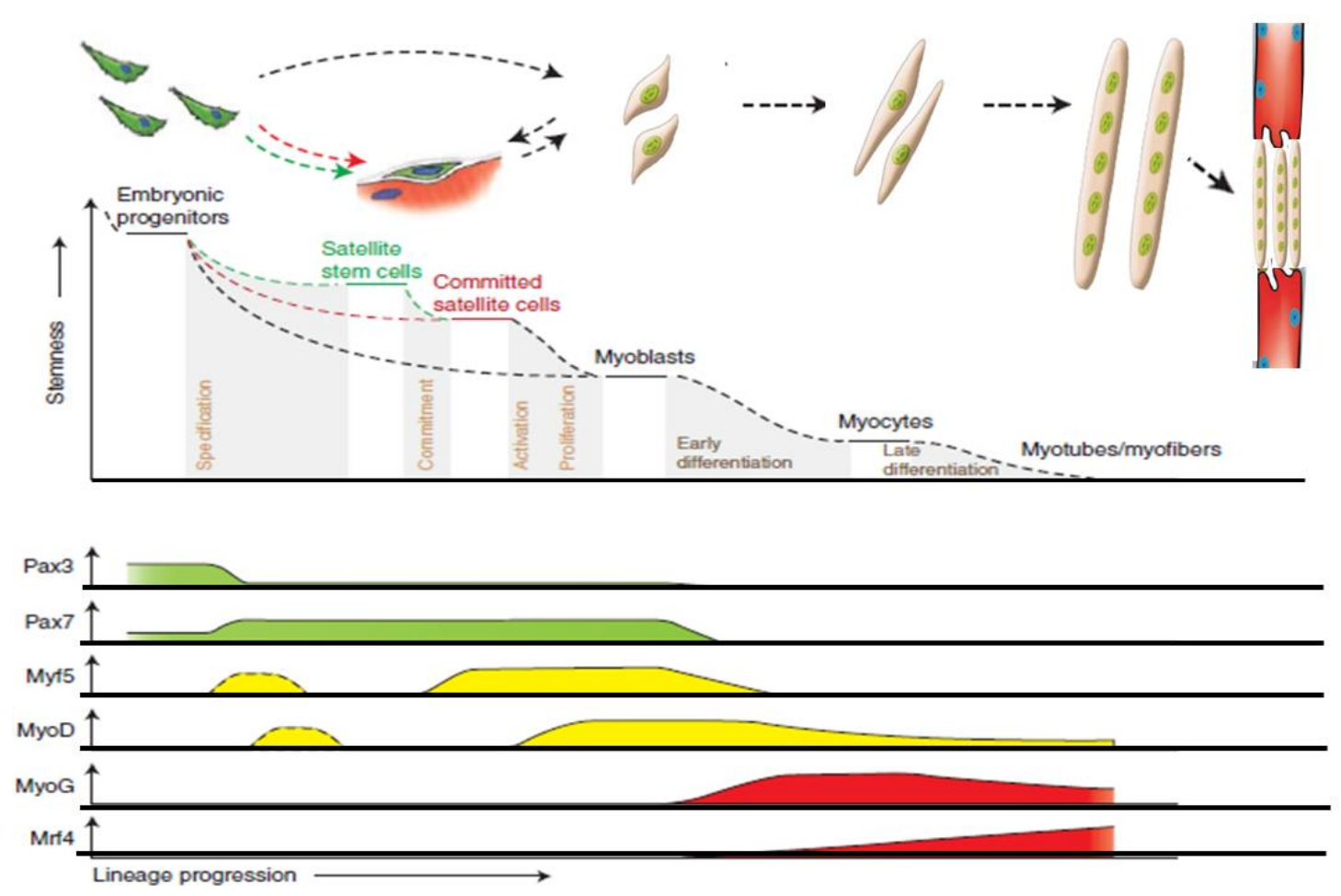

Figura 1: Representação esquemática dos fatores miogênicos envolvidos na ativação, proliferação e diferenciação de células-satélite durante a regeneração muscular. Modificado de Bentzinger et al. (2012).

Após lesão, o reparo muscular mediado por células satélite pode ser dividido em 3 fases (Huard et al., 2002; Charge \& Rudnicki, 2004; Turner \& Badylak, 2012): fase de degeneração, fase de regeneração e fase de remodelamento (Fig. 2). 
a. Fase de degeneração: após lesão, ocorre ruptura e necrose das fibras pela ativação de proteases cálcio-dependentes. A resposta inflamatória inicia-se nas primeiras horas após lesão, com infiltração de neutrófilos e macrófagos.

b. Fase de regeneração: ocorre fagocitose do tecido lesionado para remoção dos debris celulares. As células-satélite, antes em estado quiescente, são ativadas, proliferam e se diferenciam em mioblastos que sofrem fusão para formar miotubos. Estes se unem a miofibras pré-existentes, causando aumento da massa muscular (hipertrofia) ou formando novas fibras (hiperplasia). Nessa fase observam-se fibras de calibre menor e com núcleo central. Há formação de tecido cicatricial e revascularização.

c. Fase de remodelamento: em continuidade com a fase anterior, ocorre maturação e reorganização das fibras musculares. As miofibras atingem o tamanho normal e o núcleo se move para a periferia da fibra. Há remodelamento do tecido cicatricial e recuperação da capacidade funcional do músculo.
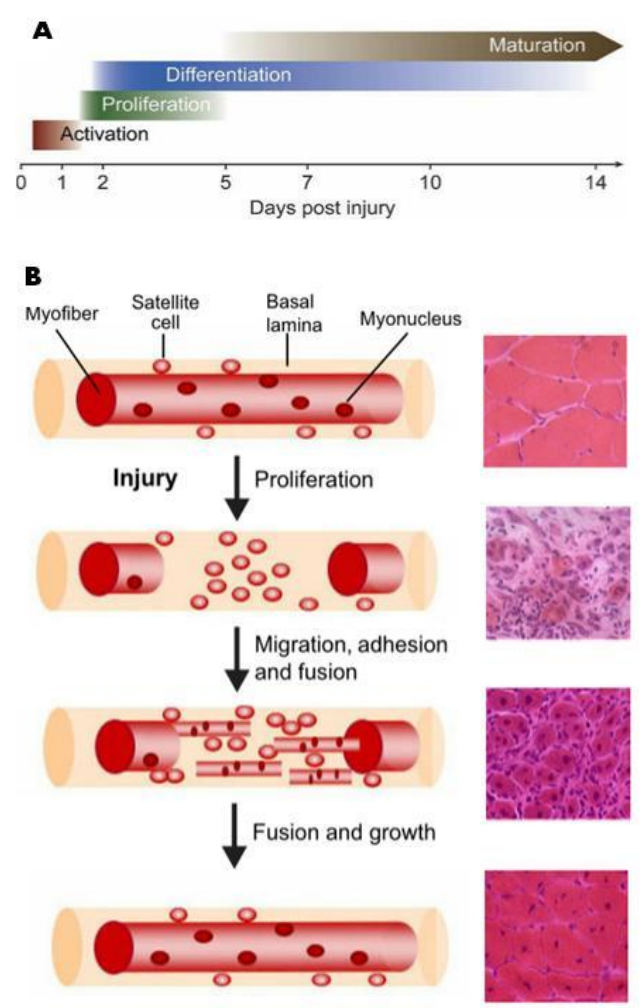

Figura 2: A -Estágios da regeneração muscular ao longo do tempo após lesão. Retirado de Shi \& Garry (2006). B - Durante a recuperação muscular, há ativação e proliferação de célulassatélite que migram para a região de lesão. Elas se diferenciam e formam novos miotubos, com núcleos centrais, ou se fundem a miofibras pré-existentes, contribuindo para o restabelecimento da citoarquitetura muscular. Retirado de Abmayr \& Pavlath (2012). 


\subsection{Distrofias musculares}

As distrofias musculares (DMs) compreendem um grupo de doenças genéticas que causam degeneração progressiva e irreversível da musculatura esquelética. A fraqueza muscular ocorre pelo desequilíbrio entre os ciclos de degeneração e regeneração, em eventos que envolvem perda de fibras musculares sem que haja subsequente reposição (Onofre-Oliveira et al., 2012). O aspecto muscular é alterado para fibras com calibre variável e núcleo centralizado, áreas de necrose e infiltração de células inflamatórias. Fatores como a citocina inflamatória TGF- $\beta 1$ (Transforming growth fator $\beta 1$ ), apresentam expressão aumentada (Gosselin et al., 2004). TGF- $\beta 1$ afeta a regeneração muscular por inibir a proliferação de células satélite e a fusão de miofibras (Allen \& Boxhorn, 1987). Na matriz extracelular, atua na síntese de colágeno e proliferação de fibroblastos (Overall et al., 1991). O processo crônico de degeneração no músculo distrófico limita a regeneração eficiente, resultando em deposição de tecido conjuntivo e adiposo (Wallace \& McNally, 2009).

A grande heterogeneidade das DMs se revela nas mais de 40 formas com genes já descritos, variando quanto ao padrão de herança, grupos musculares afetados, severidade, velocidade de progressão e início das manifestações clínicas (Mercuri \& Muntoni, 2013). De acordo com o padrão de distribuição de fraqueza muscular predominante, as DMs podem ser divididas em subgrupos que incluem Duchenne e Becker, Emery-Dreifuss, cinturas, fácio-escápulo-umeral, distal e oculofaríngea (Emery, 2002) (Fig. 3).

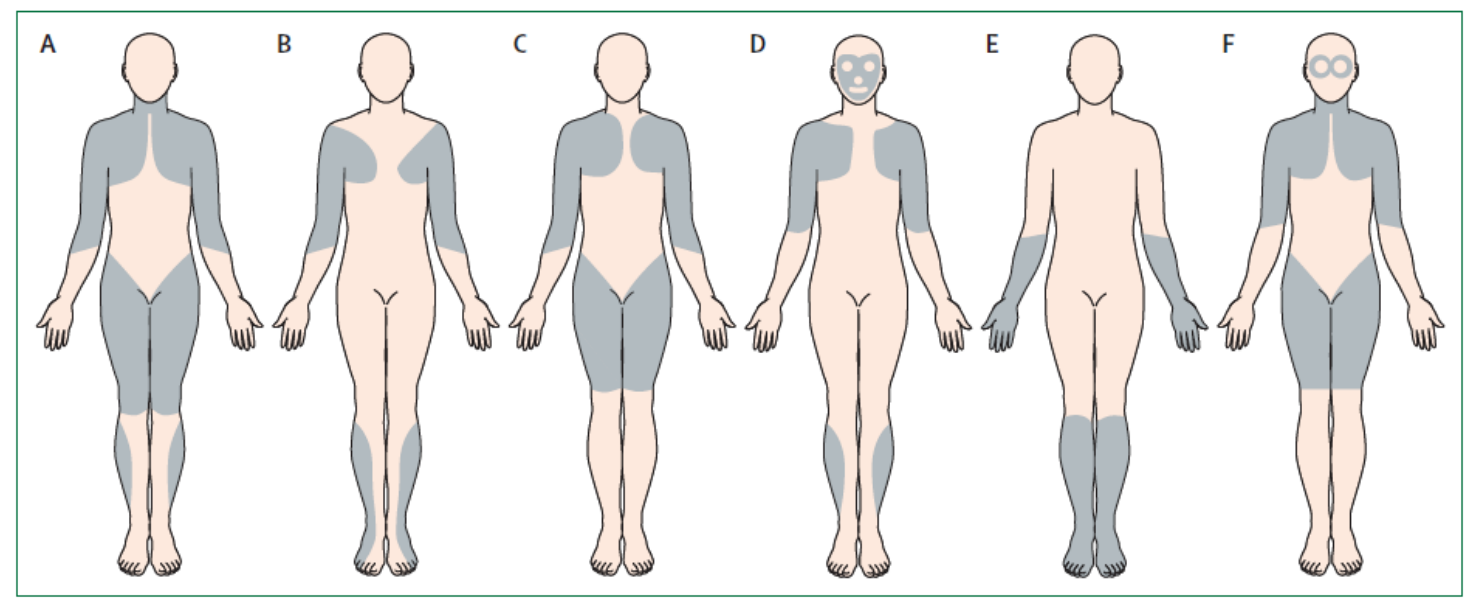

Figura 3: Padrões de distribuição de fraqueza muscular predominante nas distrofias musculares (A) Duchenne e Becker; (B) Emery-Dreifuss; (C) Cinturas; (D) Fácio-escápulo-umeral; (E) Distal; (F) Oculofaríngea. Modificado de Emery (1998). 
As DMs ocorrem devido a mutações que geram deficiência parcial ou total de proteínas musculares presentes em diversos compartimentos, incluindo sarcolema, citoesqueleto, membrana nuclear e matriz extracelular. Como consequência, há comprometimento da estabilidade estrutural do músculo esquelético devido a alterações de influxo de cálcio e ao estresse oxidativo (Shin et al., 2013). Algumas distrofias envolvem disfunções de proteínas integrais e associadas à membrana que fazem parte do complexo distrofina-glicoproteínas (CDG) (Ibraghimov-Beskrovnaya et al., 1992; Cohn \& Campbell, 2000). Uma dessas proteínas, a distrofina se liga a proteínas sarcolemais e aos filamentos de actina no citoplasma, conectando o citoesqueleto miofibrilar à matriz extracelular. A deficiência de distrofina causa a Distrofia Muscular de Duchenne (DMD), o tipo mais comum e grave de distrofia muscular, com incidência de 1:3500 meninos. Mutações em proteínas pertencentes ao subcomplexo sarcoglicano do CDG ( $\alpha-, \beta-, \gamma-$, $\delta$ - e $\varepsilon$-SG), e em uma proteína sarcolemal denominada disferlina, estão envolvidas em um grupo grande e heterogêneo de miopatias denominadas Distrofias Musculares de Cinturas (LGMD, do inglês Limb-Girdle Muscular Dystrophy) (Nigro \& Piluso, 2015)

(Fig. 4).

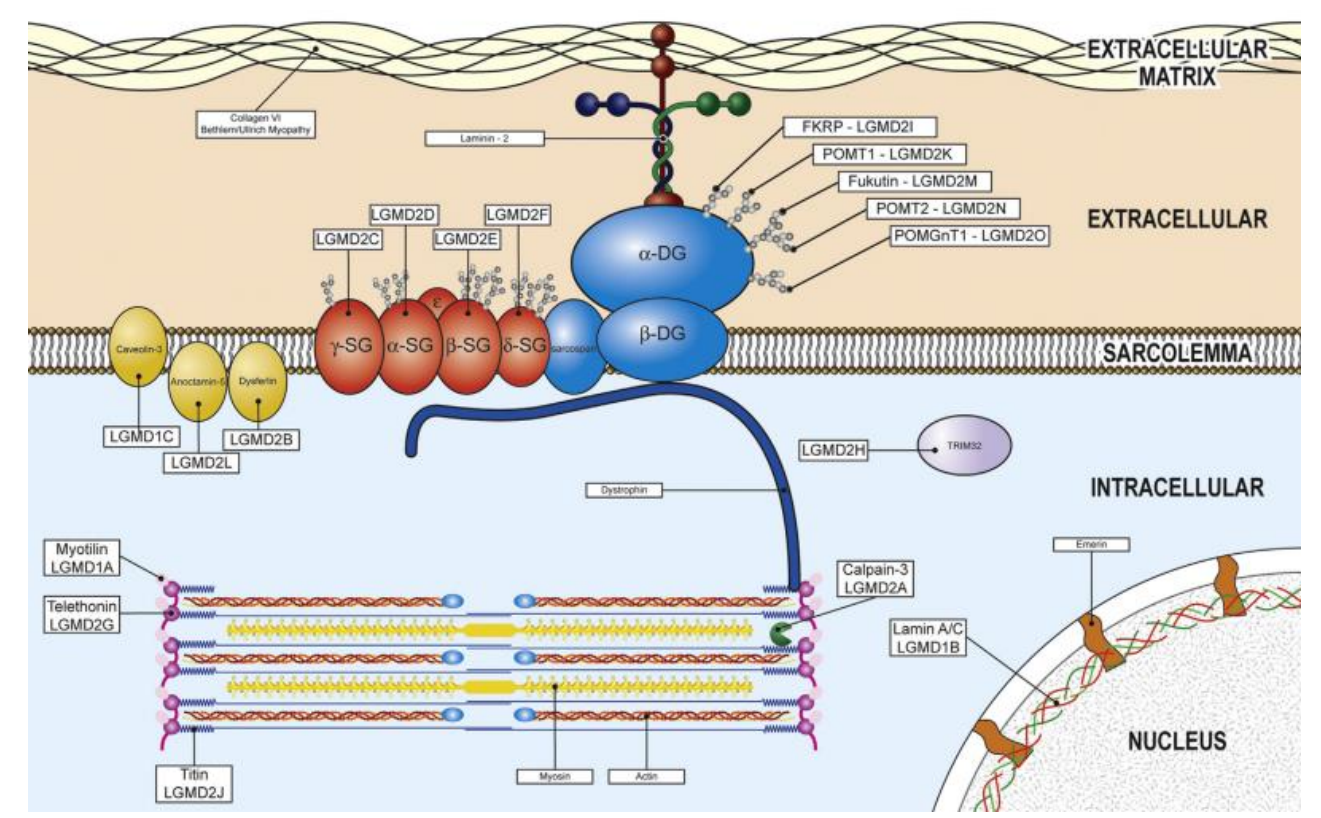

Figura 4: Organização de proteínas associadas às Distrofias Musculares de Cinturas (LGMDs). Retirado de Wicklund \& Kissel (2014). 


\section{$\underline{\text { Distrofias Musculares de Cinturas (LGMDs) }}$}

As LGMDs apresentam grande heterogeneidade de lócus, com muitos genes diferentes causando quadro clínico semelhante. Há graus variáveis de comprometimento da musculatura, principalmente afetando os músculos proximais (Vainzof \& Zatz, 2003).

Elas são classificadas de acordo com a herança em tipo 1 (LGMD1) para as autossômicas dominantes e tipo 2 (LGMD2) para as autossômicas recessivas. As diferentes miopatias dentro de cada tipo são indicadas por letras, seguindo a ordem em que foram descritas. Oito formas autossômicas dominantes (LGMD1 A-H) (Tabela 1) e vinte e quatro autossômicas recessivas (LGMD2 A-X) (Tabela 2) já foram descritas até o momento, envolvidas em funções estruturais e regulatórias, na estabilização do CDG, na glicosilação, no reparo de membrana, entre outras (Bushby, 1999; Laval \& Bushby, 2004). As formas recessivas são as mais comuns, representando $90 \%$ de todas as LGMDs, com uma incidência de 1:15000 (Nigro, 2003). Dentre elas, a LGMD2B, causada pela deficiência de disferlina, é a segunda forma recessiva mais frequente em muitos países, atrás apenas da LGMD2A, causada pela deficiência de calpaína (Nigro \& Savarese, 2014).

Tabela 1: Distrofias Musculares de Cinturas (LGMDs) - Formas autossômicas dominantes. Adaptado de (Nigro \& Savarese, 2014; Wicklund \& Kissel, 2014; http://neuromuscular.wustl.edu/syncm.html).

\begin{tabular}{|c|c|c|c|c|c|c|c|}
\hline LGMD & GENE & LOCUS & PROTEINA & FUNÇAO & LOCALIZAÇAO & INICIO & PROGRESSA $O$ \\
\hline$\overline{1 A}$ & TTID & $5 \mathrm{q} 31.2$ & miotilina & estrutural & linha Z & $20-40$ & lenta \\
\hline $1 B$ & LMNA & $1 \mathrm{q} 22$ & lamina $\mathrm{A} / \mathrm{C}$ & estrutural & $\begin{array}{c}\text { membrana } \\
\text { nuclear }\end{array}$ & $4-38$ & lenta \\
\hline $1 \mathrm{C}$ & CAV3 & $3 \mathrm{p} 25.3$ & caveolina 3 & $\begin{array}{l}\text { endocitose/ } \\
\text { pinocitose }\end{array}$ & sarcolem a & $5-25$ & $\begin{array}{c}\text { lenta/ } \\
\text { moderada }\end{array}$ \\
\hline 1D & DNAJB6 & $7 \mathrm{q} 36$ & DnaJB6 & chaperona & $\begin{array}{c}\text { citoplasm a/ } \\
\text { linha Z }\end{array}$ & $25-50$ & lenta \\
\hline $1 E$ & DES & $2 \mathrm{q} 35$ & desmina & estrutural & $\begin{array}{l}\text { filam ento } \\
\text { interm ediário }\end{array}$ & $15-50$ & lenta \\
\hline $1 F$ & TNPO3 & $7 q 32$ & transportina 3 & importina & $\begin{array}{l}\text { citoplasm a- } \\
\text { núcleo }\end{array}$ & $1-58$ & $\begin{array}{l}\text { lentad } \\
\text { m oderada }\end{array}$ \\
\hline $1 \mathrm{G}$ & HNRPDL & $4 q 21$ & $\begin{array}{l}\text { heterogeneous } \\
\text { nuclear } \\
\text { ribonucleoprotein } \\
\text { D-like }\end{array}$ & $\begin{array}{c}\text { processam ento } \\
\text { de RNA }\end{array}$ & núcleo & $13-53$ & lenta \\
\hline $1 H$ & $?$ & $3 \mathrm{p} 23-\mathrm{p} 25$ & $?$ & $?$ & $?$ & $10-50$ & lenta \\
\hline
\end{tabular}


Tabela 2: Distrofias Musculares de Cinturas (LGMDs) - Formas autossômicas recessivas. Adaptado de (Nigro \& Savarese, 2014; Wicklund \& Kissel, 2014; http://neuromuscular.wustl.edu/syncm.html).

\begin{tabular}{|c|c|c|c|c|c|c|c|}
\hline LGMD & GENE & LOCUS & PROTEINA & FUNCAO & LOCALIZACAO & INICIO & PROGRESSAO \\
\hline $2 \mathrm{~A}$ & CAPN3 & $15 \mathrm{q} 15$ & calpaina 3 & $\begin{array}{l}\text { remodelam ento do } \\
\text { citoesqueleto/ } \\
\text { reparo de membrana/ } \\
\text { controle do fluxo de } \\
\qquad \mathrm{Ca2}+\end{array}$ & citosol & $5-25$ & $\begin{array}{l}\text { moderada/ } \\
\text { rápida }\end{array}$ \\
\hline 2B & DYSF & $2 \mathrm{p} 13.2$ & disferlina & $\begin{array}{l}\text { fugăo e trăfego de } \\
\text { vesiculast } \\
\text { reparo de membrana/ } \\
\text { miogênesefinflam ação }\end{array}$ & $\begin{array}{c}\text { sarcolem af } \\
\text { vesiculas } \\
\text { citoplasnaticas } \\
\text { túbulos } \mathrm{T}\end{array}$ & 10.30 & lenta \\
\hline $2 \mathrm{C}$ & SGCG & $13 q 12$ & $\gamma$-sarcogicana & estrutural & sarcolem a & $3-20$ & rápida \\
\hline 2D & SGCA & $17 \mathrm{q} 21.33$ & a-sarcoglicana & estrutural & sarcolema & $3-20$ & rápida \\
\hline $2 \mathbf{E}$ & SGCB & $4 q^{12}$ & $\beta$-sarcogicana & estrutuaral & sarcolem a & 3.20 & rápida \\
\hline $2 F$ & SGCD & $5 \mathrm{q} 33$ & 8-sarcogicana & estrutural & sarcolema & $3-20$ & rápida \\
\hline $2 \mathbf{G}$ & TCAP & $17 q 12$ & teletonina & estrutural & sarcômero & $2-15$ & lenta \\
\hline $2 \mathbf{H}$ & TRIM32 & $9 \mathrm{q} 33.1$ & $\begin{array}{l}\text { tripartite motif } \\
\text { containing } 32\end{array}$ & ubiquitinaçäo & citosol & 5.30 & lenta \\
\hline $2 I$ & FKRP & $19 \mathrm{q} 13.3$ & $\begin{array}{l}\text { fukutin related } \\
\text { protein }\end{array}$ & glicosilação & Golgi & 1.40 & moderada \\
\hline $2 \mathrm{~J}$ & TTN & $2 q 24.3$ & titina & estrutuaral & sarcôm ero & 5.20 & severa \\
\hline $2 \mathrm{~K}$ & POMT1 & $9 \mathrm{q} 34.1$ & $\begin{array}{c}\text { protein-O-mannosy1 } \\
\text { tranaferase } 1\end{array}$ & dicosilaçäo & $\begin{array}{c}\text { retículo } \\
\text { endoplasm ático }\end{array}$ & $<5$ & lenta \\
\hline $2 \mathbf{L}$ & ANOS & $\begin{array}{c}11 \mathrm{p} 13 . \\
\mathrm{p} 12\end{array}$ & anoctamina 5 & miogênese & sarcolema & $20-50$ & lenta \\
\hline $2 \mathrm{M}$ & FKTN & $9 \mathrm{q} 31$ & fukutina & dicosilaçăo & Golgi & $<5$ & moderada \\
\hline $2 \mathrm{~N}$ & POMT2 & $14 \mathrm{q} 24$ & $\begin{array}{c}\text { protein-O-m annosyl } \\
\text { tranferase } 2\end{array}$ & dicosilação & $\begin{array}{c}\text { retículo } \\
\text { endoplasm ático }\end{array}$ & $<2$ & lenta \\
\hline 20 & POMGnTI & $1 \mathrm{p} 34.1$ & $\begin{array}{c}\text { protein O-linked } \\
\text { mannose betal,2. } \\
\text { Nacetylglucosaminy1 } \\
\text { transferase }\end{array}$ & glicosilação & Golg & 12 & moderada \\
\hline $2 \mathbf{P}$ & DAG1 & $3 \mathrm{p} 21$ & distroglicana & estrutural & sarcolem a & 3 & moderada \\
\hline $2 Q$ & PLEC1 & $8 \mathrm{q} 24$ & plectina & $\begin{array}{l}\text { dinâmica do } \\
\text { citoesqueleto }\end{array}$ & citosol & $<5$ & lenta \\
\hline $2 \mathbf{R}$ & DES & $2 \mathrm{q} 35$ & desan ina & estrutural & $\begin{array}{l}\text { falam ento } \\
\text { interm ediário }\end{array}$ & 1.25 & $\cdot$ \\
\hline $2 S$ & $\begin{array}{c}\text { TRAPPC1 } \\
1\end{array}$ & $4 \mathrm{q} 35$ & $\begin{array}{l}\text { transport protein } \\
\text { particle complex } 1\end{array}$ & tráfego de vesiculas & citosol & 5.10 & lenta \\
\hline $2 \mathrm{~T}$ & GMPPB & $3 \mathrm{p} 21$ & $\begin{array}{l}\text { GDP-m annose } \\
\text { pyrophosphcrylase B }\end{array}$ & dicoslação & citosol & $<5$ & lenta \\
\hline $2 U$ & ISPD & $7 \mathrm{p} 21$ & $\begin{array}{l}\text { I soprenoid synthase } \\
\text { dom ain containing }\end{array}$ & gicosłação & - & $<1$ & $\begin{array}{l}\text { rápidal } \\
\text { moderada }\end{array}$ \\
\hline $2 \mathrm{~V}$ & GAA & $17 \mathrm{q} 25.3$ & $\begin{array}{l}\text { Alpha-1,4- } \\
\text { ducosidase }\end{array}$ & $\begin{array}{c}\text { conversão de enzim a } \\
\text { lisossom al }\end{array}$ & lisoseomo & Variável & $\begin{array}{c}\text { variável(rópida a } \\
\text { lenta) }\end{array}$ \\
\hline $2 w$ & LIMS2 & $2 \mathrm{q}^{14}$ & $\begin{array}{l}\text { Lim and senescent } \\
\text { cell } \\
\text { antigen-like dcen ains } \\
2\end{array}$ & $\begin{array}{l}\text { Modula o crescim ento } \\
\text { e migração celular }\end{array}$ & Citosol & Infância & - \\
\hline $2 \mathrm{X}$ & $\begin{array}{l}\text { POPDC1 } \\
\text { BVES }\end{array}$ & $6 \mathrm{q} 21$ & Popdc1 & Tráfego de mem brana & $\begin{array}{l}\text { sarcolem a, } \\
\text { túbulos } T \text {, } \\
\text { mem brana nuclear }\end{array}$ & $30-50$ & Lenta \\
\hline
\end{tabular}




\subsection{Distrofia Muscular de Cintura tipo 2B (LGMD2B)}

A Distrofia Muscular de Cintura tipo 2B (LGMD2B) (Bashir et al., 1998) faz parte de um grupo de miopatias, coletivamente chamadas de disferlinopatias. Além da LGMD2B, outros fenótipos são relatados como a Miopatia de Miyoshi (Liu et al., 1998) e a Miopatia Distal com início no tibial anterior (Illa et al., 2001). Elas se distinguem por apresentarem diferenças no comprometimento muscular primário, iniciando nos músculos proximais na LGMD2B e nos músculos distais gastrocnêmio e tibial anterior nas miopatias de Miyoshi e Distal, respectivamente (Urtizberea et al., 2008). As disferlinopatias são causadas por mutações no gene que codifica a disferlina, uma proteína sarcolemal de distribuição ubíqua, com expressão predominante no músculo esquelético e no coração (Anderson et al., 1999). A deficiência dessa proteína provoca fraqueza muscular, inflamação e elevada concentração plasmática da proteína muscular creatina quinase (Bashir et al., 1994).

A LGMD2B manifesta os primeiros sintomas comumente entre 15 e 25 anos de idade. Antes disso, os indivíduos não apresentam comprometimento muscular, sendo frequentemente ativos em esportes (Angelini et al., 2011). A progressão é lenta, em geral, levando a dependência de cadeiras de rodas entre 10 a 20 anos após o início dos sintomas (Wicklund \& Kissel, 2014). O diagnóstico pode ser baseado na detecção de redução ou ausência de disferlina por western blotting ou por imunohistoquímica de biópsias musculares. Uma investigação mais precisa é obtida por sequenciamento de DNA (Kesper et al., 2009; Lo et al., 2008; Wicklund \& Kissel, 2014).

\subsubsection{Gene DYSF e mutações}

O gene responsável pela LGMD2B foi mapeado no cromossomo 2p13, composto por 55 exons em sua forma canônica. Cerca de 266 mutações afetando diferentes regiões da proteína já foram descritas, sem indícios de hotspots, tornando a análise mais trabalhosa. A maioria das mutações é de ponto $(51,1 \%)$, das quais $64,8 \%$ são missense e $35,2 \%$ nonsense. O restante corresponde a deleções e inserções $(31,6 \%)$, além de mutações intrônicas (17,3\%) (Blandin et al., 2012).

Há relevante variedade entre os pacientes quanto à severidade das manifestações clínicas. A heterogeneidade clínica ocorre mesmo entre pacientes da mesma família, com 
a mesma mutação causando LGMD2B ou Miopatia de Miyoshi. Por isso, uma relação genótipo-fenótipo é difícil de ser definida (Weiler et al., 1999). Possíveis causas podem estar relacionadas ao efeito de genes modificadores, interferência de fatores ambientais, modulação por interações entre proteínas e ação de microRNAs. Embora, ainda não bem compreendido, os avanços nesses segmentos podem trazer respostas para a complexa interpretação da relação genótipo-fenótipo (Carter et al., 2013).

Alguns exemplos podem ser citados para esses casos. Em estudos com camundongos $m d x$, deficientes para a proteína distrofina, a regulação positiva de mioferlina sugere sua possível função como gene modificador em distrofias musculares. Uma vez que a mioferlina partilha alto grau de homologia com a disferlina, ela poderia atuar compensando sua deficiência (Weiler et al., 1999; Davis et al., 2000). Publicações nos últimos anos também têm evidenciado a importância de intrincadas interações proteicas no entendimento de mecanismos patológicos (Hao et al., 2014). Adicionalmente, fatores externos podem contribuir para as divergências encontradas. Um estudo que investigou a influência de atividades precedentes ao início dos sintomas no curso e progressão das disferlinopatias em pacientes mostrou que indivíduos muito ativos em esportes têm uma evolução mais rápida da doença após os primeiros anos do início dos sintomas (Angelini et al., 2011). Outros fatores como a ação de microRNAs na regulação da expressão gênica revelam um campo promissor a ser aprofundado (Ge \& Chen, 2011). Eisenberg et al., 2007 relatou considerável número de microRNAs regulados positivamente em diferentes distrofias, comparados ao músculo normal e sugeriu que nas disferlinopatias, o padrão distinto de microRNAs encontrado entre a LGMD2B e a Miopatia de Miyoshi pode ser um indício de um mecanismo regulatório secundário modulando os diferentes fenótipos.

\subsubsection{Proteína disferlina}

O transcrito do gene da disferlina codifica uma proteína transmembrana de 237 $\mathrm{kDa}$. O nome disferlina foi dado devido à sua homologia com o fator fer- 1 do nematódeo Caenorhabditis elegans. Esse fator está associado à fusão de vesículas durante a espermatogênese e faz parte da família ferlina de proteínas que também inclui a otoferlina (Yasunaga et al., 1999) e a mioferlina (Davis et al., 2000), homólogas à disferlina. Membros dessa família apresentam domínios C2, encontrados nas sinaptotagminas. Eles 
funcionam como sensores de cálcio e interagem com proteínas SNARE, proporcionando o tráfego e a fusão de membranas (Bansal \& Campbell, 2004; Glover \& Brown, 2007).

A disferlina está localizada preferencialmente nos túbulos-T do músculo maduro. Os túbulos $\mathrm{T}$ são invaginações do sarcolema em estreita proximidade com retículo sarcoplasmático. Essas regiões encontram-se associadas à canais de cálcio do tipo L, desempenhando funções na manutenção da homeostase de cálcio durante estresse mecânico (Kerr et al., 2014). Estruturalmente, a disferlina é formada por sete domínios C2 e dois domínios Dysf, ancorada ao sarcolema por seu domínio C-terminal (Sula et al., 2014). A extremidade amino-terminal com o domínio C2A é a mais bem caracterizada por ligar-se a fosfolipídeos de forma cálcio-dependente. Os demais domínios, embora não bem definidos funcionalmente, têm afinidade variável por cálcio e fosfolipídeos (Davis et al., 2002).

Diversos trabalhos buscando investigar a função da disferlina foram publicados nos últimos anos, apontando para o seu papel no reparo de membrana (Bansal et al., 2003; Cenacchi et al., 2005), inflamação (Han, 2011) e miogênese (De Luna et al., 2006; Roche et al., 2008; Chiu et al., 2009, Roche et al., 2010; Cohen et al., 2012).

\subsubsection{Reparo de membrana}

As células são capazes de reparar o sarcolema em segundos a poucos minutos após estresse mecânico. A resposta a danos sarcolemais é potencializada pelo influxo de cálcio que desencadeia uma cascata de interações proteicas culminando em rápido reparo de membrana (Davenport et al., 2016).

Os mecanismos de reparo variam dependendo da extensão da lesão e alguns deles podem coexistir. Lesões mecânicas maiores que $100 \mathrm{~nm}$ promovem exocitose de agregados vesiculares no chamado patch model, enquanto em lesões formadoras de poros menores que $100 \mathrm{~nm}$, como as produzidas por toxinas bacterianas, há exocitose de lisossomos. Esses mecanismos podem coexistir (Cooper \& McNeil, 2015).

O patch model, a hipótese mais largamente aceita para lesões de alto calibre, descreve a remoção de danos pela selagem do sarcolema por exocitose. Nesse modelo, vesículas intracelulares sofrem fusão homotípica vesícula-vesícula na região subsarcolemal adjacente ao local lesionado. Em seguida, ocorre exocitose por fusão 
heterotípica dos agregados vesiculares com o sarcolema, selando a região danificada (Davenport et al., 2016). O trecho de membrana exocitado, chamado de patch, expõe o lado interno das vesículas intracelulares, rico em fosfatidilserina, para o meio extracelular. A disferlina exerce um papel importante para o acúmulo desse lipídio de membrana no local de lesão, se ligando a ele de forma cálcio dependente. Em um trabalho recente, a remoção da lesão foi associada ao reconhecimento de fosfatidilserina por macrófagos que fagocitam partes do patch, restabelecendo a integridade de membrana (Middel et al., 2016).

A origem das vesículas intracelulares ainda não está bem elucidada. Um autor propõe que após dano, actina cortical recruta sarcolema adjacente, contendo naturalmente disferlina transmembrana em sua composição para o local lesionado, comprimindo o tamanho da lesão. Nesse recrutamento, criam-se regiões ricas em disferlina próximas à lesão. Simultaneamente, porções distais do sarcolema sofrem endocitose formando as vesículas intracelulares. As vesículas sofrem fusão entre si e com lisossomos para formar vesículas maiores que reparam a lesão via interações com a zona rica em disferlina, anteriormente formada. $\mathrm{O}$ tráfego e fusão de vesículas requer microtúbulos e a cinesina KIF5B. O rompimento da ligação vesículas-microtúbulos ou a deficiência de disferlina levaria a defeitos no reparo de membrana por redução da exocitose e acúmulo citoplasmático de pequenas vesículas contendo disferlina na região subsarcolemal (McDade \& Michele, 2014) (Fig. 5). 
A
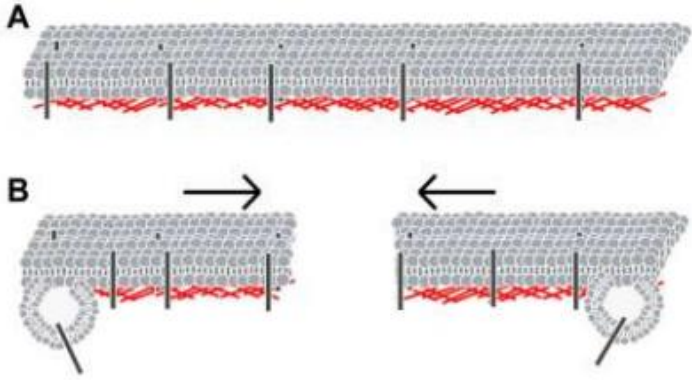

C

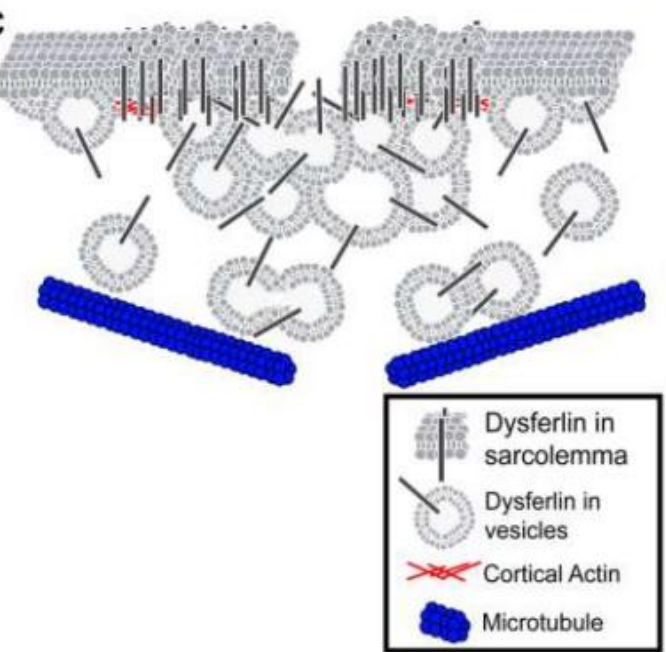

Figura 5: Modelo de reparo de membrana: patch model. A: No músculo intacto, a disferlina encontra-se no sarcolema. B: Diante de lesão, a actina cortical contribui para que regiões de membrana com disferlina adjacentes se desloquem para o local da lesão. Regiões sarcolemais distais ao local da lesão são endocitadas, formando vesículas contendo disferlina em suas membranas. C: Essas vesículas agregam-se homotipicamente, formando vesículas maiores que se fundem ao sarcolema para selar o local lesionado. Retirado de McDade - PhD Thesis (2014).

Em lesões menores, formadoras de poros, o influxo de cálcio provoca exocitose de lisossomos que se fundem individualmente à membrana, liberando o ácido esfingomielinase no meio extracelular. Essa enzima é importante para desencadear a endocitose das regiões de lesões. $\mathrm{Na}$ endocitose, o ácido esfingomielinase liberado converte um lipídio de membrana, a esfingomielina, em ceramida na região externa da membrana. O resultado é a formação de um microdomínio que é invaginado na região de lesão, permitindo a remoção dos danos (Tam et al., 2010). A deficiência de disferlina leva à redução da exocitose de lisossomos, diminuindo o reparo (Defour et al., 2014) (Fig. 6). 


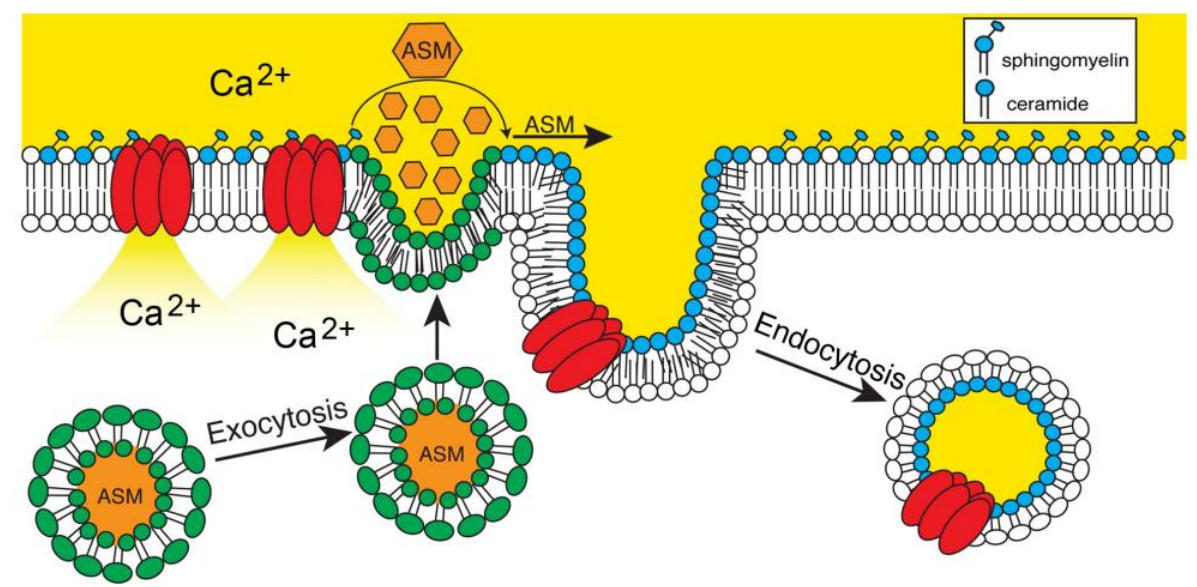

Figura 6: Modelo de reparo de membrana: exocitose de lisossomos. Há influxo de cálcio extracelular através de poros (em vermelho) formados por lesões sarcolemais, tais como causados por alguns tipos de bactérias. A resposta celular é de exocitose de lisossomos que ao ser fundirem ao sarcolema liberam seu conteúdo de ácido esfingomielinase. Essa enzima age sobre lipídios da superfície sarcolemal, convertendo esfingomielina em ceramidas. Nessas regiões criam-se microdomínios que são endocitados, internalizando e removendo as regiões lesionadas. Retirado de Tam et al. (2010).

\subsubsection{Interações proteicas e o reparo de membrana}

A disferlina encontra-se em estreita proximidade com canais de cálcio do tipo L (também referidos como DHPR - dihydropyridine receptor) nos túbulos-T (Ampong et al., 2005), consistente com sua função dependente de sinalização por cálcio. Diante de estresse mecânico, o influxo de cálcio devido a danos ao sarcolema funciona como sensor para a ativação de uma cascata de interações proteicas com a disferlina, desencadeando o reparo de membrana (Bansal et al., 2003). Nesse processo, há agregação e translocação de vesículas intracelulares, contendo disferlina em suas membranas, para a região da lesão por meio de cinesinas motoras. As vesículas se acumulam na região subsarcolemal adjacentes à lesão e fundem entre si e, por fim, com a região danificada por exocitose, restabelecendo a homeostase celular (McDade \& Michele, 2014). Nas disferlinopatias, o estresse mecânico provoca o desbalanço de cálcio por falhas no reparo de membrana. A proteólise e exposição prolongada ao ambiente extracelular oxidativo conduz à necrose e inflamação (Kerr et al., 2014).

Para exercer sua função, a disferlina interage com várias proteínas musculares, entre elas a caveolina-3 (Matsuda et al., 2001), as anexinas A1, A2 e A6 (Lennon et al., 2003; Roostalu \& Strähle, 2012), a calpaína-3 (Huang et al., 2005; Huang et al., 2008), a AHNAK (Huang et al., 2007) e a mitsugumina 53 (MG53) (Cai et al., 2009) (Fig. 7). 
No músculo normal, intacto, a caveolina-3 (cav-3) está colocalizada com a disferlina no sarcolema. A cav-3 contribui para a formação de cavéolos, invaginações do sarcolema com função de endocitose, e para a formação de túbulos-T (Parton et al., 1997; Waddel et al., 2011). Ela mantém um pool de disferlina no sarcolema por inibir sua endocitose (Hernandez-Deviez et al., 2008). Sua deficiência causa a LGMD1C e resulta em redução secundária de disferlina no sarcolema pela agregação e retenção de ambas no complexo de Golgi, o que sugere um possível papel da cav-3 no transporte pós-Golgi de disferlina para o sarcolema (Matsuda et al., 2001, Waddel et al., 2011).

A mitsugumina 53 (MG53), também chamada de TRIM72 (tripartite motif 72), interage com a disferlina e a caveolina 3, participando dos eventos iniciais do reparo de membrana. Ela se acumula na região de lesão antes da disferlina e facilita o deslocamento de vesículas para o local da lesão. A MG53 se liga à fosfatidilserina, presente na membrana das vesículas e na superfície interna do sarcolema, auxiliando na translocação de vesículas ao local da lesão. Esse processo funciona de uma maneira dependente de exposição ao meio extracelular oxidativo, o que ocorre diante de lesões sarcolemais (Cai et al., 2009). A ação antagonista da cav-3 controla a reciclagem de membranas através do equilíbrio entre exocitose e endocitose (Cai et al., 2009).

As anexinas, acionadas pelo influxo de cálcio, atuam agregando vesículas para o local da lesão. As anexinas A1, A2 e A6 são depositadas de forma ordenada na região lesionada. A adição de cada uma é dependente da correta deposição da antecedente. Inicialmente, membranas de vesículas ricas em disferlina e anexina A6 citoplasmática acumulam-se no local da lesão, de forma independente. Em seguida, a anexina A2 é depositada e, alguns minutos depois, a anexina A1 (Roostalu \& Strähle, 2012). As anexinas A1 e A2 interagem com a disferlina na região do sarcolema e também estão presentes no citoplasma, onde a anexina A1 e A2 ligam-se a proteínas da família S100, conhecidas por atuar na reorganização de actina em eventos de endocitose e exocitose. A calpaína 3, uma protease não lisossomal, atua na clivagem das anexinas A1 e A2, aumentando a afinidade dessas proteínas por fosfolipídeos, o que possibilita a agregação e fusão de vesículas próximo à região de lesão (Lennon et al., 2003).

A calpaína 3 contribui para o remodelamento do citoesqueleto cortical, removendo a barreira física para os eventos de fusão. Além disso, estimula o domínio C2A da disferlina a recrutar vesículas intracelulares para a exocitose através da 
modulação da interação da disferlina com determinadas proteínas. A deficiência de calpaína 3 causa a LGMD2A e, em pacientes com LGMD2B, é relatada uma redução secundária dos níveis dessa proteína (Huang et al., 2008).

A AHNAK interage com a disferlina em seu domínio C2A e sugere-se que proporcione a rápida exocitose de agregados de vesículas para o sarcolema. A calpaína 3 modula essa interação, utilizando AHNAK como substrato. Nas disferlinopatias, a deficiência de disferlina é acompanhada por uma redução secundária de AHNAK. No músculo normal em regeneração, ambas as proteínas se deslocam para o citoplasma, consistente com a direta interação entre elas (Huang et al., 2007; Huang et al., 2008).

Em muitas distrofias musculares, a expressão de disferlina está reduzida (Matsuda et al., 2001; Huang et al., 2008) ou alterada para um acúmulo em vesículas citoplasmáticas. Ainda não foi elucidado o que provoca essa distribuição diferencial (Piccolo et al., 2000; Bansal \& Campbell, 2004).

Apesar dos avanços, mais estudos são necessários para entender o papel da disferlina, bem como suas interações com outras proteínas.

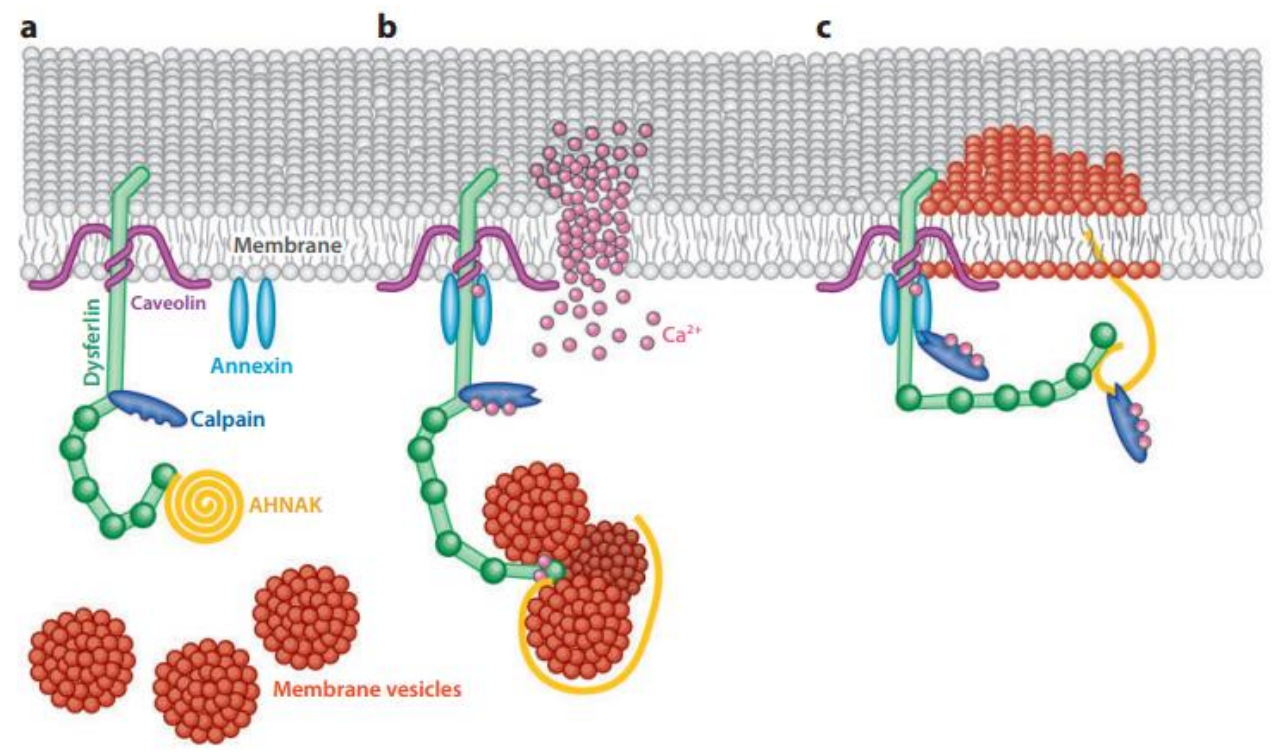

Figura 7: Sequência de eventos após lesão sarcolemal e proteínas envolvidas no reparo de membrana. a: A disferlina, localizada no sarcolema e túbulos $\mathrm{T}$, interage com a caveolina, anexinas, calpaína e AHNAK. b: Diante de lesão, o influxo de cálcio promove ativação e modificações na conformação de proteínas. Informações mais detalhadas estão descritas no texto. C: Ao final, vesículas celulares agregadas se fundem à membrana, selando a região lesionada. Modificado de Wallace \& McNally (2009). 


\subsubsection{Miogênese e o tricomplexo DYSF-FAM65B-HDAC6}

Na impossibilidade de reparar a membrana, como em lesões que comprometem a viabilidade celular, as fibras musculares sofrem necrose e são repostas pela proliferação e diferenciação de células satélite (Middel et al., 2016).

As complexas interações com a disfelina não se restringem à função de reparo de membrana. Outras proteínas têm sido descobertas por atuarem conjuntamente com a disferlina durante a miogênese.

A expressão de disferlina aumenta durante a diferenciação muscular o que sugere sua função na regeneração muscular. Apesar disso, o modo como a disferlina interfere na formação de miotubos ainda se encontra pouco compreendido. Azakir et al., 2010 relatou que a disferlina interage, através de seus domínios $\mathrm{C} 2 \mathrm{~A}$ e $\mathrm{C} 2 \mathrm{~B}$, com a forma polimerizada da $\alpha$-tubulina, um componente dos microtúbulos, tanto em mioblastos como em miotubos, de uma forma independente de cálcio. A forma acetilada da $\alpha$-tubulina está associada à estabilidade dos microtúbulos, necessária para a elongação do miotubos (Asthana et al., 2013).

Acetiltransferases e desacetilases atuam no controle dinâmico do estado de polimerização de tubulinas dos microtúbulos, particularmente a HDAC6 (histone deacetylase 6) é bem caracterizada por sua função como desacetilase, catalisando a remoção de grupos acetil. Além disso, participa de múltiplas funções atuando sobre a motilidade celular, sobrevivência celular, inflamação, degradação de proteínas, sinalização celular e transcrição. Dessa forma, HDAC6 é um promissor alvo terapêutico, dado o seu envolvimento com diversos processos biológicos. Essa enzima tem localização predominantemente citoplasmática e atua sobre substratos não histônicos como Hsp90 (heat shock protein-90), cortactina e $\alpha$-tubulina acetilada (Hubbert et al., 2002; Di Fulvio et al., 2011; Li et al., 2013; Asthana et al., 2013). No músculo, a presença de HDAC6 livre permite a desacetilação, provocando a despolimerização dos microtúbulos. A disferlina interage com HDAC6 e aumenta a acetilação de $\alpha$-tubulina por ligar-se a HDAC6 através de seu domínio C2D e inibir fisicamente sua ação enzimática. A modulação da acetilação é importante durante a diferenciação miogênica. A hiperacetilação de $\alpha$-tubulina no início da miogênese compromete a diferenciação, mas em estágios posteriores é importante para a elongação dos miotubos. Esse controle dinâmico do estado de acetilação é condizente com a expressão temporal de disferlina. 
No início da diferenciação, com os níveis reduzidos de disferlina, HDAC6 livre pode atuar na desacetilação, impedindo uma hiperacetilação nessa fase que prejudicaria a formação de miotubos. No entanto, o aumento da acetilação de $\alpha$-tubulina no decorrer da diferenciação, associado ao aumento da expressão de disferlina e menos HDAC6 livre, é importante para que haja a elongação dos miotubos (Di Fulvio et al., 2011) (Fig. 8).

Adicionalmente, no início da diferenciação, outra proteína citoplasmática, a FAM65B foi relatada recentemente por ligar-se transientemente à disferlina. A FAM65B apresenta múltiplas isoformas, com funções na migração de mioblastos e rearranjo do citoesqueleto. No músculo está presente sob a isoforma 2, que fica ativada quando em associação com HDAC6 e disferlina, formando um tricomplexo que atua na fase inicial da diferenciação de mioblastos (Balasubramanian et al., 2014). A inibição de Fam65b causa diminuição expressiva de miogenina, afetando a fusão e diferenciação de mioblastos, enquanto a sua superexpressão induz a formação de protrusões celulares (Yoon et al., 2007; Hirayama \& Kim, 2007; Diaz-Horta et al., 2014). O efeito da deficiência de disferlina na expressão dos componentes do tricomplexo é desconhecido (Balasubramanian et al., 2014).

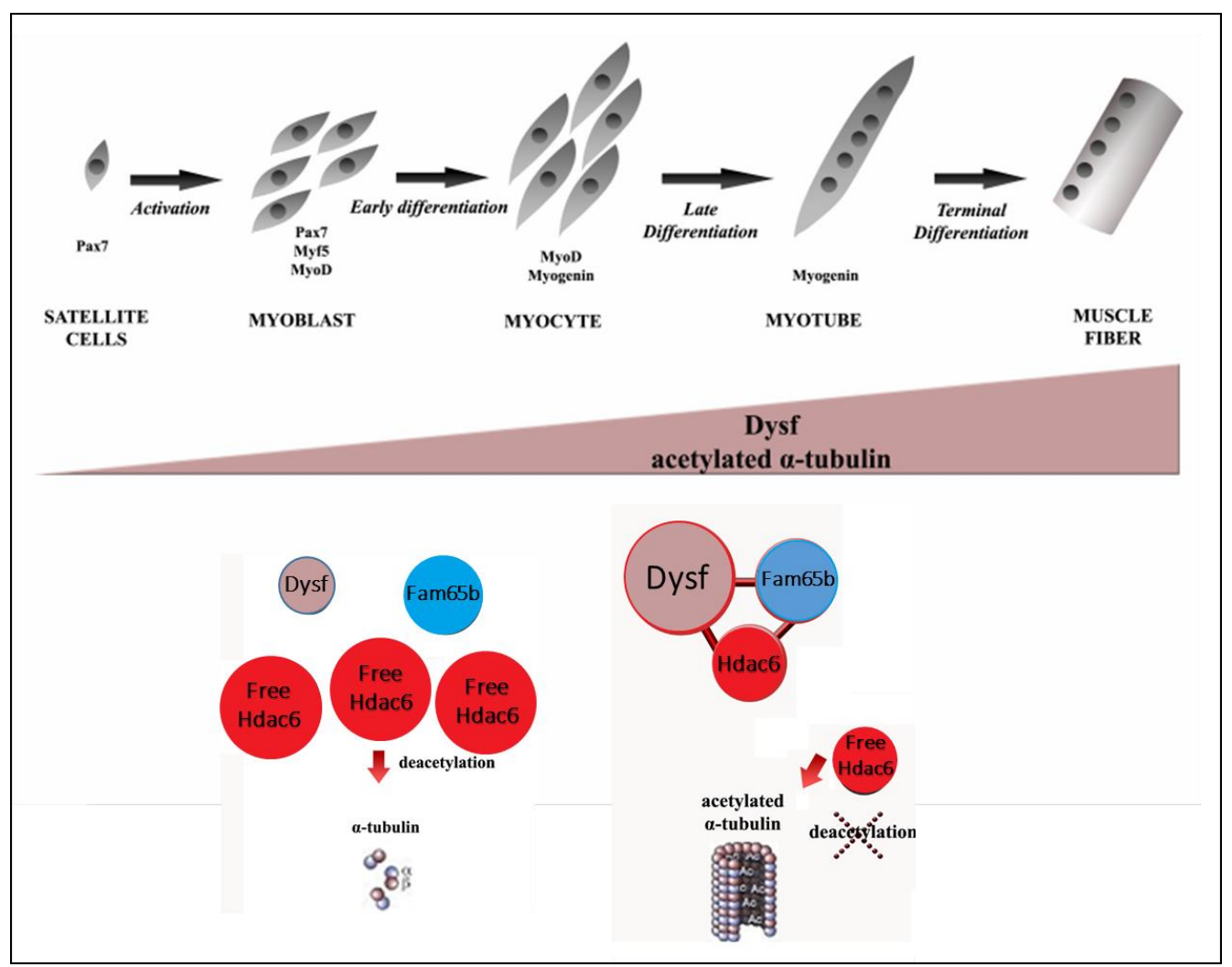

Figura 8: Expressão de fatores miogênicos e do tricomplexo FAM65B-HDAC6-DYSF durante a diferenciação muscular. 


\subsection{Modelos animais}

Diversos modelos animais, com fenótipos de doenças neuromusculares, encontrados na natureza ou produzidos em laboratório, podem ser utilizados para estudos histopatológicos, fisiológicos, genéticos e clínicos. Tais modelos geralmente apresentam alterações semelhantes às encontradas em humanos e podem, dessa forma, ser utilizados para a melhor compreensão dos mecanismos fisiopatológicos, assim como ferramenta para o estudo e viabilização de terapias (Vainzof et al., 2008). Apresentando deficiência de disferlina, o $S J L / J$ é utilizado como modelo natural no estudo da Distrofia Muscular de Cintura tipo 2B (LGMD2B). Os camundongos apresentam redução na quantidade de disferlina para aproximadamente $15 \%$ do encontrado em animais normais. Isso se deve a uma mutação em um sítio de splicing do gene que codifica a disferlina, levando a uma deleção de 171pb (exon 45), com remoção de 57 aminoácidos no domínio C2E. As alterações histológicas são discretas e há pouco comprometimento muscular, que pode se intensificar com a idade (Bittner et al., 1999). O fenótipo brando dificulta o estudo da regeneração, o que pode ser contornado por indução de lesão muscular, método rápido que permite avaliar in vivo o grau de comprometimento em diferentes linhagens distróficas.

Não há no momento cura para as distrofias musculares. O tratamento é apenas paliativo através de corticoesteróides, fisioterapia e intervenções cirúrgicas. Dessa forma, é essencial compreender os mecanismos de doenças neuromusculares para obter potenciais alvos terapêuticos.

Vários modelos de lesão muscular têm sido utilizados para o estudo da regeneração muscular, incluindo danos induzidos por vias químicas e mecânicas. Nos métodos químicos que utilizam toxinas, apesar da fácil aplicação e reprodutibilidade, nem todos tem os efeitos biológicos são totalmente conhecidos (Chargé \& Rudnicki, 2004). Dessa forma, foi utilizado nesse estudo um modelo de lesão mecânica, implantando previamente no laboratório, através da indução de danos por eletroporação. Esse método mostrou-se rápido e eficaz para o estudo do processo de degeneração/regeneração.

Com base nessas premissas, foi traçado um padrão dos processos de degeneração e regeneração no modelo murinho distrófico $S J L / L$ após indução de lesão muscular e 
correlacionada a deficiência de disferlina com o grau de comprometimento no reparo tecidual por análises das alterações moleculares e histológicas. Adicionalmente foram caracterizadas as alterações da expressão dos componentes do tricomplexo DYSFFAM65B-HDAC6 no decorrer da recuperação muscular. Os resultados sugerem que não há comprometimento da regeneração em camundongos com deficiência de disferlina. No entanto, o padrão de regeneração é alterado, iniciando precocemente nos primeiros dias após a lesão, enquanto uma expressão tardia dos fatores miogênicos é observada no controle normal. Fam65b e Hdac6, assim como os fatores miogênicos, aumentaram durante a regeneração muscular. No entanto, os níveis de expressão gênica em $S J L / J$ foram significativamente maiores, indicando que a deficiência de disferlina também afeta a expressão desses componentes. Adicionalmente, analisamos a expressão de fatores miogênicos e dos componentes do tricomplexo em experimentos de diferenciação muscular in vitro, utilizando células de paciente com LGMD2B. Observamos atraso do desenvolvimento de miotubos, com maior frequência de miotubos com menor diâmetro e poucos núcleos nas culturas de células disferlina-deficientes. FAM65B apresentou expressão inalterada durante a diferenciação de células normais e disferlina-deficientes. No entanto, o pico de expressão de miogenina ocorreu antes nas células normais. Além disso, a expressão de DYSF aumentou durante a diferenciação e os níveis de HDAC6 tiveram um aumento transiente após $24 \mathrm{~h}$ da diferenciação muscular apenas nas células normais, enquanto expressão inalterada desses genes foram detectadas nas células com ausência de disferlina. Esses resultados, em conjunto, indicam que a deficiência de disferlina afeta a progressão da diferenciação muscular, prejudicando a formação de miotubos, mas não parece comprometer os estágios iniciais de fusão de mioblastos, uma vez que pequenos miotubos são encontrados com grande frequência nessas culturas.

A identificação da disferlina como possível reguladora da expressão dos componentes do tricomplexo e dos fatores miogênicos pode indicar novos direcionamentos para avançarmos na compreensão dos mecanismos de ação da disferlina, bem como investigar potenciais alvos para terapias. 


\section{II - Objetivos}

\section{Objetivo geral}

Estudar os efeitos da deficiência de disferlina na miogênese e regeneração muscular in vivo e in vitro.

\section{Objetivos específicos}

1) Em um modelo de degeneração/regeneração in vivo, por indução de lesão mecânica do camundongo disferlina-deficiente $S J L / J$, avaliar, ao longo do tempo de recuperação muscular, os seguintes parâmetros:

a) Alterações histológicas, através da análise de infiltração de tecido conjuntivo, de áreas de fagocitose ativa e da presença de fibras em regeneração e centronucleadas;

b) Expressão gênica de fatores envolvidos nas vias de degeneração: $T g f-\beta 1$ e $C D 11 b$, e de regeneração: Pax7, Myf5, MyoD e miogenina;

d) Expressão dos componentes do tricomplexo Fam65b e Hdac6 diante da deficiência de disferlina;

e) Comparar as alterações moleculares com as observações histológicas.

2) Em cultura de mioblastos humanos de paciente com ausência de disferlina, avaliar durante a diferenciação em miotubos:

a) A expressão dos fatores miogênicos $M Y F 5, M Y O D$ e miogenina;

b) A expressão gênica dos componentes do tricomplexo DYSF, FAM65B e HDAC6;

c) A eficiência da fusão de membranas e formação de miotubos, pelo índice de fusão de mioblastos e diâmetro dos miotubos. 


\section{CAPÍTULO 2}

\section{Metodologia geral}

\section{1. $\underline{\text { Camundongos }}$}

\subsubsection{Obtenção dos animais}

Machos de linhagens de camundongos distróficos, $S J L / J$, e normais, Swiss, foram mantidos no biotério do Centro de Estudos do Genoma Humano (IB-USP) em salas com temperatura e iluminação controladas, em gaiolas com água e comida ad libitum. Os animais $S J L / J$ são criados em nosso próprio biotério e os camundongos Swiss foram cedidos gentilmente pelo biotério do Departamento de Patologia da Faculdade de Medicina Veterinária e Zootecnia da USP.

Um total de 48 camundongos de 3 meses de idade de cada linhagem foi dividido randomicamente nos diferentes grupos experimentais $(n=6)$ para análise do músculo gastrocnêmio submetido à lesão. Todos os procedimentos experimentais foram aprovados pelo Comitê de Ética no Uso de Animais do IB (CEUA - Protocolo $\mathrm{n}^{\mathrm{o}}$ 218/2015).

\subsubsection{Indução de lesão muscular por eletroporação}

Utilizamos uma técnica de eletroporação do músculo, padronizada em nosso laboratório, que causa lesão aguda seguida de rápida regeneração, para análise das alterações histológicas e moleculares nos tempos 0, 3, 5, 10, 15, 21 e 30 dias após a indução de lesão no músculo gastrocnêmio de ambas as patas, comparados ao músculo intacto. O tempo 0 , imediatamente após lesão, não mostrou diferenças histológicas e moleculares em relação ao músculo intacto (dados não mostrados), sendo os tempos experimentais analisados apenas em relação ao músculo intacto.

Os pulsos elétricos foram aplicados nas duas patas de cada animal na região do gastrocnêmio após injeção intraperitoneal de anestésico geral (quetamina 10\% 80mg/kg + xilazina $2 \% 10 \mathrm{mg} / \mathrm{kg}+$ acepromazina $1 \% 3 \mathrm{mg} / \mathrm{kg}$ ). Os pelos foram removidos e aplicado um gel de condução a fim de melhorar o contato com os eletrodos do eletroporador BTX®-ECM®830 (Harvard Apparatus). Para a aplicação dos pulsos 
elétricos, os animais foram mantidos em decúbito dorsal, com a pata imobilizada manualmente em um ângulo de $90^{\circ} \mathrm{C}$. O eletroporador foi ajustado para a aplicação de oito pulsos elétricos de 100 volts, com duração de $20 \mathrm{~ms}$ (milisegundos) e intervalo de 0,5 segundo. A análise do gastrocnêmio foi feita pela observação do grau e extensão da degeneração causada pela eletroporação, assim como os eventos de regeneração subsequentes, por técnicas histológicas e moleculares.

\subsubsection{Coleta, preparação e congelamento dos músculos}

Os animais foram sacrificados em câmara de $\mathrm{CO}_{2}$ e dissecados para coleta do músculo gastrocnêmio de ambas as patas. O peso total dos camundongos e do gastrocnêmio foram registrados. Os tecidos foram congelados em nitrogênio líquido para análise histológica e molecular.

\subsubsection{Cortes histológicos}

Para a análise histológica, o gastrocnêmio de uma das patas foi fixado a uma rolha de cortiça com Tissue Tek O.C.T. (Qiagen), envolto por talco para crioproteção antes do congelamento em nitrogênio líquido. $\mathrm{O}$ fragmento foi fixado na rolha de forma que as fibras musculares pudessem ser cortadas transversalmente em uma espessura de $8 \mu \mathrm{m}$ no criostato (Microm HM 505E) a temperatura de $-25^{\circ} \mathrm{C}$. Os cortes histológicos foram aderidos a lâminas previamente cobertas com polilisina, para melhor fixação dos cortes, e armazenados em freezer $-70^{\circ} \mathrm{C}$ até a aplicação das diferentes técnicas. Antes da aplicação da técnica histoquímica ou imunohistoquímica, as lâminas foram retiradas do freezer e deixadas por aproximadamente $1 \mathrm{~h}$ em temperatura ambiente.

a. Coloração de hematoxilina-eosina (HE)

Os cortes foram corados com hematoxilina por 10 minutos e lavados em água corrente por 10 minutos. A seguir, foram corados com eosina por 3 minutos e lavados até a eliminação do excesso de corante. Os cortes foram fixados em ácido acético, desidratados em concentrações crescentes de álcool etílico e xilol e montados com Bálsamo do Canadá. O aspecto geral do músculo pode ser avaliado quanto a variação no calibre e morfologia das fibras musculares, necrose, presença de fibras com núcleos centrais (CNFs), inflamação e infiltração de tecido conjuntivo. As fibras com núcleos centrais foram quantificadas em micrografias das áreas lesionadas em aumento de 20x. Os resultados foram representados como médias do número de CNFs/total de fibras em cada campo ( 5 campos, $\mathrm{n}=3$ animais/grupo experimental). 


\section{b. Fosfatase ácida}

A fosfatase ácida é uma enzima presente em lisossomos de células fagocitárias como os macrófagos, tem atividade aumentada nos processos degenerativos, particularmente inflamatórios, indicando necrose em reação a processos como estresse mecânico e patologias. As lâminas foram colocadas, por $1 \mathrm{~h}$ a $37^{\circ} \mathrm{C}$, em meio de incubação pH 4,0-5,0 (solução de pararosanilina $0,8 \mathrm{ml}$; solução de nitrito de sódio $0,8 \mathrm{ml}$; naftolAS-BI-fosfato, 10mg diluído em $1 \mathrm{ml}$ de $\mathrm{NN}=$ =dimetilformamida; tampão veronal acetato, $5 \mathrm{ml}$ em $13 \mathrm{ml}$ de $\mathrm{H}_{2} 0$ destilada), lavadas, coradas com verde de metila por 3 minutos (coloração de fundo), desidratadas em concentrações crescentes de álcool e xilol e montadas com bálsamo do Canadá. A atividade da enzima, indicando fagocitose ativa em eventos degenerativos, geralmente na fase aguda, foi marcada com uma coloração avermelhada. A comparação da resposta inflamatória entre as duas linhagens foi realizada pela análise qualitativa de regiões marcadas positivamente com vermelho $(n=6$ animais/grupo experimental).

\section{c. Coloração de Picrossírius}

A coloração de Picrossírius permite visualizar o aumento de colágeno, indicativo de infiltração de tecido conjuntivo entre as fibras musculares. As lâminas foram imersas em fixador Bouin por 20 minutos e lavadas em água corrente. Os cortes foram corados com solução de Picrossírius (Sirius red $0,2 \mathrm{~g}$ e solução aquosa saturada de ácido pícrico $100 \mathrm{ml}$ ) por 15 minutos a 1h, observando ao longo do tempo se atingiu uma coloração homogênea. As lâminas foram então lavadas, desidratadas em concentrações crescentes de álcool e xilol e montadas com bálsamo do Canadá. A quantificação de áreas positivas à coloração, marcada em vermelho, foi quantificada com auxílio do Image J para calcular a área relativa de tecido conjuntivo em relação à área total do corte (3-4 campos, n= 5-6 animais/grupo experimental).

d. Imunohistoquímica

A miosina de cadeia pesada de desenvolvimento (dMHC), uma proteína sarcomérica, foi utilizada para identificar áreas de regeneração, indicando fibras recémdiferenciadas em vermelho. As lâminas foram cobertas com PBS e incubadas overnight com o anticorpo primário mouse anti-dMHC (diluição de 1:30; Vector; VP-M664) e rabbit anti-laminina (1:50; Dako; Z0097), lavadas e, em seguida, incubadas por 1h com anticopo secundário sheep anti-mouse IgG conjugado com Cy3 (1:100; Sigma; C2181) e donkey anti-rabbit IgG conjugado com FITC (1:100; Amersham; N1034), 
respectivamente. Após lavagem, as lâminas foram montadas com Vectashield. A análise dos cortes histológicos foi feita em microscópio de fluorescência (Zeiss). A formação de novas fibras foi quantificada pela contagem de células vermelhas, $\mathrm{dMHC}+$, em relação ao número total de fibras ( 5 campos, $n=3-6$ animais/grupo experimental).

\subsubsection{Extração de RNA e PCR em tempo real (qRT-PCR)}

O RNA total das amostras previamente maceradas foi extraído utilizando o RNeasy Microarray Tissue Mini Kit (Qiagen) e tratado com rDNase (Macherey-Nagel), de acordo com as recomendações do fabricante. O RNA foi quantificado e teve sua pureza analisada em espectrofotômetro. A qualidade do RNA foi avaliada em gel de agarose $1 \%$ para verificar a integridade das amostras, utilizando o protocolo descrito em Aranda et al., 2012.

Para a síntese de cDNA, com volume final de $20 \mu 1$, foi feita a transcriptase reversa de $1 \mu \mathrm{g}$ de RNA total, a partir de $1 \mu$ l oligo dT $(500 \mu \mathrm{g} / \mathrm{ml}), 0,1 \mu 1$ de random primer $(3 \mu \mathrm{g} / \mu \mathrm{l}), 1 \mu \mathrm{l}$ de dNTP mix $(10 \mathrm{mM})$ e água DEPC q.s.p. $12 \mu 1$. Essa mistura foi aquecida a $65^{\circ} \mathrm{C}$ no termociclador por 5 minutos. Em seguida, adicionou-se $4 \mu 1$ de tampão 5x First Strand (Tris-HCl buffer 50mM pH 8.3; 75mM KCl; 3mM MgCl2); $2 \mu 1$ de DTT (0,1mM) e $1 \mu 1$ de RNAse OUT (40U/ $\mu 1)$, para incubação no termociclador a $37^{\circ} \mathrm{C}$ por 2 minutos. Após retirar as amostras, foram adicionados $1 \mu 1$ de transcriptase reversa MMLV e nova incubação a $25^{\circ} \mathrm{C}$ por 10 minutos, seguida de $37^{\circ} \mathrm{C}$ por 50 minutos e, por fim, a $70^{\circ} \mathrm{C}$ por 15 minutos. $\mathrm{O}$ cDNA foi mantido no freezer $-20^{\circ} \mathrm{C}$ até o uso.

As reações de qRT-PCR foram aplicadas em duplicata em placa de 96 poços, $5 \mu 1$ de água DEPC, $2 \mu 1$ de cada primer do gene de interesse, 10 $\mu 1$ FastStart Universal SYBR Green Master (Rox) (Roche) e 1 $\mu 1$ de cDNA (diluição 1:3 em água RNase free), num volume total de $20 \mu \mathrm{L}$. Cada placa foi corrida no termociclador para Real-Time 7500 Fast da Applied Biosystems/Life com o seguinte programa: $50^{\circ} \mathrm{C}$ por 2 minutos, $95^{\circ} \mathrm{C}$ por 10 minutos, 40 ciclos a $95^{\circ} \mathrm{C}$ por 15 segundos e $60^{\circ} \mathrm{C}$ por 1 minuto.

Para a quantificação da expressão dos genes de interesse, foram utilizados fatores envolvidos nas vias de degeneração: $T g f-\beta 1$ e $C D 11 b$; e regeneração $M y f 5, M y o D$, miogenina, Fam65b e Hdac6; além de Gapdh como gene de referência para a normalização dos dados, utilizando as sequências de primers discriminadas na Tabela 3.

Para calcular o valor de expressão, cada amostra foi normalizada para o gene de referência Gapdh e para a amostra calibradora (músculo intacto) e expressa como $2^{-\Delta \Delta \mathrm{CT}}$. 
Tabela 3: Primers murinos

\begin{tabular}{|c|c|c|c|}
\hline Gene & Forward sequence & Reverse sequence & Referência \\
\hline $\boldsymbol{T g f - \beta 1}$ & CCC CAC TGA TAC GCC TGA GT & AGC CCT GTA TTC CGT CTC CTT & $\begin{array}{c}\text { Onofre-Oliveira et } \\
\text { al. (2012) }\end{array}$ \\
\hline $\boldsymbol{C D 1 1 \boldsymbol { b }}$ & ATG GAC GCT GAT GGC AAT ACC & TCC CCA TTC ACG TCT CCC A & $\begin{array}{c}\text { Neves et al. } \\
(2015)\end{array}$ \\
\hline $\boldsymbol{P a x 7}$ & GAGTTCGATTAGCCGAGTGC & GAGTTCGATTAGCCGAGTGC & Primer bank \\
\hline $\boldsymbol{M y f 5}$ & CTG TCT GGT CCC GAA AGA AC & GAC GTG ATC CGA TCC ACA ATG & $\begin{array}{c}\text { Onofre-Oliveira et } \\
\text { al. (2012) }\end{array}$ \\
\hline MyoD & TAC AGT GGC GAC TCA GAT GC & TAG GCG GTG TCG TAG CC & $\begin{array}{c}\text { Onofre-Oliveira et } \\
\text { al. (2012) }\end{array}$ \\
\hline Miogenina & CAG TAC ATT GAG CGC CTA CAG & GGA CCG AAC TCC AGT GCA T & $\begin{array}{c}\text { Onofre-Oliveira et } \\
\text { al. (2012) }\end{array}$ \\
\hline Fam65b & GGG CTT GAT GAG TAC CTG GA & GAA GGC TTG CTT CAT TTT GC & $\begin{array}{c}\text { Diaz-Horta et al. } \\
\text { (2014) }\end{array}$ \\
\hline Hdac6 & AAG TGG AAG CCG TGC TA & CTC CAG GTG ACA CAT GAT GC & Ratti et al. (2015) \\
\hline Gapdh & AGG TCG GTG TGA ACG GAT TTG & TGT AGA CCA TGT AGT TGA GGT CA & $\begin{array}{c}\text { Onofre-Oliveira et } \\
\text { al. (2012) }\end{array}$ \\
\hline
\end{tabular}

Antes dos procedimentos do qRT-PCR, foram determinadas as concentrações dos primers e realizados os procedimentos de curva padrão para verificação da eficiência de amplificação da reação e o threshold de cada gene estudado (Tabela 4).

Tabela 4: Valores da padronização dos primers murinos

\begin{tabular}{|c|c|c|c|c|}
\hline Gene & Threshold & Slope & R2 & Eff\% \\
\hline$T g f \beta-1$ & 0,367593 & $-3,312$ & 0,999 & 100,412 \\
\hline$C D 11 b$ & 0,45153 & $-3,32$ & 0,993 & 100,089 \\
\hline Myf5 & 0,347951 & $-3,401$ & 0,996 & 96,818 \\
\hline MyoD & 0,201814 & $-3,586$ & 0,996 & 90,037 \\
\hline Miogenina & 0,268133 & $-3,559$ & 0,998 & 90,958 \\
\hline Fam65b & 0,347951 & $-3,569$ & 0,992 & 90,63 \\
\hline Hdac6 & 0,585942 & $-3,306$ & 0,992 & 100,661 \\
\hline Gapdh & 0,506934 & $-3,544$ & 0,993 & 91,513 \\
\hline
\end{tabular}

\subsubsection{Análise estatística}

Utilizamos Kruskal-Wallis seguido de teste de Dunn-Bonferroni para comparações múltiplas e Mann-Whittney quando comparando dois grupos. A análise estatística foi realizada no Minitab, considerando diferenças com $p \leq 0,05$ como estatisticamente significantes. 


\subsection{Cultura de células humanas}

\subsubsection{Obtenção das amostras e imortalização}

Mioblastos de uma paciente (Dysf-/-) de 11 anos com mutação em homozigose (c.2954G>A), geradora de um stop códon, foram obtidos a partir de biópsia do músculo bíceps de uma paciente do Centro de Estudos do Genoma Humano (CEGH-USP). Mioblastos controle de um indivíduo normal (Dysf+/+) foram gentilmente pelo Dr. Vincent Mouly a partir de amostras isoladas do quadríceps de um homem de 53 anos de idade. As células foram imortalizadas no Institut de Myologie (França), utilizando o método de transdução com vetores lentivirais que codificam hTERT e cdk4, com marcadores de seleção de puromicina e neomicina, respectivamente. As células transduzidas foram selecionadas com puromicina $(1 \mu \mathrm{g} / \mathrm{ml})$ durante 6 dias e neomicina $(1 \mathrm{mg} / \mathrm{ml})$ durante 10 dias. As células infectadas foram purificadas utilizando um sistema de classificação imunomagnética de células (MACS, Miltenyi), de acordo com as instruções do fabricante com microbeads anti-CD56. As células foram então cultivadas e os clones miogênicos individuais foram isolados, caracterizados e constatada a manutenção das características das linhagens primárias originais quanto à proliferação e diferenciação de mioblastos.

\subsubsection{Fusão de miotubos}

Foram plaqueadas $2 \times 10^{4}$ células sobre lamínulas em placas de 6 poços, com meio de proliferação (Skeletal Muscle Cell Growth Medium kit - Promocell), com 20\% de soro fetal bovino e $50 \mu \mathrm{g} / \mathrm{mL}$ de gentamicina (Invitrogen). Após $48 \mathrm{~h}$ de proliferação, quando as células atingiram uma confluência de aproximadamente $80 \%$, foi substituído o meio de proliferação pelo meio de diferenciação DMEM GlutaMAX ${ }^{\mathrm{TM}}$ (Invitrogen) com insulina $1 \%(10 \mu \mathrm{g} / \mathrm{mL})$ e gentamicina $0,1 \%(50 \mu \mathrm{g} / \mathrm{mL})$. Após $72 \mathrm{~h}$ do início da diferenciação, as células foram fixadas em paraformaldeído 4\% por 20 minutos, seguido por permeabilização em Triton X-100 0,2\% por 30 minutos, bloqueio em BSA 5\% por 1 hora e incubação overnight com anticorpo para alfa-actinina (1:500; Sigma; A2543). As amostras foram lavadas 3x em PBS e incubadas com anticorpo secundário goat antirabbit conjugado a Cy3 (1:100; Amersham; PA43004) por 1 hora, no escuro. A seguir foram lavadas 3x com PBS e montadas com Vectashield +DAPI. As imagens foram feitas com microscópio de fluorescência (Zeiss). 
A capacidade de fusão para formar miotubos multinucleados foi mensurada a partir de 3 campos em aumento 20x, quantificados em 3 experimentos individuais para cada linhagem celular. Foram representados o índice de fusão, que corresponde à porcentagem de núcleos em miotubos em relação ao número de núcleos totais, e a distribuição da frequência de números de núcleos/miotubo. Um total de 5443 núcleos foram contados para Dysf+/+ e 5250 para Dysf-/-.

\subsubsection{Diâmetro de miotubos}

Para avaliar o desenvolvimento dos miotubos, foram medidos os diâmetros dos mesmos miotubos quantificados nos experimentos de fusão. Utilizando ImageJ, o diâmetro médio de cada miotubo foi calculado a partir de 3 medidas de diâmetro tomadas ao longo de seu comprimento. Foram medidos pelo menos 100 miotubos de cada linhagem em três campos em aumento 20x, a partir de 3 experimentos individuais (Dysf+/+: 108 miotubos; Dysf-/-: 188). Os dados foram apresentados pela média do diâmetro dos miotubos e pela distribuição de frequência de diâmetros.

\subsubsection{Extração de RNA e PCR e qRT-PCR}

Para análise da expressão de fatores miogênicos, as células foram coletadas em diferentes tempos ao longo da diferenciação. Três experimentos independentes foram realizados. Para cada experimento, $2,5 \times 10^{5}$ células foram plaqueadas em paralelo em garrafas T75 até atingirem uma confluência maior que 80\%. Foi substituído o meio de proliferação por meio de diferenciação. As coletas foram realizadas após12 horas, 1 dia, 2 dias e 6 dias, comparados ao tempo 0 indiferenciado. $\mathrm{O}$ meio de diferenciação foi retirado e as células foram lavadas com PBS $1 \mathrm{X}$ gelado. Utilizando cell scrapper, as células foram removidas mecanicamente da garrafa, transferidas para um falcon de $15 \mathrm{ml}$ e centrifugadas a $3000 \mathrm{~g}$ por 5 minutos a $4 \mathrm{oC}$. O pellet de células foi ressuspendido em $500 \mu 1$ de PBS para retirar o meio de diferenciação e centrifugado novamente. O sobrenadante foi descartado e o pellet congelado rapidamente em nitrogênio e estocado no freezer $-70^{\circ} \mathrm{C}$ até o uso.

O RNA total foi extraído utilizando TRIzol (Invitrogen), seguindo o protocolo do fabricante. O cDNA e a qRT-PCR seguiram os mesmos procedimentos descritos acima para os camundongos. A expressão gênica foi quantificada para os genes $F A M 65 B$, HDAC6, MYF5, MYOD, miogenina e DYSF, utilizando RPLPO como gene de referência. Os primers utilizados estão discriminados na Tabela 5. Os valores da curva padrão para 
verificação da eficiência de amplificação da reação e o threshold de cada gene estudado são mostrados na Tabela 6.

Tabela 5: Primers humanos

\begin{tabular}{|c|c|c|c|}
\hline Gene & Forward sequence & Reverse sequence & Referências \\
\hline MYF5 & CTCAGCAGGATGGACGTGAT & TATGCAGGAGCCGTCGTA & Yang et al. (2005) \\
\hline MYOD & TGCCACAACGGACGACTTC & CGGGTCCAGGTCTTCGAA & Yang et al. (2005) \\
\hline Miogenina & CAG TGC CAT CCA GTA CAT CG & AGG TTG TGG GCA TCT GTA GG & $\begin{array}{c}\text { Balasubramanian } \\
\text { et al. (2014) }\end{array}$ \\
\hline DYSF & CAG TCC CAG AGA GTT CAC AGG & CCA GGG AGA GCA GAA GCC A & Di Fulvio (2013) \\
\hline $\begin{array}{c}\text { FAM65B } \\
+F A M 65 B \Delta 12\end{array}$ & GCC CAG GAA GTA CTC AG & GAT TTT CAG AGC CAG GCA AG & $\begin{array}{c}\text { Balasubramanian } \\
\text { et al. (2014) }\end{array}$ \\
\hline HDAC6 & ATG GCC ATC ATT AGG CCT CC & CGG ATG CGG TGT TTC TGT TG & Ratti et al. (2015) \\
\hline RPLPO & GGA TTA CAC CTT CCC ACT TGC T & GCC ACA AAG GCA GAT GGA TCA & $\begin{array}{c}\text { Chechi et al. } \\
\text { (2012) }\end{array}$ \\
\hline
\end{tabular}

Tabela 6: Valores da padronização dos primers humanos

\begin{tabular}{|c|c|c|c|c|}
\hline Gene & Threshold & Slope & R2 & Eff\% \\
\hline MYF5 & 0,203406 & $-3,508$ & 0,997 & 92,777 \\
\hline MYOD & 0,267292 & $-3,366$ & 0,996 & 98,213 \\
\hline Miogenina & 0,305446 & $-3,553$ & 0,999 & 91,198 \\
\hline DYSF & 0,203406 & $-3,332$ & 0,988 & 99,565 \\
\hline FAM65B & 0,276286 & $-3,48$ & 0,998 & 93,786 \\
\hline HDAC6 & 0,181383 & $-3,57$ & 0,991 & 90,595 \\
\hline RPLPO & 0,447272 & $-3,39$ & 0,996 & 97,22 \\
\hline
\end{tabular}

\subsubsection{Análise estatística}

As diferenças entre as linhagens foram determinadas pelo teste t, utilizando o Minitab. Valores de p menores que 0,05 foram considerados significantes. 


\title{
CAPÍTULO 3
}

\section{Time course of regeneration is altered in dysferlin-deficient mice}

\author{
Ishiba, R. ${ }^{1}$; Santos, A.L.F. ${ }^{1}$; Almeida, C.F. ${ }^{1}$; Caires, L.C.J. ${ }^{1}$; Vainzof, M. ${ }^{1}$.
}

\section{Affiliations}

1 Human Genome and Stem-cell Research Center, Biosciences Institute, University of São Paulo, São Paulo, Brazil.

\section{Corresponding author}

Mariz Vainzof

Human Genome and Stem-cell Research Center, University of São Paulo

Rua do Matão, Travessa 13, nº 106

São Paulo, SP, 05508-090, Brazil

mvainzof@usp.br 


\begin{abstract}
Mutations in the DYSF gene encoding the sarcolemmal protein dysferlin cause clinically distinct forms of muscular dystrophy, collectively named dysferlinopathies. Dysferlin is associated with the processes of membrane repair, trafficking and fusion of intracellular vesicles and muscle regeneration. The $S J L / J$ mouse is the natural model for dysferlin deficiency, presenting a reduction of the protein to $15 \%$ of its normal levels. This model, however, shows mild weakness and discrete histopathological alterations. To study the effect of dysferlin deficiency in the muscle regenerative process, we used a model of electroporation inducing muscle degeneration/regeneration in the $S J L / J$ mouse. The histopathological evaluation and the relative expression of the genes $P a x 7, M y o D, M y f 5$ and myogenin were accompanied during muscle recovery at different time points after electrical injury. In addition, we investigated the effects of dysferlin deficiency in the expression of genes encoding two interacting proteins, FAM65B and HDAC6, recently described as forming a tricomplex with dysferlin in the beginning of myoblast differentiation. We observed an altered time course through the process of degeneration and regeneration in dysferlin-deficient mice, with remarkable regenerative capacity characterized by a faster and effective response in the first days after injury, as compared to the WT mice. Moreover, Fam65b and Hdac6 are activated at the early stages of muscle regeneration and seem to be affected by dysferlin deficiency. These results have important implications when selecting targets for future therapies.
\end{abstract}




\section{Resumo}

Mutações no gene DYSF, que codifica a proteína sarcolemal disferlina, causam formas clinicamente distintas de distrofia muscular, coletivamente denominadas disferlinopatias. A disferlina está associada aos processos de reparo de membrana, tráfego e fusão de vesículas intracelulares e regeneração muscular. O camundongo $S J L / J$ é o modelo natural para a deficiência de disferlina, apresentando uma redução da proteína para 15\% dos seus níveis normais. Este modelo, entretanto, apresenta leve fraqueza e discretas alterações histopatológicas. Para estudar o efeito da deficiência de disferlina no processo de regeneração muscular, utilizou-se um modelo de eletroporação para induzir degeneração/regeneração muscular no camundongo $S J L / J$. A avaliação histopatológica e a expressão relativa dos genes $\operatorname{Pax} 7, M y o D, M y f 5$ e miogenina foram acompanhadas durante a recuperação muscular em diferentes tempos após a lesão elétrica. Além disso, investigamos os efeitos da deficiência de disferlina na expressão de genes que codificam duas proteínas, FAM65B e HDAC6, recentemente descritas por formar um tricomplexo com a disferlina no início da diferenciação de mioblastos. Observamos um curso de tempo alterado durante o processo de degeneração e regeneração, com notável capacidade regenerativa dos camundongos disferlina-deficientes, caracterizado por uma resposta mais rápida e eficaz nos primeiros dias após a lesão, em comparação com os camundongos normais. Além disso, Fam65b e Hdac6 são ativados nos estágios iniciais da regeneração muscular e parecem ser afetados pela deficiência de disferlina. Estes resultados representam implicações importantes ao selecionar alvos para futuras terapias. 


\section{Introduction}

Dysferlin is a $\sim 230 \mathrm{kDa}$ sarcolemmal protein expressed mainly in skeletal and cardiac muscle. Reduced levels or absence of dysferlin due to mutations in the DYSF gene cause a group of clinically heterogeneous myopathies characterized by progressive weakness and muscle degeneration, collectively known as dysferlinopathies. The different clinical presentations include Limb-girdle muscular dystrophy type 2B (LGMD2B) (Bashir et al., 1998), Miyoshi myopathy (MM) (Liu et al., 1998) and distal anterior compartment myopathy (DACM) (Illa et al., 2001).

The muscle is a mechanically active tissue undergoing frequent membrane stress, being therefore, highly adapted to repairing when submitted to various stimuli or demands generated by physical activity, growth and injury. However, in progressive conditions, such as muscular dystrophies, the imbalance between degeneration and regeneration cycles leads to degenerative processes and irreversible loss of the musculature with the advance of the chronic disease (Ceco \& McNally, 2013). Understanding the mechanism of muscular disorders at cellular and molecular levels is essential for the development of therapeutic targets. Despite advances, the role of dysferlin still remains largely unclear. Some of the functions related to dysferlin in recent years include traffic and fusion of intracellular vesicles (Glover \& Brown Jr, 2007), membrane repair (Bansal et al., 2003), inflammation (Rawat et al. 2010) and myogenesis (De Luna et al., 2006).

In dysferlinopathies, mechanical stress causes calcium imbalance and failure of membrane repair, which leads to proteolysis and prolonged exposure to an oxidative extracellular environment, conducting to necrosis (Kerr et al., 2014). In chronic degenerative changes in muscle disorders, TGF- $\beta 1$ has been found in higher levels, acting as a cytokine, which inhibits myogenic differentiation and induces fibrosis by the transformation of myogenic cells into fibrotic cells (Allen \& Boxhorn, 1987; Li et al., 2004). In addition, the inflammatory response interferes with the progression of myogenic differentiation. Mononuclear cells, as macrophages $\mathrm{CD} 11 \mathrm{~b}^{+}$, are required for the clearance of necrotic debris, being essential for effective muscle regeneration (Arnold et al, 2007). However, abnormal activation and prolonged macrophage accumulation could contribute to exarcebate the dystrophic process (Cohen et al., 2012). 
The consequent regenerative response to muscle degeneration is activated by the action of several myogenic determinants. In normal muscle, Pax7 is involved in the activation of satellite cells committed to the formation of myoblasts and muscle differentiation. Once activated, they give rise to precursors expressing a group of myogenic factors known as Myogenic Regulatory Factors (MRFs), belonging to the superfamily of bHLH transcription factors (basic helix-loop-helix). Their expression is regulated temporally. MyoD and Myf5 are the primary factors that act in the activation and proliferation of myogenic precursors cells, while myogenin acts on the later stages of differentiation of myoblasts into myotubes (Sabourin \& Rudnicki, 2000; Rudnicki et al., 2008).

The observation that dysferlin and myogenin mRNA levels increase during myogenic differentiation of human skeletal muscle cells and that the levels of myogenin decrease at myotube stages in dysferlin-deficient cells suggests that dysferlin may have important functions in myogenesis (De Luna et al., 2006).

For its function in membrane repair, dysferlin interacts with several proteins, such as caveolin-3 (Matsuda et al., 2001), annexins A1, A2 and A6 (Lennon et al., 2003; Roostalu \& Strähle, 2012), calpain 3 (Huang et al., 2005), AHNAK (Huang et al., 2007) and MG53 (Cai et al., 2009). Additionally, a role of dysferlin in myogenesis has been recently suggested, since it was reported that this protein binds to FAM65B and HDAC6 transiently, forming a tricomplex in the beginning of myoblast differentiation (Balasubramanian et al., 2014). However, the effects of dysferlin deficiency in the tricomplex components and their expression during the regenerative process are still unknown.

Here we used $S J L / J$ mouse, the natural murine model for LGMD2B, to study the regenerative process under dysferlin deficiency. In this model, a deletion of $171 \mathrm{bp}$ in exon 43 of the dysferlin gene leads to a loss of $85 \%$ of protein levels in the muscle. Although a good model for molecular studies, $S J L / J$ displays a mild phenotype when compared to the phenotype in patients. Histological changes are also very mild, starting between 2 and 4 months of age, however the active myopathy develops after 6 months (Weller et al., 1997). Thus, induction of muscle injury provides a quick mechanism to evaluate changes in the regenerative process of dystrophic animals with such mild phenotype. Thus, we used a technique developed in our laboratory to assess dystrophic 
muscle recovery after electrical-induced injury to study the influence of dysferlin deficiency in the myogenesis process in vivo. The degree and extent of injury were analysed, as well as subsequent regeneration events by histological assessment and mRNA analysis of myogenic factors and tricomplex components.

Our results suggest that there is no impairment of regeneration in dysferlindeficient $S J L / J$ mice. However, an altered time course of regeneration was observed, which was vigorous in the first days of muscle recovery of the dysferlin-deficient mice, while less accentuated expression and prolonged myogenesis was observed in the normal mice. Also, dysferlin deficiency seems to significantly alter the gene expression of Fam65b and Hdac6 during the time course of regeneration, since higher levels of expression of both genes were observed in dysferlin-deficient mice. These results need further attention to define their relevance and potential therapeutic application.

\section{Materials and methods}

\section{Animals}

We examined gastrocnemius muscles of male $S J L J J$ with 12-14 weeks of age and respective wild-type Swiss mice (WT). SJL/J mice were obtained from our animal colonies and Swiss mice were obtained from School of Veterinary Medicine and Animal Science of University of São Paulo (FMVZ/USP). During the experiments, animals were bred and housed in controlled temperature and light in the animal house of Human Genome and Stem Cell Research Center (HUG-CELL). All experiments were performed in accordance with the ethical committee of animal use of Institute of Bioscience of University of São Paulo (protocol number 218/2015).

\section{Muscle injury/repair system}

We used a muscle electroporation technique standardized in our laboratory, that cause acute damage followed by rapid regeneration for examination of histological and molecular changes after 3, 5, 10, 15, 21 and 30 days, compared to uninjured muscles (day 0 ). A total of 42 mice for each strain was divided randomly at different time points ( $n=6$ per group). 
The electrical pulses were applied in both legs of each animal in gastrocnemius region, under general anesthesia induced by intraperitoneal injection (ketamine $10 \%+$ xylazine $2 \%$ + acepromazine $1 \%$, loading doses of 80,10 and $3 \mathrm{mg} / \mathrm{kg}$, respectively). The posterior legs were shaved and a conductive gel was used to improve the contact of the electrodes with the skin. Gastrocnemius was electroporated by applying eight square electrical pulses of $100 \mathrm{~V}, 20-\mathrm{ms}$ (milliseconds) per pulse at 0.5 -s intervals through electrodes $(7 \mathrm{~mm}$ diameter) using a BTX®-ECM®830 electroporator (Harvard Apparatus).

\section{Tissue collection and histological analysis}

We collected gastrocnemius muscles, frozen in liquid nitrogen, to study gene expression and histological alterations at different time points during muscle recovery.

Hematoxylin-eosin (H\&E): Transverse cross sections of right gastrocnemius were stained with $H \& E$ and histopathological evaluation was performed by generating a qualitative assessment of the changes in morphology of muscle fibers, necrosis, presence of centrally nucleated muscle fibers (CNFs), inflammation and connective tissue infiltration. In addition, CNFs were counted under 20x magnification ( 5 fields, $n=3$ animals/experimental group), and results were represented as the number of CNFs/total number of myofibers in each section. The stained sections were observed under a light microscope (Zeiss).

Acid phosphatase: For histochemical detection of phagocytosis, muscle sections were incubated for $1 \mathrm{~h}$ at $37^{\circ} \mathrm{C}$ in a solution ( $\mathrm{pH}$ 4.0-5.0) containing pararosaniline solution $0.8 \mathrm{ml}$, sodium nitrite solution $0.8 \mathrm{ml}$, naphthol-AS-BI-phosphate $(10 \mathrm{mg} / \mathrm{ml}$, diluted in $\mathrm{N}, \mathrm{N}=$ dimethylformamide $)$ and veronal acetate buffer $(5 \mathrm{ml} / 13 \mathrm{ml}$ of distilled H20), washed, stained with methyl green for three minutes, dehydrated in alcohol and mounted with Canada balsam. The acid phosphatase activity indicates active phagocytosis in degenerating events, usually in the acute phase, showing necrosis or response to mechanical stress or disease, which is marked with a red stain. A qualitative analysis, evaluating the intensity of positively labeled fibers was done ( $n=6$ animals/experimental group).

Picrosirius: To identify regions with collagen deposition, indicative of connective tissue replacement and infiltration between muscle fibers, the sections were stained with Sirius red $(0.2 \mathrm{~g})$ dissolved in saturated picric acid $(100 \mathrm{ml})$ for 40 minutes. The slides were immersed in Bouin fixative for twenty minutes, washed in water, dehydrated and 
mounted in Canada balsam. The differences were quantified by the positive area of staining, labeled in red, relative to the total area of the section, with the aid of ImageJ software (3-4 fields, $\mathrm{n}=5-6$ animals/experimental group).

Immunofluorescence analysis for developmental isoform myosin heavy chain (dMHC): indicates myogenic activity by newly differentiated fibers labeled in red. The muscle sections were colabeled with primary antibodies to dMHC (1:30; Vector; VPM664) and laminin (1:50; Dako; Z0097), washed, and then incubated for 1h with secondary antibodies Cy3-labeled sheep anti-mouse IgG (1:100; Sigma; C2181) and FITC-labeled donkey anti-rabbit IgG (1:100; Amersham; N1034), respectively. After washing, the slides were mounted with Vectashield-DAPI. The analysis of histological sections was done with a fluorescence microscope (Zeiss) and quantified the percentage of dMHC+/total fibers ( 5 fields, $\mathrm{n}=3-6$ animals/experimental group).

\section{RNA extraction, $c D N A$ synthesis and $q R T-P C R$}

Total RNA from left gastrocnemius was extracted using the RNeasy Microarray Tissue Mini Kit (Qiagen), following manufacture instructions and then quantified in a spectrophotometer. For the cDNA synthesis, $1 \mu \mathrm{g}$ of total RNA was used with random primer $0.1 \mu \mathrm{l}(3 \mu \mathrm{g} / \mu \mathrm{l}), 1 \mu \mathrm{l}$ oligo dT $(500 \mu \mathrm{g} / \mathrm{ml}), 1 \mu \mathrm{l} \mathrm{dNTP} \operatorname{mix}(10 \mathrm{mM})$ and DEPC water adjusted to the volume of $12 \mu \mathrm{l}$. This mixture was left at $65^{\circ} \mathrm{C}$ in thermocycler for 5 minutes. Then was added $4 \mu \mathrm{l} 5 \mathrm{x}$ First Strand Buffer, $2 \mu \mathrm{l}$ DTT $(0.1 \mathrm{mM})$ and $1 \mu \mathrm{l}$ RNase OUT ( $40 \mathrm{U} / \mu \mathrm{l}$ ) to incubation in the thermocycler at $37^{\circ} \mathrm{C}$ for 2 minutes. After removing the samples $1 \mu \mathrm{l}$ of MMLV reverse transcriptase was added and samples were then incubated at $25^{\circ} \mathrm{C}$ for 10 minutes, $37^{\circ} \mathrm{C}$ for 50 minutes and finally at $7^{\circ} \mathrm{C}$ for 15 minutes. The cDNA was diluted (1: 3 in RNase free water) and applied in duplicates in 96 well plate. Samples were amplified using the MasterMix containing Sybr Green (Applied Biosystems) and primers (detailed in Table 1) in a total volume of $20 \mu \mathrm{L}$. Each plate was run on thermocycler 7500 Fast (Applied Biosystems/Life). To data analysis, each time point was normalized by Gapdh mRNA and the uninjured WT mice and expressed as 2$\Delta \Delta \mathrm{CT}$. 
Table 1: Primers sequences

\begin{tabular}{|c|c|c|}
\hline Gene & Forward sequence & Reverse sequence \\
\hline$T g f-\beta 1$ & CCC CAC TGA TAC GCC TGA GT & AGC CCT GTA TTC CGT CTC CTT \\
\hline CD11b & ATG GAC GCT GAT GGC AAT ACC & TCC CCA TTC ACG TCT CCC A \\
\hline $\operatorname{Pax} 7$ & GAGTTCGATTAGCCGAGTGC & GAGTTCGATTAGCCGAGTGC \\
\hline Myf5 & CTG TCT GGT CCC GAA AGA AC & GAC GTG ATC CGA TCC ACA ATG \\
\hline MyoD & TAC AGT GGC GAC TCA GAT GC & TAG TAG GCG GTG TCG TAG CC \\
\hline Miogenina & CAG TAC ATT GAG CGC CTA CAG & GGA CCG AAC TCC AGT GCA T \\
\hline Fam65b & GGG CTT GAT GAG TAC CTG GA & GAA GGC TTG CTT CAT TTT GC \\
\hline Hdac6 & AAG TGG AAG AAG CCG TGC TA & CTC CAG GTG ACA CAT GAT GC \\
\hline Gapdh & AGG TCG GTG TGA ACG GAT TTG & TGT AGA CCA TGT AGT TGA GGT CA \\
\hline
\end{tabular}

\section{Statistical analysis}

Differences between groups were assessed using Kruskal-Wallis followed by Dunn-Bonferroni test and Mann-Whittney when comparing only two groups. The statistical analyses were calculated using Minitab and a p-value of less than 0.05 was considered to be significant.

\section{Results}

Altered time course of regeneration in dysferlin-deficient mice

To assess dysferlin function in muscle regeneration, we used gastrocnemius muscle of 3-month-old dysferlin-deficient $S J L / J$ in order to evaluate morphological changes during regeneration process at different time points after electrical-induced injury.

The uninjured muscle of $S J L J J$ had slight dystrophic alterations, with sparsely centrally nucleated muscle fibers. Histological changes observed in both strains after injury, included foci of muscle degeneration and infiltration of monuclear cells, mainly in the first days after injury. Intense inflammation and necrosis with hyaline ghost-like appearance were observed at day 3 and 5. From day 10, they start to decrease. At day 15, there is extensive regeneration in $S J L / J$ muscle, however small degeneration foci are still observed near the periphery only in WT mice, indicating a faster muscle recovery in dysferlin-deficient mice (Fig. 1A). 
It's worth noting that the mean weight of muscle showed a statistically significant reduction at day $5(\sim 14.22 \%, \mathrm{p}<0.05)$ in WT mice and at day $5(\sim 22.25 \%, \mathrm{p}<0.001)$ and $10(\sim 16.99 \%, \mathrm{p}<0.01)$ in $S J L / J$, which subsequently returned to pre-injury levels by day 10 and 15, respectively. This loss of weight suggests muscular atrophy and reflects the period of intense degeneration remedied by the onset of muscle regeneration with first signs of recovery from day 5 (Fig. 1B).

Signs of regeneration appeared at day 3 and became more evident at day 5 with small basophilic CNFs. As regeneration progresses, CNFs undergo maturation, fibers start to increase, and the nucleus migrates to muscle fiber periphery. The quantitative analysis revealed that the number of CNFs increased from day 5 in both strains, but is slightly reduced in $S J L J J$ muscle at day 21 and 30, despite not being statistically significant (Fig. 1C).

A
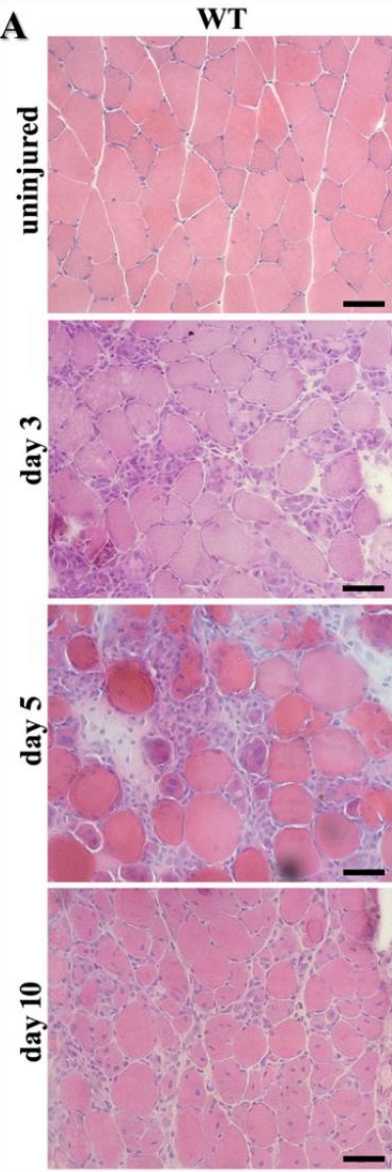

$S J L / J$
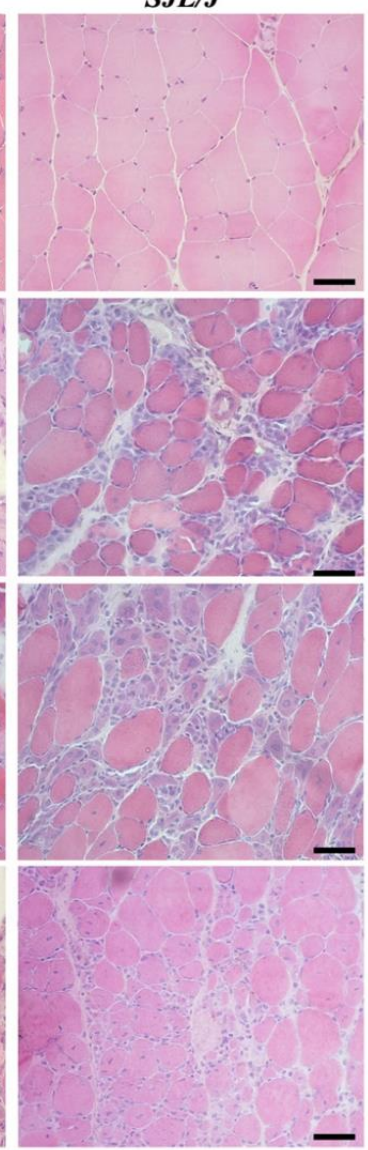

WT
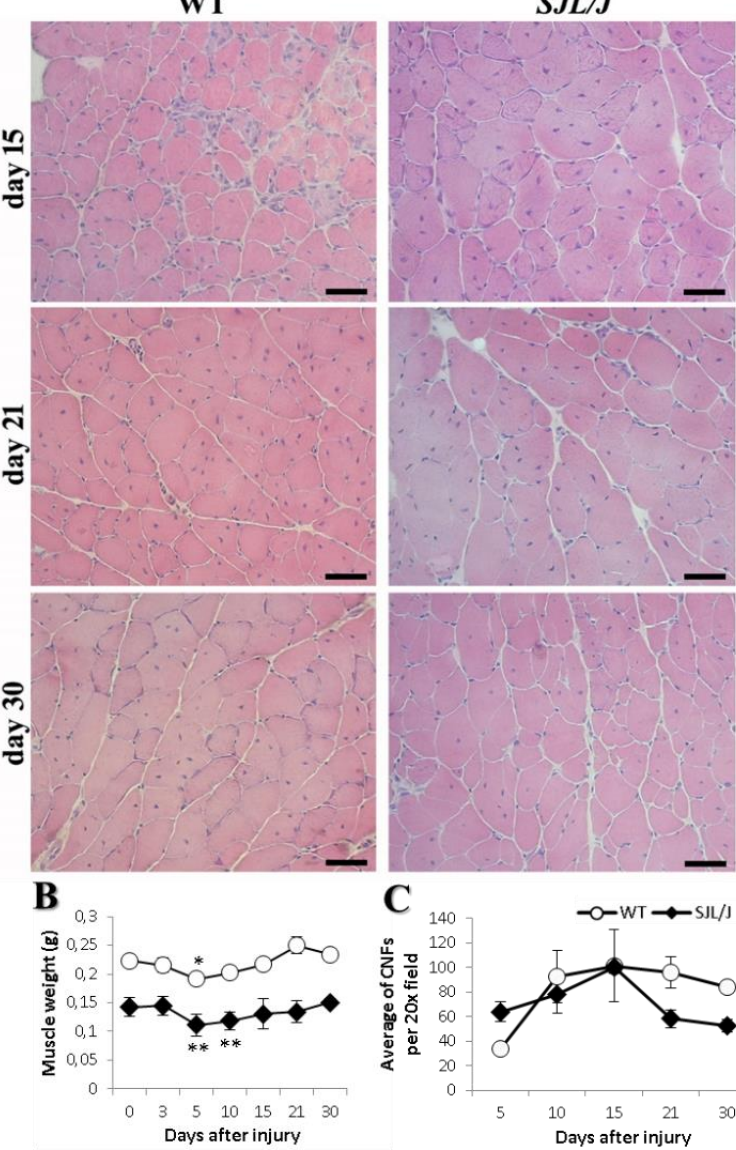

Figure 1: Altered time course of muscle regeneration in dysferlin-deficient mice after electricalinduced muscle injury. A: Gastrocnemius muscle from 3-month-old wild-type (WT) and $S J L / J$ mice stained with H\&E. B: Muscle weight at different time points post-injury ( $n=6)$. C: Average of CNFs ( 5 fields, $n=3$ ). Data are means $\pm S D$. Significant differences relative to uninjured muscle (day 0): $* \mathrm{p}<0.05$ and $* * \mathrm{p}<0.01$. Bars: $50 \mu \mathrm{m}$. 
Abnormally increased expression of degenerative factors in the SJL/J model (Tgf- $\beta 1$ and $C D 11 b)$

We next examined the mRNA expression of two important factors in the degenerative phase in injured muscle tissue, to determine whether the dysferlin deficiency induces altered degenerative molecular response. Our results showed peak of $T g f-\beta 1$ expression in $S J L / J$ at day 3, decreasing at day 5. In contrast, WT mice showed a modest increase at day 3 that raised on the day 5, matching the levels of $S J L / J$. In the following days, expression returned to normal levels (Fig. 2A-B).

As expected, $C D 11 b$ mRNA levels were significantly increased at day 3 in both strains, consistent with the histological data showing high influx of inflammatory cells. This increase was considerably higher in $S J L / J$, about twice the value of normal mice. From day 5, the levels were reduced to half in $S J L J$ and became very similar between the strains, although still high. By day 10, they returned to baseline levels found in intact tissue (Fig. 2A-B).

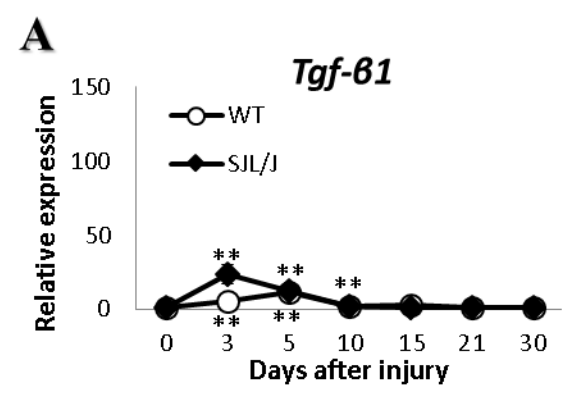

B

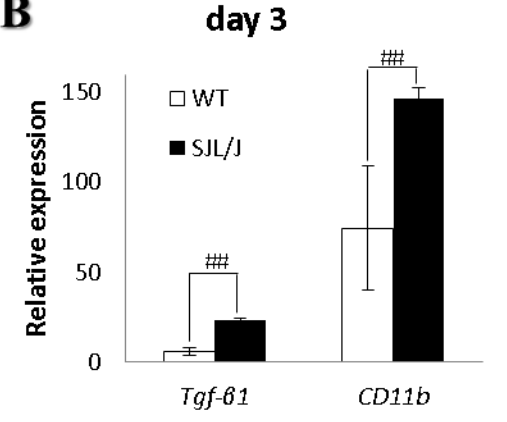

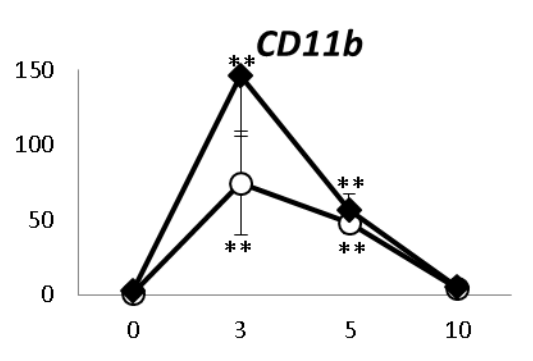

day 5

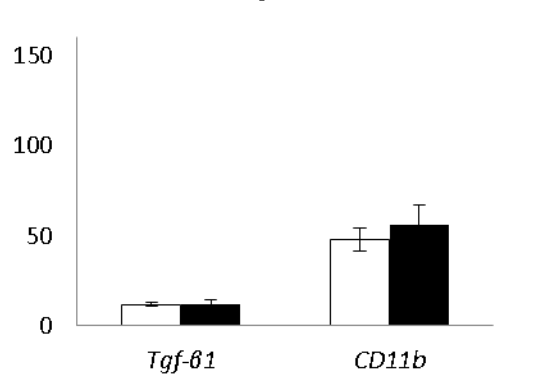

Figure 2: Increased expression of degenerative factors in the $S J L / J$ muscle. A: $T g f-\beta 1$ and $C D 11 b$ mRNA expression during skeletal muscle regeneration in WT and $S J L / J$ mice. B: Expression of $T g f-\beta 1$ and $C D 11 b$ at days 3 and 5, when they achieved the higher values. Values are means \pm $\mathrm{SD}(\mathrm{n}=6)$. Significant differences relative to uninjured muscle (day 0$): * * p<0.01$, and between strains: \#\#p < 0.01 . 


\section{Efficient restoration of fibrosis}

To investigate the ability of dysferlin-deficient mice to restore muscle cytoarchitecture, the dynamic deposition and remodeling of the connective tissue were visualized by picrosirius red staining, identifying positively areas with collagen. Our data showed extensive areas of connective tissue mainly at day 3 and 5, with peak at day 5 . The extent of connective tissue was reduced in the subsequent days and replaced by newly formed fibers, with no significant differences between the strains, except at d15, in which WT mice appears increased compared to the $S J L J$, indicating that connective tissue replacement is not a main feature in the dysferlin-deficient mouse (Figure 3A). These observations were confirmed by quantitation of area of collagen deposition (Figure 3B).

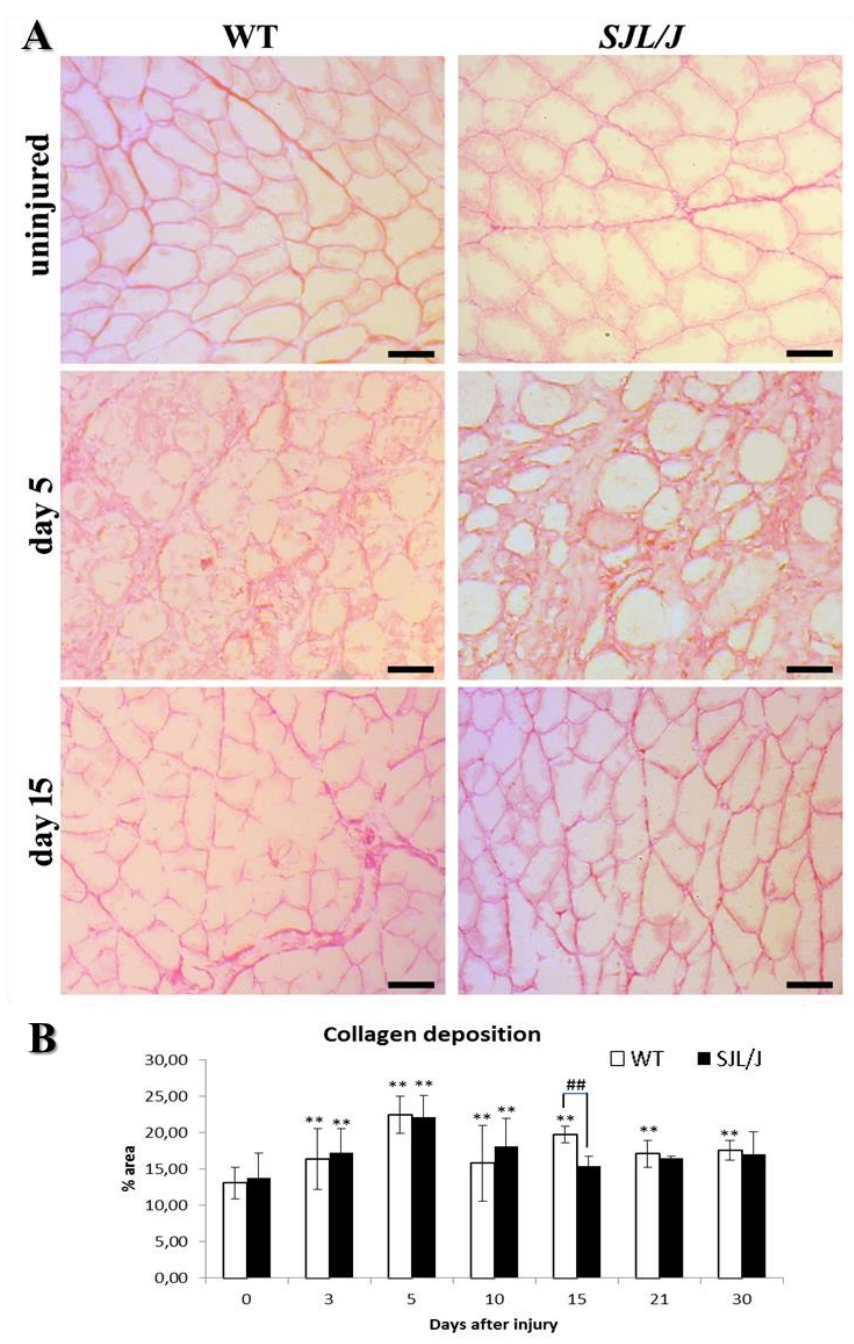

Figure 3: A: Representative images of collagen deposition by Picrosirius red staining of gastrocnemius muscles of WT and $S J L / J$ mice at day 3,5 and 15 after electrical injury. B: Quantitation of percentage area of collagen deposition $(n=3-6)$. Data are means \pm SD. Significant differences relative to uninjured muscle (day 0 ): $* \mathrm{p}<0.05$ and $* * p<0.01$ and between strains. $\# \#$ p $<0.01$. Bars: $50 \mu \mathrm{m}$. 
Dysfelin deficiency enhances phagocytosis of necrotic skeletal muscle in early regeneration

Necrosis and inflammation, indicating lysosomal activity, are characteristic of muscle degenerative processes (Tidball, 2005) and can be detected by acid phosphatase staining. Increased degeneration at day 3 and 5 were evidenced by areas of positive acid phosphatase fibers, persisting until day 10 in both strains. However, the staining was more intense in the $S J L J$ in the same period. While the activity decreased in the dystrophic animals after this time, in normal muscle small foci were visualized up to $\mathrm{d} 15$, suggesting prolonged degenerative events, compatible with observations of areas of degeneration in HE staining (Fig. 4A-B).

A

营

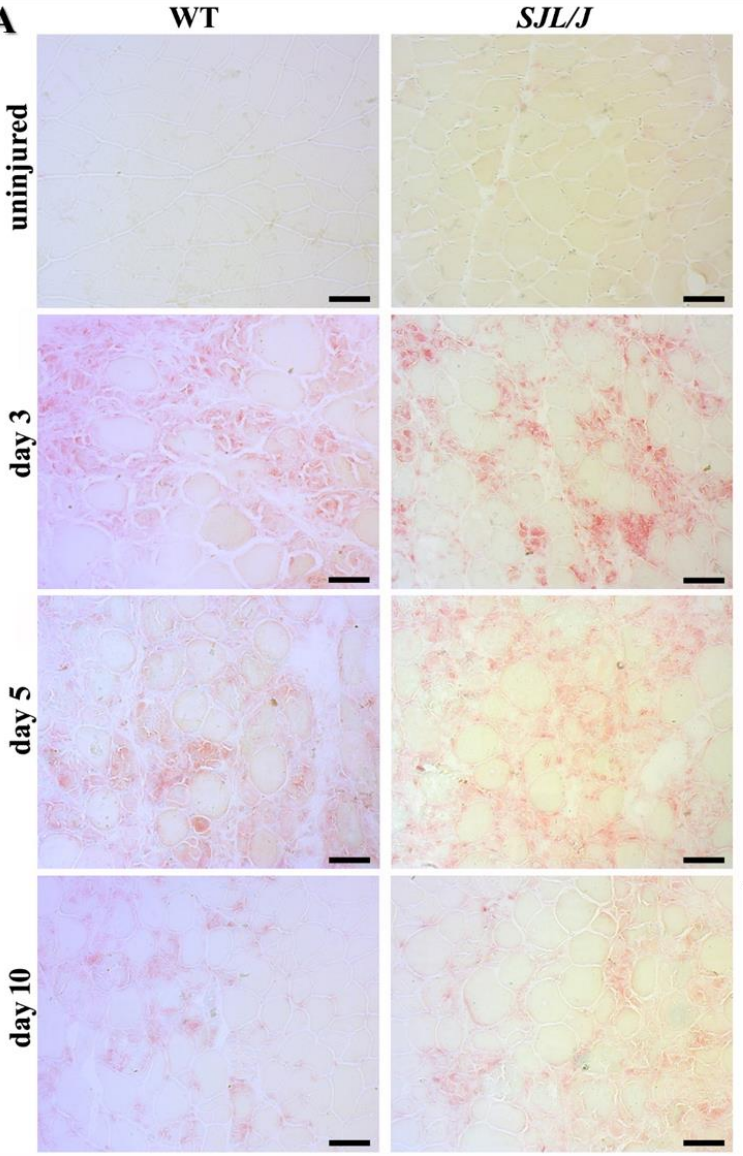

WT

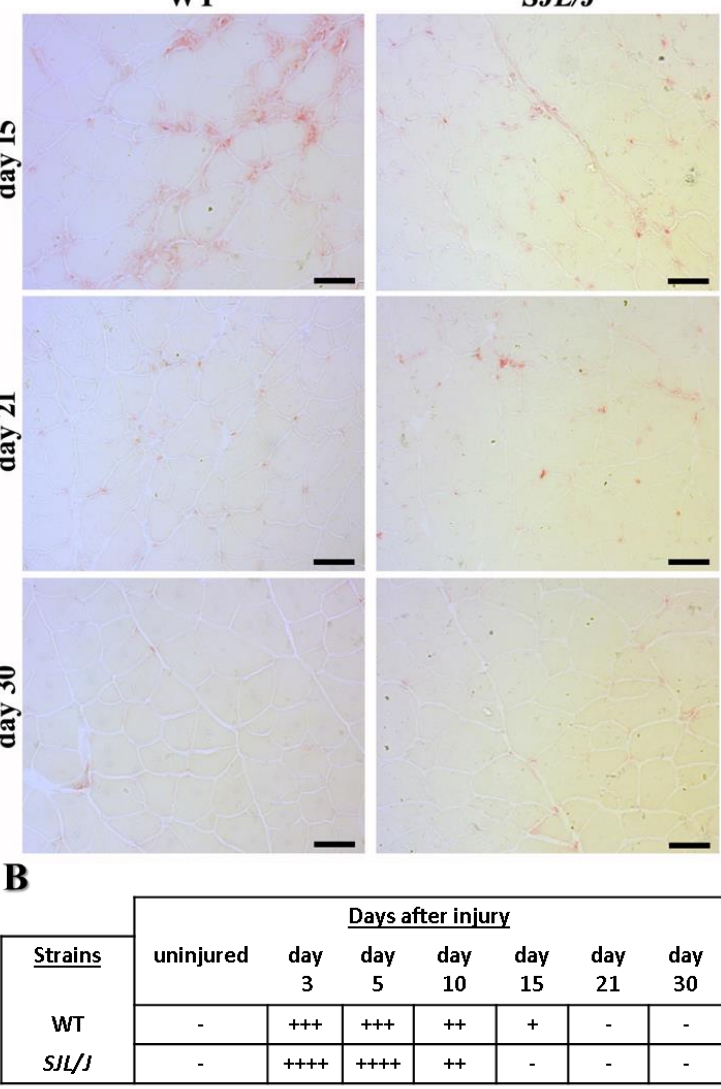

Figure 4: Dysfelin deficiency enhances phagocytosis of necrotic skeletal muscle in early regeneration. A: Phagocytic cells stained in red by acid phosphatase. Bars: $50 \mu \mathrm{m}$. B: Qualitative evaluation of intensity of positive areas of necrosis $(n=6)$.

\section{Early activation of myogenic markers in dysferlin-deficient mice}

The regenerative response to injury was further studied by examining gene expression levels of myogenic transcripts $\operatorname{Pax} 7, M y f 5, M y o D$ and myogenin to determine 
whether dysferlin deficiency interfered in the earlier and later stages of muscle regeneration. All transcripts had increased values mainly in the days 3 and 5 after injury in both strains. However, an earlier stimulation of myogenesis was observed in $S J L J$, which had peaked at day 3 , decreasing at day 5 , whereas normal mice had peaked only at d5. From d10 onward, the mRNA levels decreased, but appeared slightly increased in the WT mice compared to $S J L / J$ until day 30 (Fig. 5A).

Comparing to the WT mice, all myogenic transcripts were significantly higher in dysferlin-deficient muscle at day 3 . Then they appear similar at day 5 , with exception of $M y o D$ that was significantly elevated in normal mice (Fig. 5B). These results suggest that early activation peak of myogenic factors could contribute to faster muscle regeneration observed in dysferlin-deficient $S J L / J$.
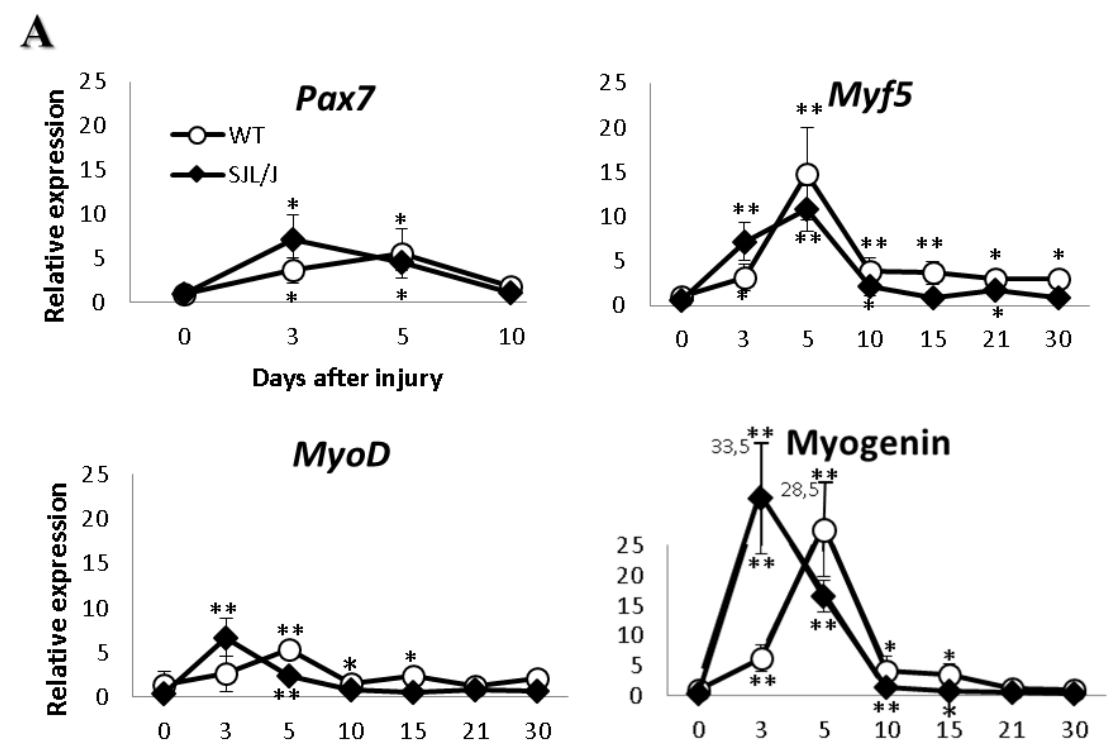

\section{B}

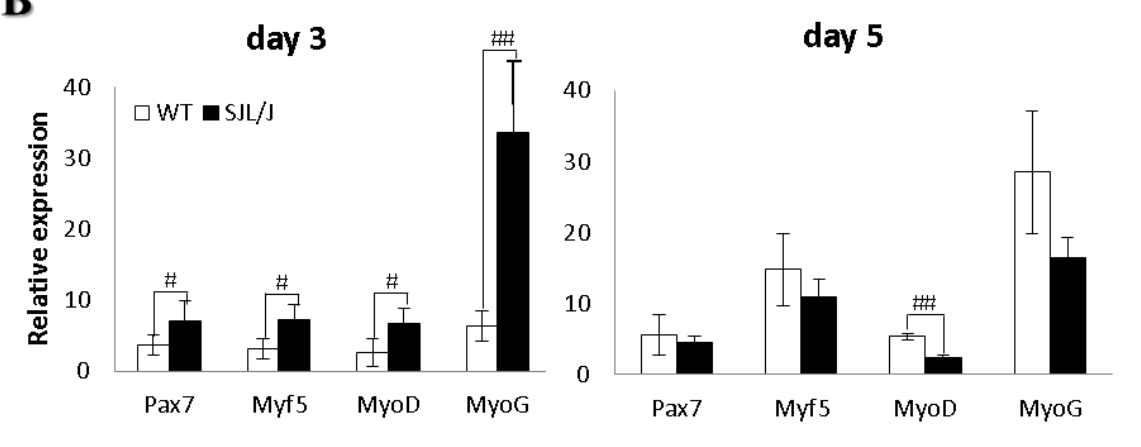

Figure 5: Early activation of myogenic transcripts in dysferlin-deficient mice after electricalinduced muscle injury. A: Pax7, Myf5, MyoD and myogenin mRNA levels in the injured muscles at different time points from WT and $S J L / J$ gastrocnemius muscle determined by qRT-PCR. B: Comparative analysis of all transcripts at day 3 and 5, highlighting the days of higher expression. Values are means $\pm S D(n=6)$. Significant differences relative to uninjured muscle (day 0$): * p<$ $0.05 ;{ }^{* *} \mathrm{p}<0.01$, and between strains: ${ }^{\#} \mathrm{p}<0.05 ;{ }^{\#} \mathrm{p}<0.01$. 
Based on these results, we then checked whether this profile is reflected in the pattern of regeneration of new myofibers using markers of developmental myosin isoform (Fig. 6A). During the first days after injury, fibers marked with developmental isoform of myosin heavy chain (dMHC) indicated newly formed fibers. Our data showed that the formation of new muscle fibers started at day 3 , reached a significant peak at day 5 and decreased at day 10 in both strains (Fig. 6B). At day 5, the increased dMHC positive fibers suggest no impairment of muscle recovery from injury in $S J L / J$, although no statistical significance was achieved between the strains (WT: $11.85 \% \pm 4.89$ vs $S J L J J$ : $18.78 \% \pm 4.32 ; \mathrm{p}=0.06$ ).

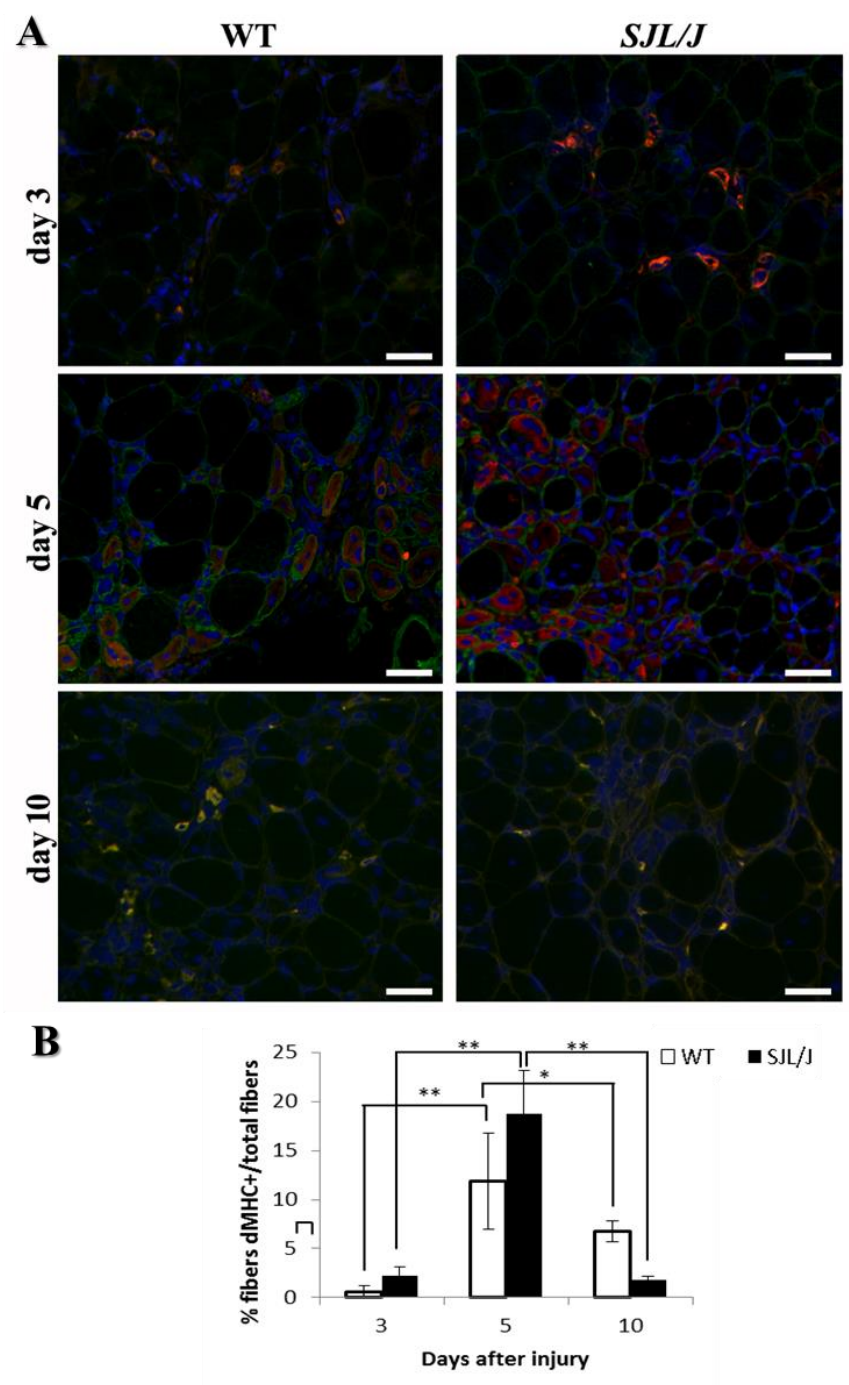

Figure 6: $S J L / J$ shows no impairment of new myofibers formation in the first days after injury. A: Immunofluorescence staining for developmental isoform of myosin heavy chain (dMHC). $\mathrm{dMHC}+$ fibers are labeled in red to identify newly formed myofibers, indicating regenerative response after injury. Bars: $50 \mu \mathrm{m}$. B: Quantitative analysis of percentage of fibers dMHC+/total fibers at days 3, 5 and 10 after injury. Values are means \pm SD $(n=3-6)$. Significant differences: $* \mathrm{p}<0.05 ; * * \mathrm{p}<0.01$. 


\section{Dysferlin deficiency affects the components of the tricomplex}

We next examined the time course changes in the expression of Fam $65 b$ and $H d a c 6$, components of the tricomplex with dysferlin, to verify the pattern of expression during the different stages of muscle recovery and determine whether the dysferlin deficiency interferes also in this pathway. Fam65b and Hdac6 gene expression were upregulated during early regeneration, at days 3 and 5 in dysferlin-deficient and WT mice (Fig. A). However, in $S J L J$, higher Fam65b mRNA levels were observed at day 3 and 5, and Hdac6 at day 5, compared to WT mice (Fig. 7B). These results suggest that Fam65b and $H d a c 6$ expression are affected by dysferlin deficiency.

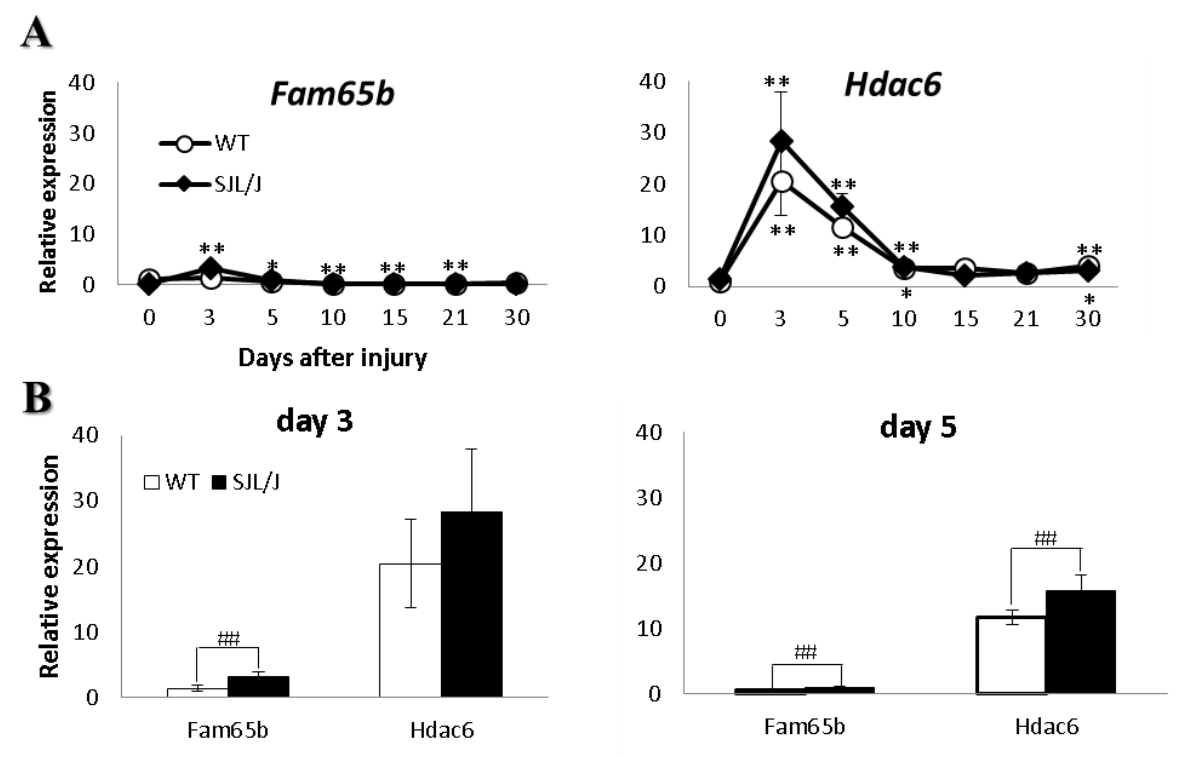

Figure 7: Dysferlin deficiency affects the components of the tricomplex. A: mRNA expression analysis of Fam65b and Hdac6 in the injured muscle. B: Comparative analysis of Fam65b and Hdac6 at day 3 and 5. Values are means $\pm \mathrm{SD}(\mathrm{n}=6)$. Significant differences relative to uninjured muscle (day 0): *p < 0.05; **p $<0.01$, and between strains: ${ }^{\# \# p ~}<0.01$.

\section{Discussion}

Several animal models for neuromuscular diseases are found in nature or produced in laboratory. They can be useful for physiological, genetic and clinical studies. Such models mimics human diseases and thus can be used for better understanding its pathophysiological mechanisms, being powerful tools for the study of potential therapies (Vainzof et al., 2008). Here, we studied the regeneration of the dysferlin-deficient mouse $S J L J$, a natural murine model for LGMD2B, largely used in studies of dysferlin 
deficiency. Due to the mild phenotype of disease observed in this model when compared to humans, we applied a methodology of electrical-induced injury developed in our laboratory. This method was chosen because it produces a mechanical damage followed by a rapid regeneration, which allows us to analyse the events in a short period. Additionally, as compared to models of degeneration induced by some myotoxic and chemicals agents (Hardy et al., 2016), this mechanical method can be considered less interfering in the mechanisms of muscle degeneration and regeneration.

Dysferlin is reported to increase during muscle differentiation, suggesting its role in regeneration and myoblasts fusion events (De Luna et al., 2006). Nevertheless, the underlying cellular mechanism of how dysferlin interferes with myotube formation remains unclear. Here, we assessed the histological and molecular events over the course of $S J L / J$ muscle recovery after injury. The aim of this study was, therefore, to investigate how dysferlin deficiency affects the time course of degeneration/regeneration processes as well as how it modulates the expression of the genes encoding two recently described interacting proteins, FAM65B and HDAC6, that form a tricomplex with dysferlin (Balasubramanian et al., 2014). Our findings showed altered time course of regeneration in dysferlin-deficient mice $S J L J$, with intense inflammatory response, followed by efficient removal of necrotic tissue and faster muscle recovery compared to WT mice. We found that myogenic factors are upregulated earlier in this lineage. Moreover, enhanced expression of Fam65b and Hdac6 was observed. Taken together, active phagocytosis and early activation of myogenic factors appear to account for rapid regeneration in $S J L J J$. In addition, this is the first study of the molecular regulation of Hdac6 and Fam65b in models of muscle regeneration applied to dysferlinopathic mice and it points to the possible regulation of these components by dysferlin.

\section{Dysferlin deficiency enhances phagocytic activity}

Muscle injury induces a sequence of well-defined cellular events involving degeneration, followed by regeneration and remodeling to restore muscle cytoarchitecture (Chargé \& Rudnicki, 2004). During muscle recovery, macrophages particularly perform phagocytic activity, removing necrotic cell debris (Novak et al., 2014). The proper regulation of this process is important to muscle regeneration. To investigate the influence of dysferlin in phagocytosis, Nagaraju et al. (2008) performed experiments of inhibition of dysferlin expression by RNA interference in the mouse J774 
macrophage cell line. Interestingly, they demonstrated that enhanced phagocytosis is a consequence of dysferlin deficiency and not a secondary effect of dystrophic environment. However, controversial data about the active phagocytosis in dysferlindeficient mice is still reported. While some authors found an earlier and more effective phagocytosis associated with extensive myotube formation in $S J L J J$ (Mitchell et al., 1992), others described no difference in the phagocytic capacity (Chiu et al., 2009). Our data showed a pronounced positive acid phosphatase reaction, indicative of phagocytic activity, mainly at day 3 and 5 in both murine lineages. In agreement with the former reports, it was more intense in $S J L J J$, but interestingly it appeared extended in normal mice, with small foci of labelling still present at day 15, with the persistence of cellular debris. Nagaraju et al. (2008) suggested that the excessive signaling to immune cell could exacerbate the dystrophic process. Accordingly, we found that the extent of phagocytosis in the intense degeneration caused by electric injury in the WT mice delayed muscle recovery. The increase in phagocytic activity in the $S J L / J$ mice, restricted to the early stages of muscle recovery, seems to have contributed to efficient removal of cellular debris, without impairment of muscle regeneration.

\section{Increased expression of Tgf- $\beta 1$ and $C D 11 \mathrm{~b}$ in the $S J L / J$ model}

As we found significant increase in phagocytic activity and macrophages are the main infiltrating leukocytes in the dysferlin-deficient muscle (Nemoto et al., 2007), we assessed mRNA expression of CDIl b. Significant enhanced mRNA expression of $C D 11 b$ was detected at day 3 in $S J L J$, compared to WT mice. The intense inflammatory activation in the $S J L J J$ mice is in agreement with histological analysis and corroborates other previous studies showing enhanced inflamatory activity in this strain (Gallardo et al., 2001; Han, 2011).

Another important factor to the inflammation phase is the transforming growth factor-beta1 (TGF- $\beta 1$ ) (Shull et al., 1992), a cytokine that is further implicated as a modulator of fibrosis and myogenic differentiation. TGF- $\beta 1$ inhibits differentiation by repression of transcription of the MyoD family members (Hawke \& Garry, 2001; Liu et al., 2001) and it is reported in the literature to have altered expression in dystrophic muscle (Chen et al., 2005) and in injured muscle (Lefaucheur et al, 1995). Moreover, previous report suggests that macrophages modulate the level of $T g f-\beta 1$ (Shen et al., 2008). We detected higher levels of $T g f-\beta 1$ at day 3 in $S J L / J$. Interestingly, despite greater 
levels of $C D 11 b$ and $T g f-\beta 1$ mRNA expression found in $S J L / J$, we did not observe an increase in fibrosis, impaired myogenesis or failure to resolve tissue inflammation in histological analysis.

\section{Altered time course of regeneration in dysferlin-deficient mice}

Despite the significant stimulus to inflammation and the presence of connective tissue infiltration, electrical injury does not seem to compromise the subsequent muscle recovery in the $S J L J$ dysferlin-deficient mouse. Instead, remarkable regenerative capacity of the skeletal muscle was observed when compared to WT mice. SJLJJ exhibited higher levels of expression of regenerative genes at the earlier time point after injury (day 3) as compared to the WT mice. Myogenic factors were much more upregulated, indicating a vigorous cellular response after injury. In addition, enhanced regeneration was confirmed through the intense expression of developmental isoform of myosin heavy chain (dMHC), proving the formation of new myofiber. At the later time points, mRNA expression followed a similar pattern but slightly elevated in normal muscle. Together, our findings suggest that dysferlin deficiency affects muscle recovery modifying the time course of the regenerative response. Based on our results, we could suggest that the faster regeneration in dysferlin-deficient muscle would be due to ongoing regenerative events in the intrinsic dystrophic process, already exposed to degeneration and regeneration cycles (Maley et al., 1994; Sorokin, 2000). A preactive state in the dystrophic muscle could lead, at least in the young dystrophic mice, to the prompt response observed, while WT muscle, not previously activated, requires to be stimulated to initiate the myogenic response. It would be a possible compensation for early muscle damage in young mice, but later it would change as time goes by and the chronic dystrophic process was installed (Weller et al., 1997).

Our findings are in agreement with previous studies that demonstrated faster and more extensive myogenic response in the first days after crush injury in $S J L / J$ compared to Balb/c (Grounds \& McGeachie, 1989; Mitchell et al., 1992). In contrast, others authors suggested that the lack of dysferlin results in slower myogenesis after severe contractioninduced injuries in dysferlin-deficient $A / J$ mice (Roche et al., 2008). In other study, analysis of notexin-injured C57BL/10-SJL.Dysf muscles showed impaired regeneration, however it was suggested that it is not at the level of myogenic factors expression, but it is associated with perturbed recruitment of neutrophils and failure to clear necrotic debris 
(Chiu et al., 2009). It is important to note that several factors can account to the discrepancies observed among the studies (Kobayashi et al., 2012). The dynamics of skeletal muscle regeneration produced by different type of injury, age of the animals, methodologies and experimental controls are variables, making difficult a comparison among studies (Czerwinska et al., 2012). The use of different methodologies to induce degeneration can result in large experimental variation, since alterations in muscle recovery mechanism depend on the type of muscle injuries. In a study that involved two degree of muscle injury, Roche et al., 2010 showed that the recovery from large-strains lengthening contractions involves necrosis followed by myogenesis activation in dysferlin-deficient muscles, whereas WT muscles perform membrane repair without significant myogenesis. On the other hand, the recovery from small strains is performed by myogenesis in both.

It is also noteworthy the importance of genetic background modulating the regenerative mechanism. The insertion of the dysferlin mutation in the background $C 57 B L / 6$ accentuates the disease, while in the 129 background, a milder phenotype was observed, highlighting the effect of modifying genes in the phenotypic manifestation (Demonbreun et al. 2016). Similarly, in a recent study in our laboratory, we transferred the mdx mutation to the $129 / S v$ strain with the aim to create a more severe model for Duchenne Muscular Dystrophy, but surprisingly this new model showed an amelioration of phenotype (Calyjur et al., 2016). Therefore, genetic modifiers can alter significantly the primary genetic mutation and should be considered to explain discrepancies among studies and the variable phenotype observed in humans. Further studies to examine different sources of strains and backgrounds under the same experimental conditions are needed to address these questions.

\section{The dysferlin-FAM65B-HDAC6 tricomplex}

The identification of protein complexes has contributed progressively to better understanding the pathologic pathways of neuromuscular disorders. Dysferlin is known to interact with various proteins to perform its role in membrane repair (Matsuda et al., 2001; Lennon et al., 2003; Huang et al., 2005; Huang et al., 2007; Cai et al., 2009). However, proteins that interact with dysferlin related to its function in myogenesis are still little investigated. Recently two cytoplasmic proteins that interact with dysferlin in the beginning of myoblast differentiation have been identified. FAM65B interacts 
transiently with both HDAC6 and dysferlin and is essential for dysferlin-HDAC6 binding, forming a tricomplex (Balasubramanian et al., 2014). This tricomplex is dynamically regulated and it has been suggested to be important for the progression of myogenesis. HDAC6, a histone deacetylase, acts on deacetylation of acetylated $\alpha$-tubulin present in the polymerized form of microtubules. With the increase of dysferlin during differentiation, lower levels of "free" HDAC6 provide a higher acetylation of $\alpha$-tubulin and consequent elongation of myotubes (Di Fulvio et al, 2011). Inhibition of FAM65B or HDAC6 do not alter DYSF expression (Balasubramanian et al., 2014). During muscle regeneration in vivo, however, it is still unknown whether dysferlin deficiency can alter the expression of FAM65B and HDAC6. Thus, here we analysed the mRNA expression of $H d a c 6$ and Fam $65 b$ at different time points of dysferlin-deficient and WT mice muscle recovery following electrical injury. Our results showed that these two genes are activated during regeneration. The peak expression at day 3 coincided in $S J L / J$ and WT muscle. Similar to our results, Fam65b was previously reported peaking at 2-4 days after cardiotoxin-injured normal mouse muscle (Balasubramanian et al., 2014). However, when comparing the level of expression, we found a higher level in $S J L / J$. Fam $65 b$ was higher at day 3 and 5 and $H d a c 6$ at day 5, showing that dysferlin deficiency affects Fam $65 b$ and $H d a c 6$ expression during muscle regeneration.

In conclusion, our results suggest that dysferlin deficiency alters the time course of the regeneration with the expression of myogenic factors peaking earlier after electrical-induced muscle injury. The infiltration of connective tissue and inflammation, though intense, is resolved in the first days after injury. Additionally, dysferlin influences the expression of the tricomplex components Fam $65 b$ and Hdac6.

\section{References}

ALLEN, R. E.; BOXHORN, L. K. Inhibition of skeletal muscle satellite cell differentiation by transforming growth factor-beta. Journal of Cellular Physiology, v. 133, p. 567-572, 1987.

ARNOLD, L. et al. Inflammatory monocytes recruited after skeletal muscle injury switch into antiinflammatory macrophages to support myogenesis. The Journal of Experimental Medicine, v. 204, n. 5, p. 1057-1069, 2007. 
BALASUBRAMANIAN, A. et al. Fam65b is important for formation of the HDAC6dysferlin protein complex during myogenic cell differentiation. FASEB journal: official publication of the Federation of American Societies for Experimental Biology, v. 28, n. 7, p. 2955-69, 2014.

BANSAL, D. et al. Defective membrane repair in dysferlin-deficient muscular dystrophy. Nature, v. 423, p. 168-172, 2003.

BASHIR, R. et al. A gene related to Caenorhabditis elegans spermatogenesis factor fer1 is mutated in limbgirdle muscular dystrophy type 2B. Nature Genetics, v. 20, p. 37-42, 1998.

CAI, C. et al. Membrane repair defects in muscular dystrophy are linked to altered interaction between MG53, caveolin-3, and dysferlin. The Journal of biological chemistry, v. 284, n. 23, p. 15894-902, 2009.

CALYJUR, P. C. et al. The mdx Mutation in the 129/Sv Background Results in a Milder Phenotype: Transcriptome Comparative Analysis Searching for the Protective Factors. PLoS ONE, v. 11, n. 3, p. e0150748, 2016.

CECO, E.; MCNALLY, E. M. Modifying muscular dystrophy through transforming growth factor-beta. The FEBS journal, v. 280, n. 17, p. 4198-209, 2013.

CHARGÉ, S. B. P.; RUDNICKI, M. A. Cellular and Molecular Regulation of Muscle Regeneration. Physiol. Ver., v. 84, p. 209-238, 2004.

CHEN, Y. et al. Early onset of inflammation and later involvement of TGFbeta in Duchenne muscular dystrophy. Neurology, v. 65, n. 6, p. 826-34, 2005.

CHIU, Y. et al. Attenuated muscle regeneration is a key factor in dysferlin-deficient muscular dystrophy. Human Molecular Genetics, v. 18, n. 11, p. 1976-89, 2009.

COHEN, T. V.; COHEN, J. E.; PARTRIDGE, T. A. Myogenesis in dysferlin-deficient myoblasts is inhibited by an intrinsic inflammatory response. Neuromuscular disorders: NMD, v. 22, n. 7, p. 648-58, 2012.

CZERWINSKA, A. M. et al. Mouse gastrocnemius muscle regeneration after mechanical or cardiotoxin injury. Folia Histochem. Cytobiol., v. 50, n. 1, p. 144-53, 2012.

DE LUNA, N. et al. Absence of dysferlin alters myogenin expression and delays human muscle differentiation "in vitro". The Journal of biological chemistry, v. 281, n. 25, p. 17092-98, 2006.

DEMONBREUN, A. R. et al. An actin-dependent annexin complex mediates plasma membrane repair in muscle. The Journal of cell biology, v. 213, n. 6, p. 705-18, 2016.

DI FULVIO, S. et al. Dysferlin Interacts with Histone Deacetylase 6 and Increases alphaTubulin Acetylation. PLoS ONE, v. 6, n. 12, p. e28563, 2011.

GALLARDO, E. et al. Inflammation in dysferlin myopathy: immunohistochemical characterization of 13 patients. Neurology, v. 57, p. 2136-2138, 2001.

GLOVER, L.; BROWN JR., R. H. Dysferlin in membrane trafficking and patch repair. Traffic (Copenhagen, Denmark), v. 8, n. 7, p. 785-94, 2007. 
GROUNDS, M. D.; MCGEACHIE, J. K. A comparison of muscle precursor replication in crush-injured skeletal muscle of Swiss and BALBc mice. Cell Tissue Res., v. 255, n. 2, p. 385-91, 1989.

HAN, R. Muscle membrane repair and inflammatory attack in dysferlinopathy. Skeletal muscle, v. 1, n. 1, p. 10, 2011.

HARDY, D. et al. Comparative Study of Injury Models for Studying Muscle Regeneration in Mice. PloS ONE, v. 11, n. 1, p. e0147198, 2016.

HAWKE, T. J.; GARRY, D. J. Myogenic satellite cells: physiology to molecular biology. J. Appl. Physiol., v. 91, p. 534-551, 2001.

HUANG, Y. P. et al. "Protein studies in dysferlinopathy patients using llama-derived antibody fragments selected by phage display." Eur. J. Hum. Genet., v. 13, n. 6, p. 721-30, 2005.

HUANG, Y. et al. AHNAK, a novel component of the dysferlin protein complex, redistributes to the cytoplasm with dysferlin during skeletal muscle regeneration. FASEB journal: official publication of the Federation of American Societies for Experimental Biology, v. 21, n. 3, p. 732-42, 2007.

ILLA, I. et al. Distal anterior compartment myopathy: a dysferlin mutation causing a new muscular dystrophy phenotype. Ann. Neurol., v. 49, p. 130-134, 2001.

KERR, J. P.; WARD, C. W.; BLOCH, R. J. Dysferlin at transverse tubules regulates $\mathrm{Ca}^{2+}$ homeostasis in skeletal muscle. Frontiers in Physiology, v. 5, p. 89, 2014.

KOBAYASHI, K. et al. Dysferlin and animal models for dysferlinopathy. Journal of Toxicologic Pathology, v. 25, n. 2, p. 135-147, 2012.

LEFAUCHEUR, J. P.; SEBILLE, A. Muscle regeneration following injury can be modified in vivo by immune neutralization of basic fibroblast growth factor, transforming growth factor beta 1 or insulin-like growth factor I. J. Neuroimmunol., v. 57, p. 85-91, 1995.

LENNON, N. J. et al. Dysferlin interacts with annexins A1 and A2 and mediates sarcolemmal wound-healing. The Journal of biological chemistry, v. 278, n. 50, p. 50466-73, 2003.

LI, Y. et al. Transforming growth factor-beta1 induces the differentiation of myogenic cells into fibrotic cells in injured skeletal muscle: a key event in muscle fibrogenesis. Am. J. Pathol., v. 164, p. 1007-1019, 2004.

LI, Y.; SHIN, D.; KWON, S. H. Histone deacetylase 6 plays a role as a distinct regulator of diverse cellular processes. The FEBS journal, v. 280, n. 3, p. 775-93, 2013.

LIU, J. Dysferlin, a novel skeletal muscle gene, is mutated in Miyoshi myopathy and limb girdle muscular dystrophy. Nat. Genet., v. 20, p. 31-36, 1998.

LIU, D.; BLACK, B. L.; DERYNCK, R. TGF- $\beta$ inhibits muscle differentiation through functional repression of myogenic transcription factors by Smad3. Genes \& Development, v. 15, p. 2950-2966, 2001.

MALEY, M. A. L. et al. Intrinsic differences in MyoD and myogenin expression between primary cultures of $S J L / J$ and Balb/c skeletal muscle. Exp. Cell Res., v. 211, p. 99-107, 1994. 
MATSUDA, C. The sarcolemmal proteins dysferlin and caveolin-3 interact in skeletal muscle. Human Molecular Genetics, v. 10, n. 17, p. 1761-66, 2001.

MITCHELL, C. A.; MCGEACHIE, J. K.; GROUNDS, M. D. Cellular differences in regeneration of murine skeletal muscle: a quantitative histological study in $S J L / J$ and Balb/c mice. Cell Tissue Res., v. 269, p. 159-166, 1992.

NAGARAJU, K. et al. Dysferlin deficiency enhances monocyte phagocytosis: a model for the inflammatory onset of limb-girdle muscular dystrophy 2B. The American journal of pathology, v. 172, n. 3, p. 774-85, 2008.

NEMOTO, H. et al. Histological and immunohistological changes of the skeletal muscles in older $S J L J$ mice. European neurology, v. 57, n. 1, p. 19-25, 2007.

NOVAK, M. L.; WEINHEIMER-HAUS, E. M.; KOH, T. J. Macrophage activation and skeletal muscle healing following traumatic injury. The Journal of pathology, $v$. 232, n. 3, p. 344-355, 2014.

RAWAT, R. et al. Inflammasome up-regulation and activation in dysferlin-deficient skeletal muscle. Am. J. Pathol., v. 176, n. 6, p. 2891-900, 2010.

ROCHE, J. A.; LOVERING, R. M.; BLOCH, R. J. Impaired recovery of dysferlin-null skeletal muscle after contraction-induced injury in vivo. NeuroReport, v. 19, n. 16, p. 1579-84, 2008.

ROCHE, J. A. et al. Extensive mononuclear infiltration and myogenesis characterize recovery of dysferlin-null skeletal muscle from contraction-induced injuries. American journal of physiology Cell physiology, v. 298, p. C298-312, 2010.

ROOSTALU, U.; STRAHLE, U. In vivo imaging of molecular interactions at damaged sarcolemma. Developmental cell, v. 22, n. 3, p. 515-29, 2012.

RUDNICKI, M. A. et al. The molecular regulation of muscle stem cell function. Cold Spring Harbor symposia on quantitative biology, v. 73, p. 323-31, 2008.

SABOURIN, L. A.; RUDNICKI, M. A. The molecular regulation of myogenesis. Clinical Genetics, v. 57, p. 16-25, 2000.

SHEN, W. et al. Interaction between macrophages, TGF-beta1, and the COX-2 pathway during the inflammatory phase of skeletal muscle healing after injury. J. Cell Physiol., v. 214, p. 405-12, 2008.

SHULL, M. M. et al. Targeted disruption of the mouse transforming growth factor- $\beta 1$ gene results in multifocal inflammatory disease. Nature, v. 359, n. 6397, p. 693699, 1992.

SOROKIN, L. M. et al. Laminin a4 and integrin a6 are upregulated in regenerating dy/dy skeletal muscle: comparative expression of laminin and integrin isoforms in muscles regenerating after crush injury. Experimental Cell Research, v. 256, p. 500-514, 2000.

TIDBALL, J. G. Inflammatory processes in muscle injury and repair. Am. J. Physiol. Regul. Integr. Comp. Physiol., v. 288, p. R345-R353, 2005.

VAINZOF, M. et al. Animal models for genetic neuromuscular diseases. Journal of molecular neuroscience: MN, v. 34, n. 3, p. 241-48, 2008. 
WELLER, A. H. et al. Spontaneous myopathy in the $S J L / J$ mouse: pathology and strength loss. Muscle Nerve, v. 20, p. 72-82, 1997. 


\title{
CAPÍTULO 4
}

\section{Defective myoblast differentiation in human dysferlin-deficient cells}

\author{
Ishiba, R. ${ }^{1}$, Bigot, A. ${ }^{2}$, Ribeiro Jr. A.F. ${ }^{1}$, Mouly, V. ${ }^{2}$, Vainzof, M. ${ }^{1}$.
}

\begin{abstract}
Affiliations
1 Laboratory of Muscle Proteins and Comparative Histopathology, Human Genome and Stem-cell Research Center, Biosciences Institute, University of São Paulo, São Paulo, Brazil.
\end{abstract}

2 Sorbonne Universités, UPMC Univ Paris 06, INSERM UMRS974, Center for Research in Myology, 47 Boulevard de l'hôpital, 75013 Paris, France

\section{Corresponding author}

Mariz Vainzof

Human Genome and Stem-cell Research Center, University of São Paulo

Rua do Matão, Travessa 13, nº 106

São Paulo, SP, 05508-090, Brazil

mvainzof@usp.br 


\begin{abstract}
Limb girdle muscular dystrophy type 2B (LGMD2B) is an autosomal recessive disorder caused by mutations in DYSF gene. Dysferlin is a $237 \mathrm{kDa}$ sarcolemmal protein known to interact with several proteins to allow the aggregation and fusion of vesicles to membrane injury site. Partial or total absence of dysferlin protein is responsible for defective membrane repair. Recent evidences suggest that dysferlin plays a role also in myogenesis, but the underlying mechanism remains poorly understood. Using a model of dysferlin-deficient human muscle cells, we observed the presence of thinner myotubes and reduced frequency of myonuclei per myotube, suggesting a delayed progression of myotube formation in LGMD2B cells. Similar onset of MYOD expression was observed, while myogenin occurred earlier in Dysf+/+ than in Dysf-/- cells, suggesting a change in its kinetics. Dysferlin deficiency would therefore be less involved in the first events of formation of small myotubes in early differentiation, but seems to regulate later stages of differentiation, which involves growth and elongation of myotubes. We then analysed the mRNA expression of FAM65B and HDAC6, that form a tricomplex with dysferlin in the earlier stages of myoblast differentiation. While $F A M 65 B$ was not apparently affected by dysferlin deficiency during differentiation, HDAC6 exhibited a transient peak in healthy cells after 24 hours, which was not increased in LGMD2B cells. Based on these findings, we propose that dysferlin deficiency alters HDAC6 expression causing delayed differentiation. Taken together, these results provide an interesting candidate for further investigation of how dysferlin deficiency affects myogenic regulators during differentiation.
\end{abstract}




\section{Resumo}

A distrofia muscular de cintura tipo 2B (LGMD2B) é uma doença autossômica recessiva causada por mutações no gene DYSF. A disferlina é uma proteína sarcolemmal de $237 \mathrm{kDa}$ conhecida por interagir com várias proteínas para permitir a agregação e fusão de vesículas ao local de lesão da membrana. A ausência parcial ou total da proteína disferlina é responsável por defeitos no reparo de membrana. Evidências recentes sugerem que a disferlina desempenha um papel também na miogênese, mas o mecanismo subjacente permanece mal compreendido. Utilizando um modelo de células musculares humanas disferlina-deficientes, observamos a presença de miotubos mais finos e reduzida frequência de núcleos por miotubo, sugerindo uma progressão atrasada de formação de miotubos em células LGMD2B. Foi observado um início semelhante da expressão de MYOD, enquanto que a miogenina ocorreu mais cedo em células Dysf $+/+$ do que em células Dysf -/-, sugerindo uma alteração na sua cinética. A deficiência de disferlina estaria, portanto, menos envolvida nos primeiros eventos de formação de pequenos miotubos no início da diferenciação, mas parece regular os estágios posteriores da diferenciação, que envolve crescimento e alongamento de miotubos. Em seguida, analisamos a expressão de mRNA de FAM65B e HDAC6, que formam um tricomplexo com disferlina nos estágios iniciais de diferenciação de mioblastos. Embora FAM65B não tenha sido aparentemente afetado pela deficiência de disferlina durante a diferenciação, HDAC6 apresentou um pico de expressão transitório nas células normais após 24 horas, que não foi observado nas células LGMD2B. Com base nestes achados, propomos que a deficiência de disferlina altera a expressão de HDAC6 causando diferenciação atrasada. Tomados em conjunto, estes resultados fornecem um candidato interessante para uma investigação mais aprofundada de como a deficiência de disferlina afeta reguladores miogênicos durante a diferenciação. 


\section{Introduction}

Mutations in the DYSF gene located on chromosome 2p13 are responsible for a group of clinically heterogeneous myopathies including Limb-girdle muscular dystrophy type 2B (LGMD2B) (Bashir et al., 1998), Miyoshi myopathy (MM) (Liu et al., 1998) and distal anterior compartment myopathy (DACM) (Illa et al., 2001). They differ in the muscles primarily affected, beginning in the proximal (LGMD2B) and distal muscles (MM and DACM). The symptoms are of late onset, usually in early adulthood, with slow progression, marked by elevated serum-creatine kinase (CK) levels, inflammatory infiltrate and muscle weakness (Wicklund \& Kissel, 2014). The most common mutations are single base substitutions, with higher proportion of missense mutations, without detectable mutational hotspot (Blandin et al., 2012). Its effects are due to partial or complete deficiency of dysferlin, a sarcolemmal protein linked to trafficking and fusion of intracellular vesicles (Posey et al., 2011), membrane repair (Bansal et al., 2003), myogenesis (Chiu et al., 2009) and inflammation (Cohen et al., 2012).

Following injury, the efficiency of the traffic and fusion of vesicles to injury site culminating in membrane repair is possible by the coordinated action of proteins and cytoskeletal components. Sarcolemmal injuries activate a cascade of interactions of these proteins with dysferlin in a $\mathrm{Ca}^{2+}$ dependent manner, leading cytoplasmic vesicles to fuse with disrupted sarcolemma to form a 'patch' (Wallace \& McNally, 2009). Another mechanism for restoring membrane integrity, such as occurs in pore-forming lesions caused by bacterial toxins, is lysosome exocytosis, which releases sphingomyelinase acid near the lesion region. This enzyme provides the alteration of lipids of certain membrane domains that internalize the membrane damaged by endocytosis (Tam et al., 2010). In dysferlin deficiency, the membrane repair is defective. The uncontrolled influx of calcium leads to oxidative stress and proteolysis. Necrosis of muscle fibers is followed by inflammatory response and release of myogenic cell activation factors (Kerr et al., 2014).

In addition, several studies have shown that dysferlin sarcolemmal protein works as an important mediator in events of myogenesis (De Luna et al., 2006; Belanto et al, 2010; Demonbreun et al., 2011; Cohen et al., 2012). During cell differentiation, dysferlin expression level is increased and seems to have an influence on myogenin expression during later stages of differentiation (De Luna et al., 2006). Moreover, recent reports 
indicate that dysferlin participates to a tricomplex with HDAC6 and FAM65B in the beginning of myoblast differentiation. HDAC6 is a histone deacetylase that coordinates dynamic modulation of the microtubule by deacetylation of tubulin, allowing the progression of differentiation. FAM65B binds transiently to dysferlin and provides the formation of a tricomplex with HDAC6. This interaction permits the hyperacetylation of tubulin by inhibiting the activity of HDAC6. Although selective inhibition studies of components of this tricomplex have revealed that dysferlin expression is not affected by the inhibition of HDAC6 or FAM65B (Balasubramanian et al., 2014), it is not yet clear whether the lack of dysferlin has an effect on them. In addition, there is no information about their expression during differentiation in human dysferlin-deficient cells.

In this study, we used a model of dysferlin-deficient human muscle cells to show that a defective myogenic differentiation occurs in the absence of dysferlin. Dysferlindeficient myotubes presented fewer nuclei and reduced diameter. Also, the expression of myogenin was activated earlier in healthy cells than in dysferlin-deficient cells, suggesting that the smaller myotubes could be the result of altered regulation of later stages of differentiation influenced by lack of dysferlin. Additionally, the expression of myogenic factors and FAM65B are not affected by dysferlin deficiency, however HDAC6 expression is altered in the absence of dysferlin in the early phases of differentiation.

\section{Materials and methods}

\section{Cell culture}

Myoblasts of an 11 years-old female patient (Dysf-/-) with a homozygous mutation (c.2954G>A), generating a stop codon, were obtained from a muscle biopsy biceps realized in the Human Genome Studies Center (CEGH-USP), for diagnostic purpose, after signing informing consent. Control myoblast from a normal individual (Dysf $+/+$ ) isolated from the quadriceps of a 53 years old man samples were isolated from a biopsy provided anonymously by Myobank, a tissue bank affiliated to Eurobiobank, in respect of the French legislation, and generously provided by Dr. Vincent Mouly (Institut de Myologie, France). Cells were immortalized by the platform for immortalization of human cells of the Institute of Myology. Briefly, human myoblasts were transduced with lentiviral vectors encoding hTERT and cdk4 containing puromycin and neomycin 
selection markers, respectively. Transduced cells were selected with puromycin $(1 \mu \mathrm{g} / \mathrm{ml})$ for 6 days and neomycin $(1 \mathrm{mg} / \mathrm{ml})$ for 10 days. Infected cells were purified using an immunomagnetic cell sorting system (MACS; Miltenyi) according to the manufacturer's instructions with anti-CD56 microbeads. Cells were seeded at clonal density, and individual myogenic clones were isolated and characterized. Maintenance of the original characteristics of the primary lines for proliferation and differentiation of myoblasts was confirmed.

\section{Fusion index}

Myoblasts were plated at $2 \times 10^{4}$ cells per well in 6-well plates on glass coverslips and were allowed to proliferate for 72 hours until reach $70-80 \%$ confluence in Skeletal Muscle Cell Growth Medium kit (Promocell) adjusted at a final 20\% FBS and $50 \mu \mathrm{g} / \mathrm{mL}$ gentamycin (Invitrogen). After 48h of proliferation, when the cells reached a confluence of approximately $80 \%$, the medium was replaced by a differentiation medium composed of DMEM GlutaMAX TM (Invitrogen) with $10 \mathrm{ug} / \mathrm{ml}$ insulin and $50 \mathrm{ug} / \mathrm{mL}$ gentamicin. At 72h after the initiation of differentiation, cells were fixed in $4 \%$ paraformaldehyde for 20 minutes, followed by permeabilization with $0.2 \%$ Triton X-100 for 30 min, blocking in 5\% BSA for 1 hour and overnight incubation with antibody for alpha- actinin (1:500; Sigma; A2543). The samples were washed 3x in PBS and incubated with a secondary antibody goat anti-rabbit IgG conjugated to Cy3 (1:100; Amersham; PA43004) for 1 hour in the dark. The cultures were then washed 3x with PBS and mounted with Vectashield DAPI +. The images were taken with a fluorescence microscope (Zeiss).

The capacity to form multinucleated myotubes was measured from 3 fields at 20x magnification and quantified from 3 independent experiments for each cell line. They were represented as fusion index, which corresponds to the percentage of nuclei in myotubes relative to total number of nuclei. The distribution was assessed to determine the frequency of numbers of nuclei/myotube. A total of 5443 nuclei were counted for Dysf +/+ and 5250 for Dysf -/-.

\section{Myotube diameter}

To evaluate the development of myotubes, we measured diameters of the same myotubes quantified in fusion experiments. Using ImageJ, the mean diameter of each myotube was calculated from three diameter measurements taken along its length. At 
least 100 myotubes were measured from each cell line ( $\mathrm{n}=3$ fields at 20x magnification) in three independent experiments. Data were presented as the mean diameter of myotubes and the frequency of diameters.

4. $q R T-P C R$

To analyze the expression of myogenic factors, the cells were collected at different times during differentiation in three independent experiments. For each experiment, $2,5 \times 10^{5}$ cells were seeded in $\mathrm{T} 75$ bottles in parallel until they reach a confluency of at least $80 \%$. The proliferation medium was discarded and replaced for differentiation medium. Samples were collected 12, 24, 48 and 144 hours after differentiation and compared to time 0 (undifferentiated). The differentiation medium was removed and cells were washed with cold PBS 1X. Using cell scrapper, cells were mechanically removed from the bottle, transferred to a Falcon $15 \mathrm{ml}$ and centrifuged at $3000 \mathrm{~g}$ for 5 minutes at $4^{\circ} \mathrm{C}$. The cell pellet was resuspended in $500 \mu \mathrm{l}$ of PBS to remove the differentiation medium and centrifuged again. The supernatant was discarded and the pellet rapidly frozen in liquid nitrogen and stored at $-70^{\circ} \mathrm{C}$ freezer.

Total RNA was extracted using TRIzol (Invitrogen) following the manufacturer's protocol. For the cDNA synthesis, $1 \mu \mathrm{g}$ of total RNA was used with random primer $0,1 \mu \mathrm{l}$ ( $3 \mu \mathrm{g} / \mu \mathrm{l}), 1 \mu \mathrm{l}$ oligo dT $(500 \mu \mathrm{g} / \mathrm{ml}), 1 \mu \mathrm{dNTP} \operatorname{mix}(10 \mathrm{mM})$ and DEPC water adjusted to the volume of $12 \mu \mathrm{l}$. This mixture was left at $65^{\circ} \mathrm{C}$ in thermocycler for 5 minutes. Then $4 \mu 15 x$ First Strand Buffer; $2 \mu 1$ DTT $(0.1 \mathrm{mM})$ and $1 \mu 1$ RNase OUT (40 U/ $\mu 1)$ was added and incubated in the thermocycler at $37^{\circ} \mathrm{C}$ for 2 minutes. One $\mu l$ of MMLV reverse transcriptase was then added to the samples and incubated at $25^{\circ} \mathrm{C}$ for 10 minutes, then at $37^{\circ} \mathrm{C}$ for 50 minutes and finally at $70^{\circ} \mathrm{C}$ for 15 minutes. The cDNA was diluted $(1: 3$ in RNase free water) and applied in duplicates in 96 well plate. Samples were amplified using the MasterMix containing FastStart Universal SYBR Green Master (Rox) (Roche) and primers (detailed in Table 1) in a total volume of $20 \mu \mathrm{L}$. Each plate was run on thermocycler 7500 Fast (Applied Biosystems/Life). For data analysis, each time point was normalized by RPLPO mRNA and expressed as $2^{-\triangle \Delta \mathrm{CT}}$ to the undifferentiated Dysf+/+ cells. 
Tabela 1: Primers sequences

\begin{tabular}{|c|c|c|}
\hline Gene & Forward sequence & Reverse sequence \\
\hline $\boldsymbol{M Y F 5}$ & CTCAGCAGGATGGACGTGAT & TATGCAGGAGCCGTCGTA \\
\hline $\boldsymbol{M Y O D}$ & TGCCACAACGGACGACTTC & CGGGTCCAGGTCTTCGAA \\
\hline Myogenin & CAG TGC CAT CCA GTA CAT CG & AGG TTG TGG GCA TCT GTA GG \\
\hline $\boldsymbol{D Y S F}$ & CAG TCC CAG AGA GTT CAC AGG & CCA GGG AGA GCA GAA GCC A \\
\hline $\boldsymbol{F A M 6 5 \boldsymbol { B }}$ & GCC CAG CAG GAA GTA CTC AG & GAT TTT CAG AGC CAG GCA AG \\
$+\boldsymbol{F A M 6 5 B 4 1 2}$ & & \\
\hline $\boldsymbol{H D A C 6}$ & ATG GCC ATC ATT AGG CCT CC & CGG ATG CGG TGT TTC TGT TG \\
\hline $\boldsymbol{R P L P O}$ & GGA TTA CAC CTT CCC ACT TGC T & GCC ACA AAG GCA GAT GGA TCA \\
\hline
\end{tabular}

\section{Statistical analysis}

Data were represented as mean \pm SD. Statistical significances were calculated using Minitab by one-way ANOVA with Dunnet post hoc for multiple comparisons. Student t-test was used when comparing the strains. P-values less than 0.05 were considered significant.

\section{Results}

Delayed myoblast fusion in human dysferlin-deficient cells

We evaluated the fusion of dysferlinopathic patient myoblasts (Dysf-/-) and normal myoblasts (Dysf $+/+$ ) by their ability to form $\alpha$-actinin positive myotubes (Fig. 1A). The fusion index, that measures the average percentage of nuclei in myotubes, and the relative distribution of nuclei per myotube were determined after 72 hours of differentiation. There were no significant differences in the fusion index between the two cultures (Dysf +/+: $42.91 \% \pm 1.82$ vs Dysf -/-: 49.96\% $\pm 5.08 ; \mathrm{p}=0.152$ ) (Fig. 1B). However, the distribution of fiber size per number of nuclei/myotube showed a disproportionately high number of myotubes with reduced number of nuclei $(<10)$ in Dysf-/-. In contrast, Dysf $+/+$ myotubes contained generally a higher number of myonuclei (>30) (Fig. 1C). Therefore, due to the alteration in myotubes fusion, a higher number of small myotubes per field is observed in dysferlin deficient cells (Dysf $+/+$ : $35.67 \pm 1.15$ vs Dysf -/-: $62.33 \pm 4.93 ; \mathrm{p}=0.012$ ) (Fig. 1D). These data suggest a requirement of dysferlin for myotube growth and maturation. 

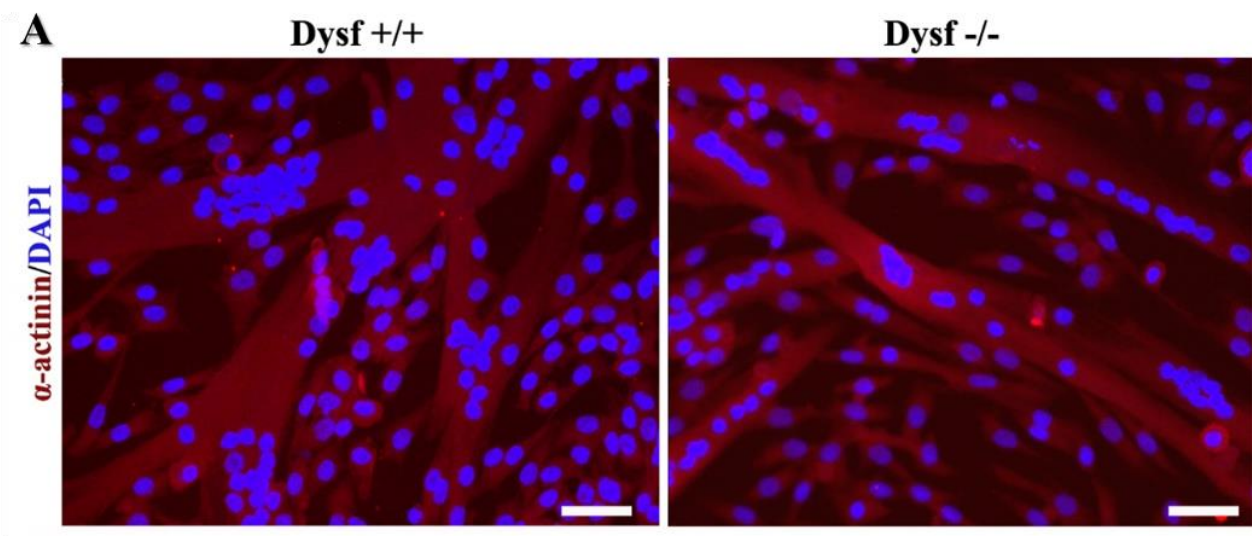

\section{B}

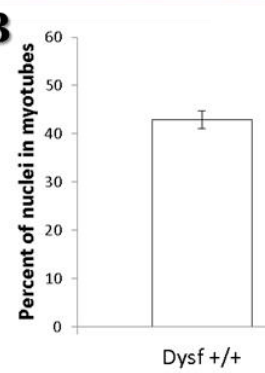

C
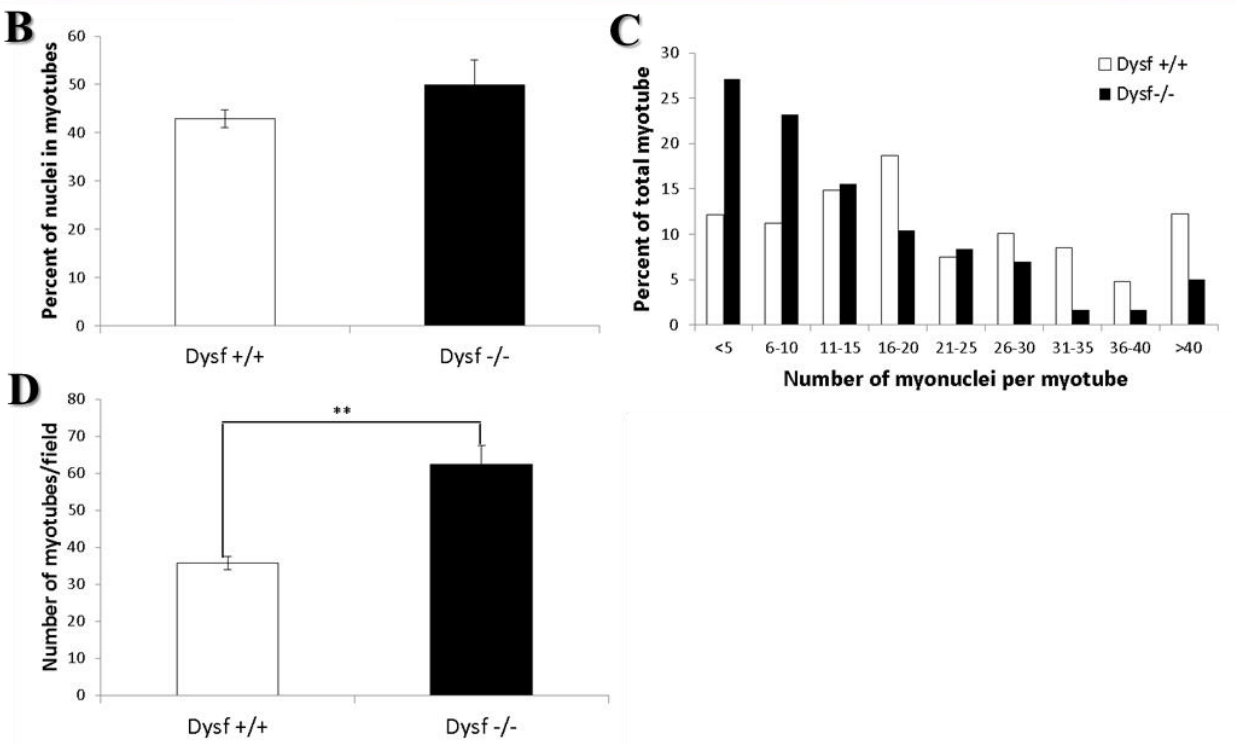

Number of myonuclei per myotube

Figure 1. Delayed myoblast fusion in human dysferlin-deficient cells. A: Myoblasts were induced to differentiate for 72 hours and stained with antibody for $\alpha$-actinin. Representative images of Dysf $+/+$ and Dysf-/- are shown. Bar: $50 \mu \mathrm{m}$. B: No significant differences in fusion index were detected between the Dysf $+/+$ and Dysf-/- cell populations. C: The distribution of fiber sizes per number of myonuclei was measured and expressed as a histogram plot of groups with increasing number on nuclei, revealing that myotubes with less nuclei are more frequent in dysferlin-deficient cells. D: Differences in number of myotubes per field. A total of 5443 nuclei (Dysf+/+) and 5250 nuclei (Dysf-/-) were counted.

\section{Dysferlin deficient myotubes have a reduced diameter}

Representative images of normal and dysferlin deficient-cells at different time points during differentiation are shown in Figure 2A. At day 1, mononucleated myoblasts begin to aggregate in both cell lineages. They fuse to form small myotubes that, as the differentiation progresses, increase in size. To quantify the differences between dysferlinopathic and control cells, we measured myotube diameter after $72 \mathrm{~h}$ in differentiation medium, assessed by fluorescence microscopy of the very same images analysed for fusion index. Analysis of myotube diameters revealed a significant reduced 
mean diameter of dysferlin-deficient myotubes (Dysf +/+: $51.64 \pm 3.48$ vs Dysf -/-: 35.35 $\pm 4.25 ; \mathrm{p}=0.014)$, as shown on Figure $2 \mathrm{~B}$. The distribution of myotube diameters showed an increase in the frequency of smaller myotubes and a reduced number of larger myotubes in dysferlin-deficient cells. In contrast, control myotubes presented $53.2 \%$ of myotubes with diameter $>50 \mu \mathrm{m}$, compared with only $10.16 \%$ of dysferlinopathic myotubes (Fig. 2C). Furthermore, significant correlation was observed between myotube width and myonuclear number, showing reduced number of nuclei and thickness diameter for dysferlinopathic cultures and more nuclei and larger diameter for normal myotubes (Fig. 2D), which confirms an impairment in myotube fusion and growth in the absence of dysferlin.

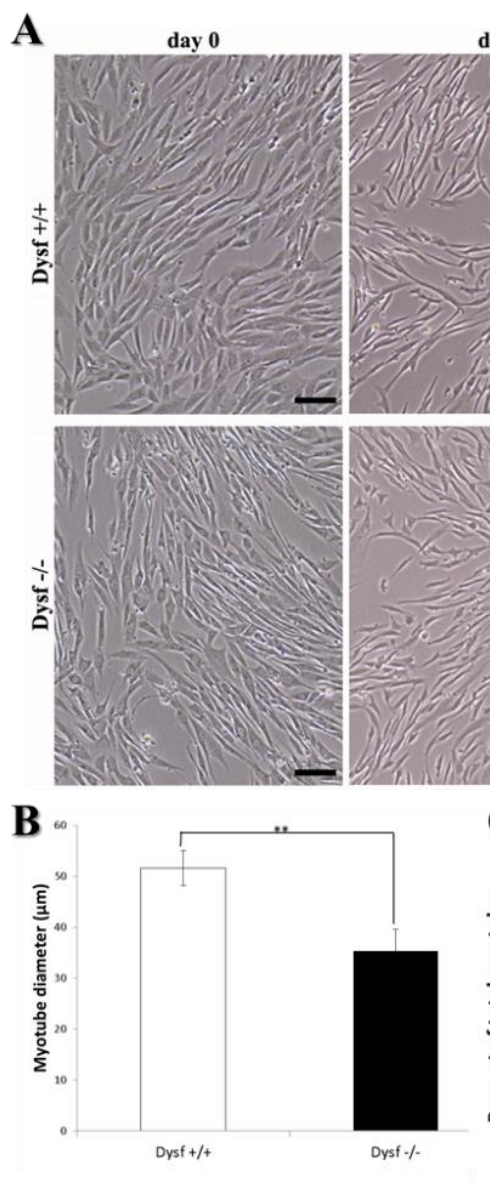

day 1
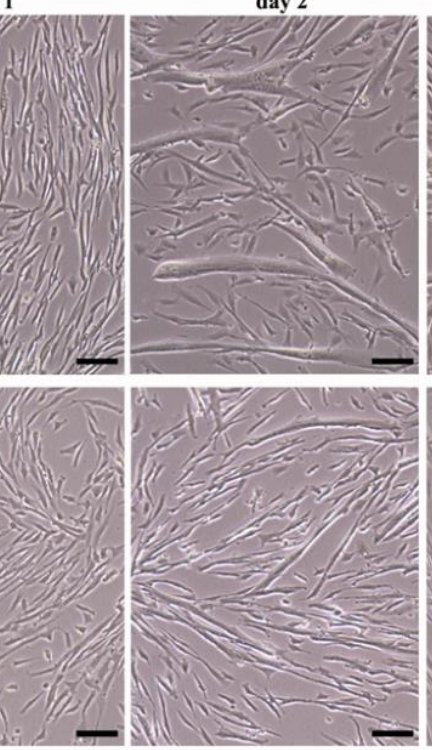

C

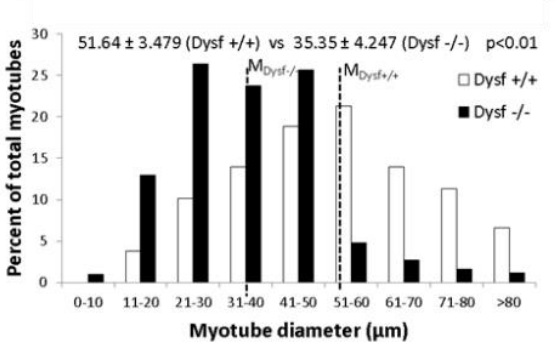

day 4

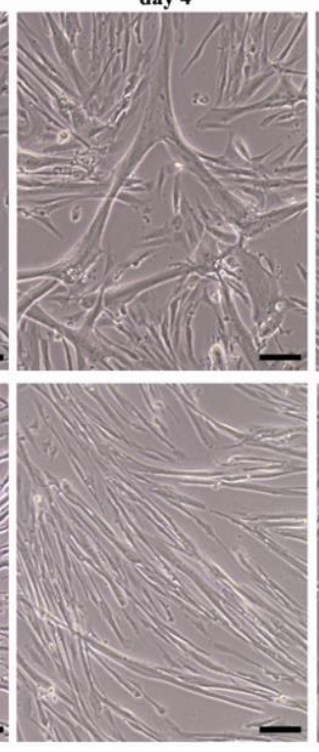

D

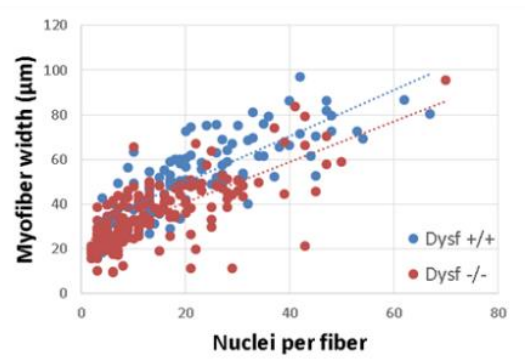

Figure 2: Comparison of myotube diameter between Dysf+/+ and Dysf-/-. A: Representative images of different time points of differentiation Bar: $100 \mu \mathrm{m}$. B: The mean diameter of myotubes was determined $72 \mathrm{~h}$ after the switch to differentiation conditions. The mean diameter for Dysf $+/+(51.64 \pm 3.48)$ myotubes was significantly larger $(\mathrm{P}<0.014)$ than for Dysf-/- $(35.35$ $\pm 4.25)$ myotubes. $\mathrm{C}$ : The distributions of myotube diameters showed higher frequency of thinner myotubes in Dysf-/-. Mean \pm SD. D: Correlation between diameter and number of nuclei revealed reduced number of nuclei per fiber and myofiber width in Dysf $-/$ - cultures compared to Dysf $+/+$. A total of 108 (Dysf $+/+)$ myotubes and 188 myotubes (Dysf-/-) were counted ( $\mathrm{n}=3$ experiments). 
Expression of myogenic factors during differentiation

We further explored the effects of dysferlin deficiency by analysing the mRNA expression of MYOD, MYF5 and myogenin as markers of progression of muscle differentiation. The general pattern of expression of differentiation markers was not altered between Dysf $+/+$ and Dysf-/- cells. However, in Dysf $+/+$ cells, as myotubes matured, MYOD started to increase at $12 \mathrm{~h}$ and $24 \mathrm{~h}$, followed by myogenin that increased from 24h, while in Dysf-/- cells, myogenin peaked only at 48h and MYOD at 12h. MYF5 remained unchanged throughout this period (Fig. 3A).

\section{Dysferlin deficiency alters HDAC6 expression}

To investigate the effect of dysferlin deficiency in the expression of the tricomplex components (DYSF, FAM65B, HDAC6), we induced myoblasts to differentiate in myotubes for up to 6 days and their mRNA levels were measured along the differentiation process. As expected, DYSF expression significantly increased during myoblast differentiation, after $48 \mathrm{~h}$ in Dysf $+/+$ cells. Conversely, in dysferlin-deficient cells, DYSF expression was unaltered during the entire time course of differentiation. FAM65B levels remained within the levels observed in the myoblasts (point zero), since no significant difference was detected during differentiation among time points and between cell lines. A transient and rapid increase of HDAC6 was observed at an early time point of differentiation (24h) only in Dysf $+/+$, followed by induction of dysferlin expression at $48 \mathrm{~h}$ (Fig. 3A-B). 
A
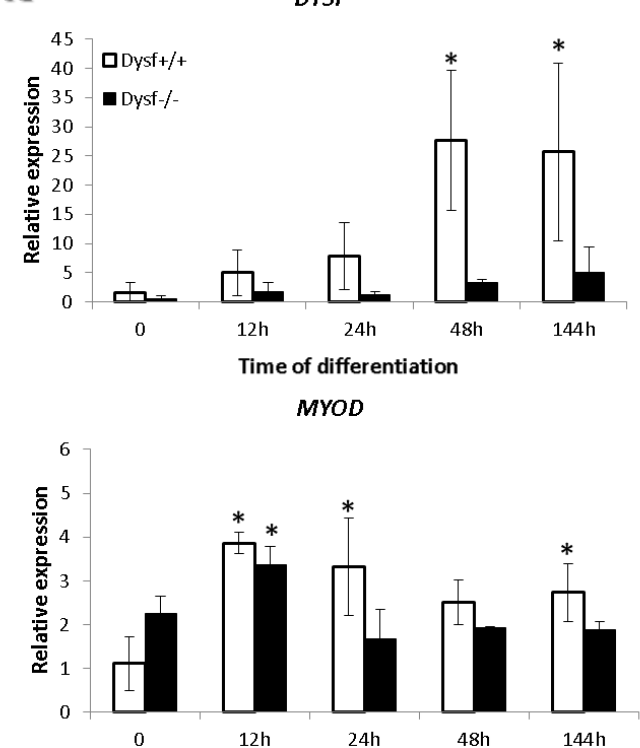

B

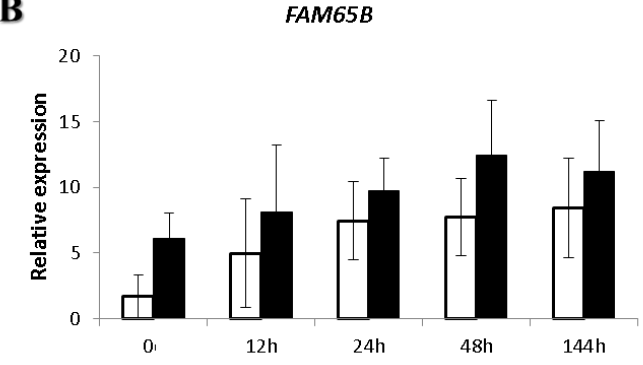

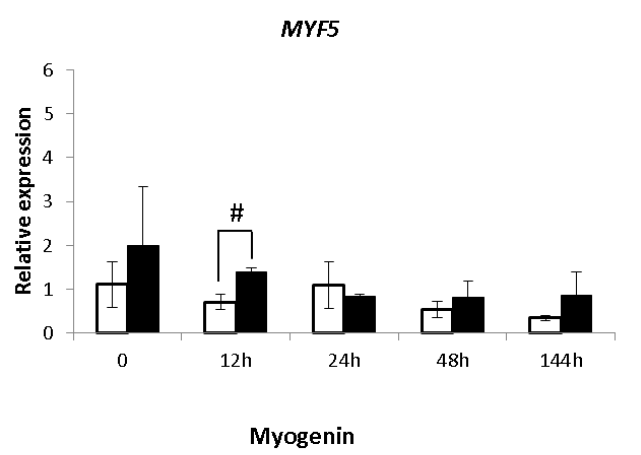
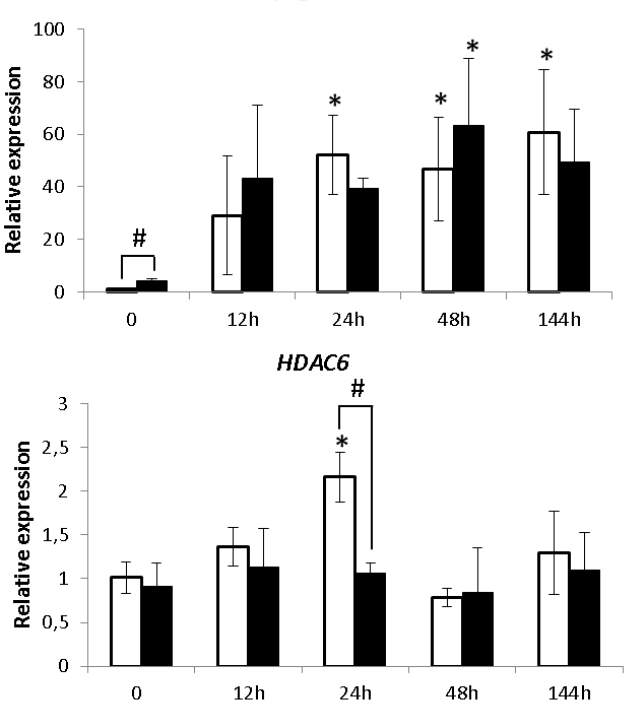

Figure 3: Time course of myogenic factors in Dysf+/+ and Dysf-/-. Data were analysed at different time points after inducing differentiation. A: Comparative pattern of mRNA expression of DYSF and myogenic factors MYF5, MYOD and myogenin. B: Relative mRNA expression of FAM65B and HDAC6 showed an increase of HADC6 expression at day 1 of differentiation in Dysf $+/+$. Mean \pm SD ( $n=3$ experiments $)$.

\section{Discussion}

\section{Dysferlin deficient myotubes have a reduced diameter and lower number of nuclei}

Understanding how dysferlin deficiency affects myoblast differentiation is crucial to enable the development of potential targets for therapies of dysferlinopathies. Myogenesis occurs during embryonic muscle development and is recapitulated in adult life following injury. The precise regulation of these processes is essential for muscle integrity (Bentzinger et al., 2012). Myogenic differentiation can be reproduced in vitro to better understand pathological mechanisms in diseases such as muscular dystrophies. However, one of the challenges is the limited proliferative capacity of primary human muscle cultured cells, particularly when isolated from patients suffering from muscular diseases. Here we used human skeletal muscle cell lines immortalized. These cells were 
previously characterized by the absence of alteration of the differentiation process when compared to primary culture counterparts (Mamchaoui et al 2011, Philippi et al 2012).

To determine the effects of dysferlin deficiency on myoblast differentiation into myotubes, we measured fusion and diameter of the myotubes, comparing dysferlin deficient cells to normal controls. Our findings showed altered events of later differentiation. Although dysferlin deficiency did not block the fusion of myoblast into myotubes, it affected their growth, potentially through the process of myotube fusion and the progression of differentiation, resulting in the formation of thinner myotubes containing less myonuclei. The fusion index was not significantly different, but dysferlindeficient cultured cells exhibited a higher frequency of myotubes with a lower number of nuclei, consistent with the decrease in myotube diameter. Although no impairment in early stages of myoblast differentiation has been described in some publications (Chiu et al., 2009; Defour et al., 2014), our data suggest that dysferlin deficiency could alter a later stage of the differentiation, in agreement with several other previously reports in murine and human cells (De Luna et al., 2006; Belanto et al., 2010; Demonbreun et al., 2011; Cohen et al., 2012). However further investigations are needed to address the possibility of other explanations to defective myotube differentiation such as defects in adhesion or migration.

Other proteins of the ferlin family also participate to membrane fusion, notably myoferlin, a protein homologous to dysferlin that is required for normal myoblast fusion. Dysferlin and myoferlin are proposed to act in a coordinated manner in which myoferlin is expressed in the prefusion myoblasts in the early stages of myogenic differentiation and decrease in mature myotubes, whereas dysferlin increases its expression upon differentiation (Davis et al., 2002). Thus, the loss of dysferlin could be partially compensated by the action of other fusogenic proteins, but does not prevent delayed differentiation. We propose that while myoferlin is active for the first events of fusion and in the formation of early small myotubes, dysferlin could play a role in later stages of fusion involved in myotube growth or fusion between myotubes, which is in correlation with the fact that dysferlin expression is increased from $48 \mathrm{hrs}$ of differentiation, after the first fusion events have occurred. 


\section{Expression of myogenic factors during differentiation}

Myogenic Regulatory Factors (MRFs), that include MYF5, MYOD, MRF4 and myogenin, are essential for muscle differentiation. MYF5 and MYOD are the primary determinants of the myogenic lineage, while MRF4 and myogenin participate to later stages of differentiation (Rudnicki et al., 2008). In our study, despite of the delayed/impaired myoblast differentiation in dysferlin deficient cells, mRNA expression of the myogenic factors showed an increase of $M Y O D$ levels after 12 hours of differentiation in both lineages. These results were not surprising, since in several protein studies, no modifications in expression of early differentiation markers were observed in diverse cellular models with dysferlin deficiency. Moreover, since the increase in MYOD expression followed by the increase in myogenin is required for differentiation, it reinforces our proposition that dysferlin does not play a crucial role during the first event of fusion at early time points of differentiation, when myoferlin is still present, but could be instrumental for myotube growth. Whether dysferlin deficiency affects fusion of small myotubes with remaining myoblasts or fusion between small myotubes remains to be investigated, although the increased number of small myotubes would favour the second hypothesis. At the mRNA level, De Luna et al. (2006) found normal MYOD and desmin mRNA expression, however reduced myogenin was reported in primary human dysferlin-deficient cultures and in cells treated with dysferlin siRNA. In our Dysf-/- cells, a difference in myogenin was also observed relative to undifferentiated cells, since the expression was significantly increased only after 48 hours of differentiation, while in normal cells the higher picks were detected after 24 hours of differentiation.

On the other hand, in muscle cells of mouse models for dysferlinopathies, downregulation of Myf5, MyoD and myogenin transcripts were observed in myotubes (Cohen et al., 2012) suggesting possible differences between murine and human models, at least in vitro. Therefore, variations found in the different studies may be due to the nature of the cell lines, murine or human, and their origin (Belanto et al., 2010). Also, culture conditions and experimental design, may affect the kinetics of cells in culture (Philippi, et al., 2012).

In conclusion, at least at the level of mRNA expression, the myogenic factors in our study are not significantly different comparing normal and dysferlin-deficient cells during muscle differentiation in vitro. However, myogenin peak of expression occurred 
earlier in Dysf+/+ than in Dysf-/- cells relative to undifferentiated cells, suggesting a change in the kinetics of the expression of this gene, which could well explain the smaller myotubes observed in Dysf-/- cells.

\section{Dysferlin deficiency alters HDAC6 expression}

The identification of the interaction among proteins is of utmost importance for understanding protein function, and several proteins interacting with dysferlin have been reported (Matsuda et al., 2001; Lennon et al., 2003; Huang et al., 2005; Cai et al., 2009). The most recent finding is related to the formation of a tricomplex of dysferlin with HDAC6 and FAM65B at the beginning of myoblast differentiation. This tricomplex is dynamically regulated and it has been suggested to be important for the progression of myogenesis (Balasubramanian et al., 2014). HDAC6, a histone deacetylase, acts inhibiting the acetylation of $\alpha$-tubulin present in polymerized form of microtubules. With the increase of dysferlin during differentiation, lower levels of "free" HDAC6 provide a higher acetylation of $\alpha$-tubulin and consequent elongation of myotubes (Di Fulvio et al, 2011). Inhibition of FAM65B or HDAC6 do not alter DYSF expression (Balasubramanian et al., 2014), however the effect of dysferlin deficiency on these two components of the tricomplex remains elusive. We extended our study to investigate the effects of dysferlin deficiency on the expression of the components of the FAM65BHDAC6-DYSF tricomplex. We observed that during human cell differentiation, the mRNA levels of $F A M 65 B$ did not statistically differ between control and dysferlin deficient cells, whereas HDAC6 presented a transient peak, statistically significant, after 24 hours and DYSF increased from $48 \mathrm{~h}$ of differentiation, only in control cells. We therefore suggest that the expression of dysferlin and HDAC6 are increased in the early stages of differentiation in normal cells, and this would be important for the subsequent step of muscle formation, acting on deacetylation of $\alpha$-tubulin and its important role for the elongation of myotubes. Based on these findings, we propose that dysferlin deficiency alters HDAC6 expression causing delayed differentiation. These results reinforce the hypothesis that dysferlin plays a role during myogenesis.

In summary, using a model of dysferlin-deficient human muscle cells, we observed the presence of thinner myotubes and reduced frequency of myonuclei per myotube, suggesting a delayed progression of differentiation in LGMD2B cells. These 
findings suggest that dysferlin would be less involved in the first events of formation of early small myotubes, but could play an important role in the later stages of differentiation, which involves myotube growth or fusion between myotubes. Additionally, the regulation of the expression of HDAC6 in the early stages of myoblast differentiation may represent a potential novel mechanism to be investigated that may reveal new potential targets for the treatment of dysferlinopathy.

\section{References}

BALASUBRAMANIAN, A. et al. Fam65b is important for formation of the HDAC6dysferlin protein complex during myogenic cell differentiation. FASEB journal : official publication of the Federation of American Societies for Experimental Biology, v. 28, n. 7, p. 2955-2969, 2014.

BANSAL, D. et al. Defective membrane repair in dysferlin-deficient muscular dystrophy. Nature, v. 423, p. 168-172, 2003.

BASHIR, R. et al. A gene related to Caenorhabditis elegans spermatogenesis factor fer1 is mutated in limb-girdle muscular dystrophy type 2B. Nat. Genet., v. 20, p. 3742, 1998.

BELANTO, J. J., Diaz-Perez SV, Magyar CE, Maxwell MM, Yilmaz Y, et al. 2010. Dexamethasone induces dysferlin in myoblasts and enhances their myogenic differentiation. Neuromuscul Disord 20(2):111-121.

BENTZINGER, C. F.; WANG, Y. X.; RUDNICKI, M. A. Building muscle: molecular regulation of myogenesis. Cold Spring Harbor perspectives in biology, v. 4, n. $2,2012$.

BLANDIN, G. et al. UMD-DYSF, a novel locus specific database for the compilation and interactive analysis of mutations in the dysferlin gene. Human mutation, v. 33, n. 3, p. E2317-31, 2012.

CAI, C. et al. Membrane repair defects in muscular dystrophy are linked to altered interaction between MG53, caveolin-3, and dysferlin. The Journal of biological chemistry, v. 284, n. 23, p. 15894-15902, 2009.

CHIU, Y. et al. Attenuated muscle regeneration is a key factor in dysferlin-deficient muscular dystrophy. Human Molecular Genetics, v. 18, n. 11, p. 1976-1989, 2009.

COHEN, T. V.; COHEN, J. E.; PARTRIDGE, T. A. Myogenesis in dysferlin-deficient myoblasts is inhibited by an intrinsic inflammatory response. Neuromuscular disorders : NMD, v. 22, n. 7, p. 648-658, 2012.

DAVIS, D. B. et al. Calcium-sensitive phospholipid binding properties of normal and mutant ferlin C2 domains. The Journal of biological chemistry, v. 277, n. 25, p. 22883-22888, 2002. 
DE LUNA, N. et al. Absence of dysferlin alters myogenin expression and delays human muscle differentiation "in vitro". The Journal of biological chemistry, v. 281, n. 25, p. 17092-17098, 2006.

DEFOUR, A. et al. Dysferlin regulates cell membrane repair by facilitating injurytriggered acid sphingomyelinase secretion. Cell death \& disease, v. 5, p. e1306, 2014.

DEMONBREUN, A. R. et al. et al. Impaired muscle growth and response to insulin-like growth factor 1 in dysferlin-mediated muscular dystrophy. Human Molecular Genetics, v. 20, n. 4, p. 779-789, 2011.

DI FULVIO, S. et al. Dysferlin interacts with histone deacetylase 6 and increases alphatubulin acetylation. PloS one, v. 6, n. 12, p. e28563, 2011.

HUANG, Y. et al. Protein studies in dysferlinopathy patients using llama-derived antibody fragments selected by phage display. European journal of human genetics : EJHG, v. 13, n. 6, p. 721-730, 2005.

ILLA, I. et al. Distal anterior compartment myopathy: a dysferlin mutation causing a new muscular dystrophy phenotype. Ann. Neurol., v. 49, p. 130-4, 2001.

KERR, J. P.; WARD, C. W.; BLOCH, R. J. Dysferlin at transverse tubules regulates $\mathrm{Ca}(2+)$ homeostasis in skeletal muscle. Frontiers in physiology, v. 5, p. 89, 2014.

LENNON, N. J. et al. Dysferlin interacts with annexins A1 and A2 and mediates sarcolemmal wound-healing. The Journal of biological chemistry, v. 278, n. 50, p. 50466-50473, 2003.

LIU, J. et al. Dysferlin, a novel skeletal muscle gene, is mutated in Miyoshi myopathy and limb girdle muscular dystrophy. Nat. Genet., v. 20, p. 31-6, 1998.

MATSUDA, C. The sarcolemmal proteins dysferlin and caveolin-3 interact in skeletal muscle. Human Molecular Genetics, v. 10, n. 17, p. 1761-1766, 2001.

MAMCHAOUI, K. et al. Immortalized pathological human myoblasts: towards a universal tool for the study of neuromuscular disorders. Skelet Muscle, v. 1, p. 134, 2011.

PHILIPPI, S. et al. Dysferlin-deficient immortalized human myoblasts and myotubes as a useful tool to study dysferlinopathy. PLoS Curr, v. 4, p. RRN1298, 2012.

POSEY, A. D., JR; DEMONBREUN, A.; MCNALLY, E. M. Ferlin proteins in myoblast fusion and muscle growth. Current topics in developmental biology, v. 96, p. 203-230, 2011.

RUDNICKI, M. A. et al. The molecular regulation of muscle stem cell function. Cold Spring Harbor symposia on quantitative biology, v. 73, p. 323-331, 2008.

TAM, C. et al. Exocytosis of acid sphingomyelinase by wounded cells promotes endocytosis and plasma membrane repair. The Journal of cell biology, v. 189, $\mathrm{n}$. 6, p. 1027-1038, 2010.

WALlACE, G. Q.; MCNALlY, E. M. Mechanisms of muscle degeneration, regeneration, and repair in the muscular dystrophies. Annual review of physiology, v. 71, p. 37-57, 2009. 
WICKLUND, M. P.; KISSEL, J. T. The limb-girdle muscular dystrophies. Neurologic clinics, v. 32, n. 3, p. 729-49, ix, 2014. 


\section{CAPÍTULO 5}

\section{Discussão geral e conclusões}

Nesse estudo, tivemos como objetivo expandir o conhecimento sobre a função da disferlina durante a miogênese em camundongos e humanos com distrofia muscular de cinturas tipo 2B (LGMD2B). Desde a descoberta de que mutações no gene da disferlina causam LGMD2B e outras variantes clínicas (Bashir et al., 1998; Liu et al., 1998), diversos estudos têm sido realizados para determinar de que forma a deficiência da disferlina afeta a integridade muscular, aumentando a suscetibilidade ao estresse mecânico e lesão. A disferlina é relatada por exercer funções ligadas à fusão e ao tráfego intracelular de vesículas (Posey et al., 2011), reparo de membrana (Bansal et al., 2003) e inflamação (Rawat et al., 2010). Dados conflitantes também relacionam a função da disferlina à miogênese pela regulação da fusão de membranas durante a diferenciação muscular. Alguns autores sugerem que a deficiência de disferlina causa defeitos na miogênese (De Luna et al., 2006; Demonbreun et al., 2011; Cohen et al., 2012), enquanto outros não observaram alterações neste processo (Chiu et al., 2009; Humphrey et al., 2012; Defour et al., 2014).

A mioferlina, uma proteína da família das ferlinas homóloga à disferlina, é proposta por agir de forma coordenada com a disferlina. A mioferlina é expressa nos mioblastos nos estágios iniciais de sua fusão, diminuindo nos miotubos maduros, enquanto a disferlina aumenta durante a diferenciação, com maior expressão em miotubos (Davis et al., 2002). Além disso, alguns trabalhos vêm descobrindo funções da disferlina dependentes da interação com outras proteínas (Lennon et al., 2003; Cai et al., 2009; Azakir et al., 2010). A identificação de genes que apresentam expressão alterada diante da deficiência de disferlina, permite avanços na compreensão dos mecanismos de ação associados às disferlinopatias, contribuindo para a descoberta de potenciais alvos para a aplicação de terapias. O envolvimento de outras proteínas nos eventos de fusão e formação de miotubos necessitam ser melhor investigados. Um recente estudo descreveu a formação transiente de um tricomplexo no início da diferenciação, composto por FAM65B, HDAC6 e disferlina, que participa da regulação da progressão da miogênese pelo controle dinâmico da polimerização de microtúbulos (Balasubramanian et al., 2014). Baseado nesse estudo, buscamos investigar o efeito da deficiência de disferlina sobre a 
expressão de Fam65b e Hdac6, assim como de fatores miogênicos durante a diferenciação muscular.

$\mathrm{Na}$ primeira parte do trabalho (Capítulo 3), em experimentos in vivo com a linhagem murina $S J L / L$, modelo animal para a LGMD2B, foram analisados os efeitos da deficiência de disferlina na recuperação muscular após lesão mecânica induzida por eletroporação. Nossos resultados mostraram que a deficiência de disferlina não comprometeu a recuperação muscular em $S J L / J$, mas alterou temporalmente os eventos de degeneração e regeneração após lesão. Apesar dos níveis elevados de expressão de fatores de inflamação e fibrose, as análises histológicas mostraram que a miogênese não é comprometida e o músculo é capaz de restabelecer sua citoarquitetura. $\mathrm{O}$ aumento da fagocitose parece contribuir para a eficiente remoção de necrose causada pela degeneração muscular, seguida por rápida resposta regenerativa, evidenciada pelo pico de ativação de fatores miogênicos ocorrendo antes em $S J L / J$, comparado ao controle normal. O padrão de regulação de Fam65b e de Hdac6 revelou expressão aumentada desses componentes do tricomplexo durante os primeiros dias de recuperação muscular, tanto na linhagem disferlina-deficiente quanto no controle normal, indicando a atuação desses componentes na regeneração muscular. No entanto, a expressão também foi maior em $S J L / L$, o que sugere uma possível regulação de Fam65b e Hdac6 pela disferlina. Investigações adicionais sobre a influência da deficiência de disferlina na expressão desses componentes do tricomplexo e seus efeitos na diferenciação miogênica são necessárias.

Eficiente regeneração muscular nos camundongos $S J L / J$ foi observada em estudos anteriores (Grounds et al., 1989; Mitchell et al., 1992; Maley et al., 1994). Uma possível explicação seria de que um estado pré-ativado de estímulo à regeneração ocorre no músculo distrófico de camundongos jovens e poderia contribuir para a rápida resposta regenerativa após lesão (Maley et al., 1994; Sorokin, 2000), enquanto músculos normais requerem um primeiro estímulo para a ativação e recrutamento de células satélite para a recuperação muscular. Eventualmente, esse quadro mudaria, com a idade e o estabelecimento de um estado crônico da doença (Weller et al., 1997). Contrapondo-se aos nossos resultados, outros trabalhos relataram recuperação muscular comprometida em animais disferlina-deficiente (Roche et al., 2008; Chiu et al., 2009; Cohen et al., 2012). As divergências entre os dados da literatura podem estar relacionadas às diferentes 
condições experimentais, como linhagens murinas utilizadas e tipos de lesões musculares induzidas (Cohen et al., 2015). Essas variações apontam para a necessidade da difícil tarefa de aplicação de experimentos e formas de análise de resultados padronizados que unifiquem a produção de dados, tornando-os passíveis de comparação (Hornsey et al., 2013).

Adicionalmente, neste trabalho, realizamos experimentos in vitro (Capítulo 4), utilizando células musculares humanas de paciente com deficiência total de disferlina. A expressão dos genes MYF5, MYOD e miogenina e do tricomplexo DYSF, HDAC6 e FAM65B foi analisada durante a diferenciação muscular. Nossos resultados revelaram que células disferlina-deficientes apresentam formação de miotubos comprometida. Observamos uma significante frequência de miotubos com poucos núcleos e com diâmetro reduzido, indicando que a deficiência de disferlina não afeta a fusão de mioblastos nos estágios iniciais da diferenciação muscular, mas pode atuar nos estágios posteriores, provocando comprometimento do crescimento e alongamento de miotubos. Nas análises de expressão gênica, $F A M 65 B$ seguiu um padrão similar entre as células disferlinadeficiente e as normais. No entanto, o pico de expressão de miogenina ocorreu mais cedo nas células normais, sugerindo alterações na cinética de expressão desse fator em células disferlina-deficientes. Além disso, nas células disferlina-deficientes, os níveis de DYSF e HDAC6 permaneceram inalterados, enquanto nas células normais, HDAC6 teve uma elevação transiente no início diferenciação e $D Y S F$ aumentou com a progressão da diferenciação. A elevação de DYSF nas células normais é esperado, já que em condições normais a disferlina aumenta durante a diferenciação miogênica (De Luna et al., 2006). O perfil de expressão gênica de $H D A C 6$ durante a diferenciação, por outro lado, não tinha sido relatada anteriormente em células humanas com deficiência de disferlina. Em conjunto, as alterações de expressão de fatores miogênicos e de HDAC6 diante da deficiência de disferlina podem indicar novos direcionamentos para estudos dos mecanismos fisiopatológicos que comprometem a progressão da diferenciação muscular nas disferlinopatias.

Dadas as diferenças ao se comparar experimentos in vivo $\mathrm{x}$ in vitro e linhagens murinas $\mathrm{x}$ humanas (Bareja et al., 2014), observamos nos dois trabalhos que a deficiência de disferlina altera temporalmente a miogênese, seja por comprometer a progressão do crescimento e alongamento de miotubos durante a diferenciação muscular in vivo de 
células humanas ou por alterar eventos da regeneração muscular em experimentos in vivo com linhagens murinas. Estudos futuros serão necessários para melhor esclarecer as implicações dos padrões de expressão dos componentes do tricomplexo nas funções celulares. 


\section{Referências bibliográficas}

ABMAYR, S. M.; PAVLATH, G. K. Myoblast fusion: lessons from flies and mice. Development (Cambridge, England), v. 139, n. 4, p. 641-656, 2012.

ALLEN, R. E.; BOXHORN, L. K. Inhibition of skeletal muscle satellite cell differentiation by transforming growth factor-beta. J. Cell Physiol., v. 133, p. 567$572,1987$.

AMPONG, B. N. et al. Intracellular localization of dysferlin and its association with the dihydropyridine receptor. Acta Myol., v. 24, p. 134-144, 2005.

ANDERSON, L. V. B. et al. Dysferlin is a Plasma Membrane Protein and is Expressed Early in Human Development. Human Molecular Genetics, v. 8, n. 5, p. 855861, 1999.

ANGELINI, C. et al. Dysferlinopathy course and sportive activity: clues for possible treatment. Acta Myol., v. 30, p. 127-132, 2011.

ARANDA. P. S.; LAJOIE, D. M.; JORCYK, C. L. Bleach Gel: A simple agarose gel for analyzing RNA quality. Electrophoresis, v. 33, n. 2, p. 366-369, 2012.

ASTHANA, J. et al. Inhibition of HDAC6 deacetylase activity increases its binding with microtubules and suppresses microtubule dynamic instability in MCF-7 cells. The Journal of biological chemistry, v. 288, n. 31, p. 22516-22526, 2013.

AZAKIR, B. A. et al. Dysferlin interacts with tubulin and microtubules in mouse skeletal muscle. PloS one, v. 5, n. 4, p. e10122, 2010.

BALASUBRAMANIAN, A. et al. Fam65b is important for formation of the HDAC6dysferlin protein complex during myogenic cell differentiation. FASEB journal : official publication of the Federation of American Societies for Experimental Biology, v. 28, n. 7, p. 2955-2969, 2014.

BANSAL, D. et al. Defective membrane repair in dysferlin-deficient muscular dystrophy. Nature, v. 423, p. 168-172, 2003.

BANSAL, D.; CAMPBELL, K. P. Dysferlin and the plasma membrane repair in muscular dystrophy. Trends in cell biology, v. 14, n. 4, p. 206-213, 2004.

BAREJA, A. et al. Human and mouse skeletal muscle stem cells: convergent and divergent mechanisms of myogenesis. PloS one, v. 9, n. 2, p. e90398, 2014.

BASHIR, R. et al. A gene for autosomal recessive limb-girdle muscular dystrophy maps to chromosome 2p. Human Molecular Genetics, v. 3, p. 455-7, 1994.

BASHIR, R. et al. A gene related to Caenorhabditis elegans spermatogenesis factor fer1 is mutated in limb-girdle muscular dystrophy type 2B. Nat. Genet., v. 20, p. $37-$ 42, 1998.

BENTZINGER, C. F.; WANG, Y. X.; RUDNICKI, M. A. Building muscle: molecular regulation of myogenesis. Cold Spring Harbor perspectives in biology, v. 4, n. $2,2012$.

BITTNER R. E. et al.Dysferlin deletion in SJL mice (SJL-Dysf) defines a natural model for limb girdle muscular dystrophy 2B. Nat. Genet., v. 23, p. 141-142, 1999. 
BLANDIN, G. et al. UMD-DYSF, a novel locus specific database for the compilation and interactive analysis of mutations in the dysferlin gene. Human mutation, v. 33, n. 3, p. E2317-31, 2012.

BRAUN et al. Targeted inactivation of the muscle regulatory gene $M y f-5$ results in abnormal rib development and perinatal death. Cell, v. 71, p. 369-382, 1992.

BUSHBY, K. M. Making sense of the limb-girdle muscular dystrophies. Brain, v. 122, p. 1403-20, 1999.

CAI, C. et al. Membrane repair defects in muscular dystrophy are linked to altered interaction between MG53, caveolin-3, and dysferlin. The Journal of biological chemistry, v. 284, n. 23, p. 15894-15902, 2009.

CARTER, H.; HOFREE, M.; IDEKER, T. Genotype to phenotype via network analysis. Current opinion in genetics \& development, v. 23, n. 6, p. 611-621, 2013.

CENACCHI, G. et al. Ultrastructural changes in dysferlinopathy support defective membrane repair mechanism. Journal of clinical pathology, v. 58, n. 2, p. 190$195,2005$.

CHARGE, S. B. P.; RUDNICKI, M. A. Cellular and molecular regulation of muscle regeneration. Physiological reviews, v. 84, n. 1, p. 209-238, 2004.

CHECHI, K. et al. Validation of reference genes for the relative quantification of gene expression in human epicardial adipose tissue. PloS one, v. 7, n. 4, p. e32365, 2012.

CHIU, Y. et al. Attenuated muscle regeneration is a key factor in dysferlin-deficient muscular dystrophy. Human Molecular Genetics, v. 18, n. 11, p. 1976-1989, 2009.

CLARK, K. A. et al. Striated muscle cytoarchitecture: an intricate web of form and function. Annual review of cell and developmental biology, v. 18, p. 637-706, 2002.

COHEN, T. V.; COHEN, J. E.; PARTRIDGE, T. A. Myogenesis in dysferlin-deficient myoblasts is inhibited by an intrinsic inflammatory response. Neuromuscular disorders : NMD, v. 22, n. 7, p. 648-658, 2012.

COHEN, T. V. et al. Upregulated IL-1beta in dysferlin-deficient muscle attenuates regeneration by blunting the response to pro-inflammatory macrophages. Skeletal muscle, v. 5, p. 24, 2015.

COHN, R. D.; CAMPBELL, K. P. The molecular basis of muscular dystrophy. Muscle Nerve, v. 23, p. 1456-1471, 2000.

COOPER, S. T.; MCNEIL, P. L. Membrane Repair: Mechanisms and Pathophysiology. Physiological reviews, v. 95, n. 4, p. 1205-1240, 2015.

CORROTTE, M. et al. Approaches for plasma membrane wounding and assessment of lysosome-mediated repair responses. Methods in cell biology, v. 126, p. 139-158, 2015.

DAVENPORT, N. R. et al. Membrane dynamics during cellular wound repair. Molecular biology of the cell, v. 27, n. 14, p. 2272-2285, 2016.

DAVIS, D. B. Myoferlin, a candidate gene and potential modifier of muscular dystrophy. Human Molecular Genetics, v. 9, n. 2, p. 217-226, 2000. 
DAVIS, D. B. et al. Calcium-sensitive phospholipid binding properties of normal and mutant ferlin C2 domains. The Journal of biological chemistry, v. 277, n. 25, p. 22883-22888, 2002.

DE LUNA, N. et al. Absence of dysferlin alters myogenin expression and delays human muscle differentiation "in vitro". The Journal of biological chemistry, v. 281, $\mathrm{n}$. 25, p. 17092-17098, 2006.

DEFOUR, A. et al. Dysferlin regulates cell membrane repair by facilitating injurytriggered acid sphingomyelinase secretion. Cell death \& disease, v. 5, p. e1306, 2014.

DEMONBREUN, A. R. et al. et al. Impaired muscle growth and response to insulin-like growth factor 1 in dysferlin-mediated muscular dystrophy. Human Molecular Genetics, v. 20, n. 4, p. 779-789, 2011.

DI FULVIO, S. et al. Dysferlin interacts with histone deacetylase 6 and increases alphatubulin acetylation. PloS one, v. 6, n. 12, p. e28563, 2011.

DI FULVIO, S. Characterization of the dysferlin protein and its binding partners reveals rational design for therapeutic strategies for the treatment of dysferlinopathies. 2013. 168 f. Tese (Doutorado em Filosofia) Naturwissenschaftlichen Fakultät - Universität Basel, Basel, Suíça, 2013.

DIAZ-HORTA, O. et al. FAM65B is a membrane-associated protein of hair cell stereocilia required for hearing. Proceedings of the National Academy of Sciences of the United States of America, v. 111, n. 27, p. 9864-9868, 2014.

EMERY, A. E. H. The muscular dystrophies. BMJ, v. 317, p. 991-995, 1998.

EMERY, A. E. H. The muscular dystrophies. The Lancet, v. 359, n. 9307, p. 687-695, 2002 .

GE, Y.; CHEN, J. MicroRNAs in skeletal myogenesis. Cell cycle (Georgetown, Tex.), v. 10, n. 3, p. 441-448, 2011.

GLOVER, L.; BROWN, R. H., JR. Dysferlin in membrane trafficking and patch repair. Traffic (Copenhagen, Denmark), v. 8, n. 7, p. 785-794, 2007.

GOSSELIN, L. E. et al. Localization and early time course of TGF-beta 1 mRNA expression in dystrophic muscle. Muscle \& nerve, v. 30, n. 5, p. 645-653, 2004.

GROUNDS, M. D.; MCGEACHIE, J. K. A comparison of muscle precursor replication in crush-injured skeletal muscle of Swiss and BALBc mice. Cell Tissue Res., v. 255, n. 2, p. 385-391, 1989.

HAN, R. Muscle membrane repair and inflammatory attack in dysferlinopathy. Skeletal muscle, v. 1, n. 1, p. 10, 2011.

HAO, D. et al. Network-based analysis of genotype-phenotype correlations between different inheritance modes. Bioinformatics (Oxford, England), v. 30, n. 22, p. 3223-3231, 2014.

HAWKE, T. J.; GARRY, D. J. Myogenic satellite cells: physiology to molecular biology. J. Appl. Physiol., v. 91, p. 534-551, 2001. 
HERNANDEZ-DEVIEZ, D. J. et al. Caveolin regulates endocytosis of the muscle repair protein, dysferlin. The Journal of biological chemistry, v. 283, n. 10, p. 64766488, 2008.

HIRAYAMA, E.; KIM, J. Identification and characterization of a novel neural cell adhesion molecule (NCAM)-associated protein from quail myoblasts: relationship to myotube formation and induction of neurite-like protrusions. Differentiation; research in biological diversity, v. 76, n. 3, p. 253-266, 2008.

HUANG, Y. et al. Protein studies in dysferlinopathy patients using llama-derived antibody fragments selected by phage display. European journal of human genetics : EJHG, v. 13, n. 6, p. 721-730, 2005.

HUANG, Y. et al. AHNAK, a novel component of the dysferlin protein complex, redistributes to the cytoplasm with dysferlin during skeletal muscle regeneration. FASEB journal : official publication of the Federation of American Societies for Experimental Biology, v. 21, n. 3, p. 732-742, 2007.

HUANG, Y. et al. Calpain 3 is a modulator of the dysferlin protein complex in skeletal muscle. Human Molecular Genetics, v. 17, n. 12, p. 1855-1866, 2008.

HUARD, J.; LI, Y.; FU, F. H. Muscle Injuries and Repair Current Trends in Research. The journal of bone and joint surgery, v. 84-A, n. 5, p. 822-832, 2002.

HUBBERT, C. et al. HDAC6 is a microtubule-associated deacetylase. Nature, v. 417, n. 6887, p. 455-458, 2002.

HUMPHREY, G. W. et al. GREG cells, a dysferlin-deficient myogenic mouse cell line. Experimental cell research, v. 318, n. 2, p. 127-135, 2012.

IBRAGHIMOV-BESKROVNAYA, O. et al. Primary structure of dystrophin-associated glycoproteins linking dystrophin to the extracellular matrix. Nature, v. 355, p. 696-702, 1992.

ILLA, I. et al. Distal anterior compartment myopathy: a dysferlin mutation causing a new muscular dystrophy phenotype. Ann. Neurol., v. 49, p. 130-4, 2001.

KERR, J. P.; WARD, C. W.; BLOCH, R. J. Dysferlin at transverse tubules regulates $\mathrm{Ca}(2+)$ homeostasis in skeletal muscle. Frontiers in physiology, v. 5, p. 89, 2014.

KESPER, K. et al. Pattern of skeletal muscle involvement in primary dysferlinopathies: a whole-body 3.0-T magnetic resonance imaging study. Acta neurologica Scandinavica, v. 120, n. 2, p. 111-118, 2009.

LAVAL, S. H.; BUSHBY, K. M. D. Limb-girdle muscular dystrophies--from genetics to molecular pathology. Neuropathology and applied neurobiology, v. 30, n. 2, p. 91-105, 2004.

LENNON, N. J. et al. Dysferlin interacts with annexins A1 and A2 and mediates sarcolemmal wound-healing. The Journal of biological chemistry, v. 278, n. 50, p. 50466-50473, 2003.

LI, Y.; SHIN, D.; KWON, S. H.. Histone deacetylase 6 plays a role as a distinct regulator of diverse cellular processes. The FEBS journal, v. 280, n. 3, p. 775-793, 2013.

LIU, J. et al. Dysferlin, a novel skeletal muscle gene, is mutated in Miyoshi myopathy and limb girdle muscular dystrophy. Nat. Genet., v. 20, p. 31-6, 1998. 
LO, Harriet P. et al. Limb-girdle muscular dystrophy: diagnostic evaluation, frequency and clues to pathogenesis. Neuromuscular disorders: NMD, v. 18, n. 1, p. 34-44, 2008 .

MALEY, M. A. L. et al. Intrinsic differences in MyoD and myogenin expression between primary cultures of $S J L / J$ and $B a l b / c$ skeletal muscle. Exp. Cell Res., v. 211, p. 99107, 1994.

MATSUDA, C. The sarcolemmal proteins dysferlin and caveolin-3 interact in skeletal muscle. Human Molecular Genetics, v. 10, n. 17, p. 1761-1766, 2001.

MAURO, A. Satellite cell of skeletal muscle fibers. J. Biophys. Biochem. Cytol., v. 9, p. 493-495, 1961.

MCDADE, J. R. Contribution of dysferlin-containing membranes to membrane repair in skeletal muscle. 2014. 143 f. Tese (Doutorado em Filosofia - Fisiologia Molecular e Integrativa) -University of Michigan, Ann Arbor, MI, 2014.

MCDADE, J. R.; MICHELE, D. E. Membrane damage-induced vesicle-vesicle fusion of dysferlin-containing vesicles in muscle cells requires microtubules and kinesin. Human Molecular Genetics, v. 23, n. 7, p. 1677-1686, 2014.

MEGENEY, L. A. et al. MyoD is required for myogenic stem cell function in adult skeletal muscle. Genes \& Dev., v. 10, p. 1173-1183, 1996.

MERCURI, E.; MUNTONI, F. Muscular dystrophies. The Lancet, v. 381, n. 9869, p. 845-860, 2013.

MITCHELl, C. A.; MCGEACHIE, J. K.; GROUNDS, M. D. Cellular differences in regeneration of murine skeletal muscle: a quantitative histological study in $S J L / J$ and Balb/c mice. Cell Tissue Res., v. 269, p. 159-166, 1992.

MIDDEL, V. et al. Dysferlin-mediated phosphatidylserine sorting engages macrophages in sarcolemma repair. Nature communications, v. 7, p. 12875, 2016.

NEVES, J. C. et al. Neuraminidase-1 mediates skeletal muscle regeneration. Biochimica et Biophysica Acta, v. 1852, p. 1755-1764, 2015.

NIGRO V. Molecular bases of autosomal recessive limb-girdle muscular dystrophies. Acta Myol., v. 22, p. 35-42, 2003.

NIGRO, V.; PILUSO, G. Spectrum of muscular dystrophies associated with sarcolemmal-protein genetic defects. Biochimica et biophysica acta, v. 1852, n. 4, p. 585-593, 2015.

NIGRO, V.; SAVARESE, M. Genetic basis of limb-girdle muscular dystrophies: the 2014 update. Acta Myol., v. 33, p. 1-12, 2014.

ONOFRE-OLIVEIRA, P. C. G. et al. Differential expression of genes involved in the degeneration and regeneration pathways in mouse models for muscular dystrophies. Neuromolecular medicine, v. 14, n. 1, p. 74-83, 2012.

OVERALL, C. M.; WRANA, J. L.; SODEK, J. Transcriptional and post-transcriptional regulation of 72-kDa gelatinase/type IV collagenase by transforming growth factor$\beta 1$ in human fibroblasts. The Journal of Biological Chemistry, v. 266, n. 21, p. 14064-14071, 1991. 
PARTON, R. G. et al. Caveolin-3 associates with developing T-tubules during muscle differentiation. J. Cell Biol., v. 136, p. 137-154, 1997.

PICCOLO, F. et al. Intracellular accumulation and reduced sarcolemmal expression of dysferlin in limb-girdle muscular dystrophies. Annals of Neurology, v. 48, n. 6, p. 902-912, 2000.

POSEY, A. D., JR; DEMONBREUN, A.; MCNALLY, E. M. Ferlin proteins in myoblast fusion and muscle growth. Current topics in developmental biology, v. 96, p. 203-230, 2011.

RATTI, F. et al. Histone deacetylase 6 is a FoxO transcription factor dependent effector in skeletal muscle atrophy. The Journak of Biological Chemistry, v. 290, n. 7, p. 4215-4224, 2015.

RAWAT, R. et al. Kanneboyina. Inflammasome up-regulation and activation in dysferlin-deficient skeletal muscle. The American journal of pathology, v. 176, n. 6, p. 2891-2900, 2010.

RELAIX, F. Skeletal muscle progenitor cells: from embryo to adult. Cellular and molecular life sciences : CMLS, v. 63, n. 11, p. 1221-1225, 2006.

RELAIX, F.; ZAMMIT, P. S. Satellite cells are essential for skeletal muscle regeneration: the cell on the edge returns centre stage. Development (Cambridge, England), v. 139, n. 16, p. 2845-2856, 2012.

ROCHE, J. A.; LOVERING, R. M.; BLOCH, R. J. Impaired recovery of dysferlin-null skeletal muscle after contraction-induced injury in vivo. NeuroReport, v. 19, n. 16, p. 1579-1584, 2008.

ROCHE, J. A. et al. Extensive mononuclear infiltration and myogenesis characterize recovery of dysferlin-null skeletal muscle from contraction-induced injuries. American journal of physiology. Cell physiology, v. 298, n. 2, p. C298-312, 2010.

ROOSTALU, U.; STRAHLE, U. In vivo imaging of molecular interactions at damaged sarcolemma. Developmental cell, v. 22, n. 3, p. 515-529, 2012.

RUDNICKI, M. A. et al. Inactivation of MyoD in mice leads to up-regulation of the myogenic HLH gene $M y f-5$ and results in apparently normal muscle development. Cell, v. 71, p. 383-390, 1992.

RUDNICKI, M. A. et al. MyoD or Myf-5 is required for the formation of skeletal muscle. Cell, v. 75, n. 7, p. 1351-1359, 1993.

RUDNICKI, M. A. et al. The molecular regulation of muscle stem cell function. Cold Spring Harbor symposia on quantitative biology, v. 73, p. 323-331, 2008.

SABOURIN, L. A.; RUDNICKI, M. A. The molecular regulation of myogenesis. Clinical Genetics, v. 57, p. 16-25, 2000.

SAMBASIVAN, R.; TAJBAKHSH, S. Skeletal muscle stem cell birth and properties. Seminars in cell \& developmental biology, v. 18, n. 6, p. 870-882, 2007.

SAMBASIVAN, R. et al. Pax7-expressing satellite cells are indispensable for adult skeletal muscle regeneration. Development, v. 138, n. 19, p. 4333, 2011. 
SEALE, P. et al. Pax7 is necessary and sufficient for the myogenic specification of CD45+:Sca1+ stem cells from injured muscle. PLoS biology, v. 2, n. 5, p. E130, 2004.

SHI, X.; GARRY, D. J. Muscle stem cells in development, regeneration, and disease. Genes \& development, v. 20, n. 13, p. 1692-1708, 2006.

SHIN, J. et al. Wasting mechanisms in muscular dystrophy. The international journal of biochemistry \& cell biology, v. 45, n. 10, p. 2266-2279, 2013.

SOROKIN, L. M. et al. Laminin alpha4 and integrin alpha6 are upregulated in regenerating dy/dy skeletal muscle: comparative expression of laminin and integrin isoforms in muscles regenerating after crush injury. Experimental cell research, v. 256, n. 2 , p. 500-514, 2000.

SULA, A. et al. Crystal structures of the human Dysferlin inner DysF domain. BMC structural biology, v. 14, p. 3, 2014.

TAM, C. et al. Exocytosis of acid sphingomyelinase by wounded cells promotes endocytosis and plasma membrane repair. The Journal of cell biology, v. 189, n. 6, p. 1027-1038, 2010.

TURNER, N. J.; BADYLAK, S. F. Regeneration of skeletal muscle. Cell and tissue research, v. 347, n. 3, p. 759-774, 2012.

URTIZBEREA, J. A. et al. Dysferlinopathies. Neurology India, v. 56, n. 3, p. 289-297, 2008.

VAINZOF, M. et al. Animal models for genetic neuromuscular diseases. Journal of molecular neuroscience : MN, v. 34, n. 3, p. 241-248, 2008.

VAINZOF, M.; ZATZ, M. Protein defects in neuromuscular diseases. Brazilian Journal of Medical and Biological Research, v. 36, n. 5, 2003.

VENUTI, J. M. et al. Myogenin is required for late but not early aspects of myogenesis during mouse development. J. Cell Biol., v. 128, p. 563-576, 1995.

WADDELL, L. B. et al. Dysferlin, annexin A1, and mitsugumin 53 are upregulated in muscular dystrophy and localize to longitudinal tubules of the T-system with stretch. Journal of neuropathology and experimental neurology, v. 70, n. 4, p. 302-313, 2011.

WALLACE, G. Q.; MCNALLY, E. M. Mechanisms of muscle degeneration, regeneration, and repair in the muscular dystrophies. Annual review of physiology, v. 71, p. 37-57, 2009.

WEILER, T. et al. Identical Mutation in Patients with Limb Girdle Muscular Dystrophy Type 2B Or Miyoshi Myopathy Suggests a Role for Modifier Gene(s). Human Molecular Genetics, v. 8, n. 5, p. 871-877, 1999.

WELLER, A. H. et al. Spontaneous myopathy in the $S J L / J$ mouse: pathology and strength loss. Muscle Nerve, v. 20, p. 72-82, 1997.

WICKLUND, M. P.; KISSEL, J. T. The limb-girdle muscular dystrophies. Neurologic clinics, v. 32, n. 3, p. 729-49, ix, 2014.

YAN, Z. et al. Highly coordinated gene regulation in mouse skeletal muscle regeneration. The Journal of biological chemistry, v. 278, n. 10, p. 8826-8836, 2003. 
YANG, Y. et al. Time course of myogenic and metabolic gene expression in response to acute exercise in human skeletal muscle. J. Appl. Physiol., v. 98, p. 1745-1752, 2005.

YOON, S. et al. C6ORF32 is upregulated during muscle cell differentiation and induces the formation of cellular filopodia. Developmental biology, v. 301, n. 1, p. 70-81, 2007. 